\title{
The Anti-Inflammatory Actions and Mechanisms of Acupuncture from Acupoint to Target Organs via Neuro-Immune Regulation
}

\author{
Ningcen $\mathrm{Li}^{1,2, *}$ \\ Yi Guo ${ }^{1,3,4, *}$ \\ Yinan Gong ${ }^{1-3}$ \\ Yue Zhang $\mathbb{D}^{1,2}$ \\ Wen Fan ${ }^{5}$ \\ Kaifang Yao ${ }^{1,2}$ \\ Zhihan Chen ${ }^{1,2}$ \\ Baomin Dou ${ }^{1,2}$ \\ Xiaowei $\operatorname{Lin}^{1,3,4}$ \\ Bo Chen ${ }^{1-3}$ \\ Zelin Chen ${ }^{1-3}$ \\ Zhifang Xu (D) ${ }^{1-3}$ \\ Zhongxi Lyu $\mathbb{D}^{1-3}$
}

'Research Center of Experimental Acupuncture Science, Tianjin University of Traditional Chinese Medicine, Tianjin City, People's Republic of China; ${ }^{2}$ School of Acupuncture \& Moxibustion and Tuina, Tianjin University of Traditional Chinese Medicine, Tianjin City, People's Republic of China; ${ }^{3}$ National Clinical Research Center for Chinese Medicine Acupuncture and Moxibustion, Tianjin City, People's Republic of China; ${ }^{4}$ School of Traditional Chinese Medicine, Tianjin University of Traditional Chinese Medicine, Tianjin City, People's Republic of China; ${ }^{5}$ Suzuka University of Medical Science, Suzuka City, Japan

*These authors contributed equally to this work

Correspondence: Zhifang Xu; Zhongxi Lyu

School of Acupuncture \& Moxibustion and Tuina, Tianjin University of Traditional Chinese Medicine, No. 10 Poyang Lake

Road, Tuanbo New Town, Jinghai District,

Tianjin, 301617, People's Republic of

China

Tel/Fax +86 22-5959-6290

Email xuzhifangmsn@hotmail.com;

1025I17807@qq.com

\begin{abstract}
Inflammation plays a significant role in the occurrence and development of multiple diseases. This study comprehensively reviews and presents literature from the last five years, showing that acupuncture indeed exerts strong anti-inflammatory effects in multiple biological systems, namely, the immune, digestive, respiratory, nervous, locomotory, circulatory, endocrine, and genitourinary systems. It is well known that localized acupuncture-mediated anti-inflammatory effects involve the regulation of multiple populations and functions of immune cells, including macrophages, granulocytes, mast cells, and T cells. In acupuncture stimulation, macrophages transform from the M1 to the M2 phenotype and the negative TLR4 regulator PPAR $\gamma$ is activated to inhibit the intracellular TLR/MyD88 and

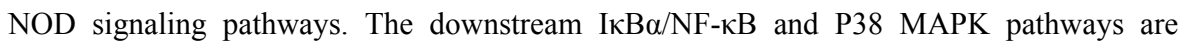
subsequently inhibited by acupuncture, followed by suppressed production of inflammasome and proinflammatory mediators. Acupuncture also modulates the balance of helper $\mathrm{T}$ cell populations. Furthermore, it inhibits oxidative stress by enhancing SOD activity via the Nrf2/ HO-1 pathway and eliminates the generation of oxygen free radicals, thereby preventing inflammatory cell infiltration. The anti-inflammatory effects of acupuncture on different biological systems are also specific to individual organ microenvironments. As part of its anti-inflammatory action, acupuncture deforms connective tissue and upregulates the secretion of various molecules in acupoints, further activating the NF-KB, MAPK, and ERK pathways in mast cells, fibroblasts, keratinocytes, and monocytes/macrophages. The somatic afferents present in acupuncture-activated acupoints also convey sensory signals to the spinal cord, brainstem, and hypothalamic neurons. Upon information integration in the brain, acupuncture further stimulates multiple neuro-immune pathways, including the cholinergic anti-inflammatory, vagus-adrenal medulla-dopamine, and sympathetic pathways, as well as the hypothalamus-pituitary-adrenal axis, ultimately acting immune cells via the release of crucial neurotransmitters and hormones. This review provides a scientific and reliable basis and viewpoints for the clinical application of acupuncture in various inflammatory conditions.
\end{abstract}

Keywords: inflammation, acupuncture, immune, vagus, sympathetic nerve

\section{Introduction}

Inflammation is an important defense mechanism in the body. Many diseases are accompanied by inflammation, which plays a significant role in disease occurrence and development. In the early stages of disease, a moderate inflammatory response helps the body recognize the lesion, eliminate both internal and external pathogenic factors, and restore homeostasis. For example, inflammatory exudates are 
interwoven into cellulose to limit the spread of pathogenic microorganisms during infectious diseases. Leukocytes have the ability to kill pathogens, remove necrotic tissue, and contribute to the repair of damaged tissue. However, long-term disordered and uncontrolled inflammatory responses can induce massive tissue cell death, resulting in abnormal reconstruction of tissues and organs, eventually leading to organ failure. ${ }^{1}$ A good example of this is the long-term inflammatory stimulation of rheumatoid arthritis (RA), which can lead to both joint deformity and multi-system functional impairment. Nonsteroidal antiinflammatory drugs or steroid anti-inflammatory drugs are commonly used to treat inflammatory diseases. However, they do not alleviate the inflammatory reaction. Moreover, these exogenous drugs are accompanied by serious multi-systemic side effects, such as hypertension, hyperlipidemia, diabetes, cataracts, glaucoma, amongst others. In addition, immunosuppression brought on by these drugs can make patients more susceptible to fungal and viral infections. ${ }^{2}$ Therefore, mobilizing the endogenous regulatory system to combat inflammation is a worldwide challenge that requires immediate attention.

Inflammatory diseases are important indicators of acupuncture. The World Health Organization (WHO) recommends acupuncture for the treatment of 16 types of inflammatory diseases, and several clinical practice guidelines suggest acupuncture for the treatment of several inflammatory diseases, including, allergic rhinitis and RA. ${ }^{3}$ Taking sepsis as an example, randomized controlled trials (RCTs) revealed that routine treatment, combined with acupuncture, offers better outcomes in reducing inflammatory responses and organ injury while improving related symptoms and survival in patients with sepsis., Several basic studies have also suggested that electroacupuncture (EA) effectively corrects sepsis via the vagal dopaminergic anti-inflammatory pathway. ${ }^{6}$ However, acupuncture is not broadly applied in the prevention and treatment of the Corona Virus Disease 2019 (COVID-19) infection, which includes a "cytokine storm" caused by the excessive release of proinflammatory cytokines, followed by sepsis. This may be due to the lack of extensive knowledge on the anti-inflammatory mechanism of acupuncture.

Prior studies have clarified the anti-inflammatory and anti-infection effects of acupuncture on multiple tissues and organs by targeting certain classical inflammatory cells, cytokines, and cellular signaling pathways. With the rapid development of omics and other technologies, the internal mechanism of acupuncture-mediated anti- inflammatory action has been revealed from different perspectives and levels. Therefore, this study comprehensively reviewed the related basic literature from the last five years and summarized the anti-inflammatory effects of acupuncture in multiple systems, as well as explored the underlying mechanisms from acupoint initiation to signal termination within the target organs via neuro-immune regulation. Our work aimed to clarify the common antiinflammatory mechanism of acupuncture, highlighting a new basis and viewpoint for the clinical application of acupuncture in various inflammatory diseases.

\section{Methods}

\section{Search Strategy}

We screened the PubMed and Embase database for published studies, from January 2016 to January 2021 (the past five years). The search keywords employed were as follows: ["acupuncture" or "electroacupuncture" or "transcutaneous electrical acupoint stimulation (TEAS)"] and ["inflammatory" or "inflammation"]. The language was limited to English. The website's search engine was used to perform the initial filtering, which identified 1181 relevant articles (after deleting 104 duplicate articles).

\section{Study Selection}

Prior to reading the full text of a given paper, we employed Excel software to manually select references that met the theme. Among them, 11 articles that lacked an abstract full text, 277 articles unrelated to acupuncture and inflammation, 255 reviews or meta-analyses, 247 clinical research articles, and 28 articles involving the use of acupuncture in combination with other therapies were excluded. Finally, 363 full texts of basic research articles, meeting the theme, were included. A flow chart of the search process is depicted in Figure 1.

\section{Data Extraction}

Due to similarities in some of the studies, we extracted key data pertaining to the anti-inflammatory action of acupuncture from typical published studies and classified the data using a pre-defined data extraction table, which specified the type of inflammation model, intervention (method, acupoint, and acupuncture parameters), and outcome measurement (inflammation-related behavior and indicators of mechanism). All data were extracted by one author and examined by the other authors before analysis of the antiinflammatory actions and mechanisms of acupuncture. 


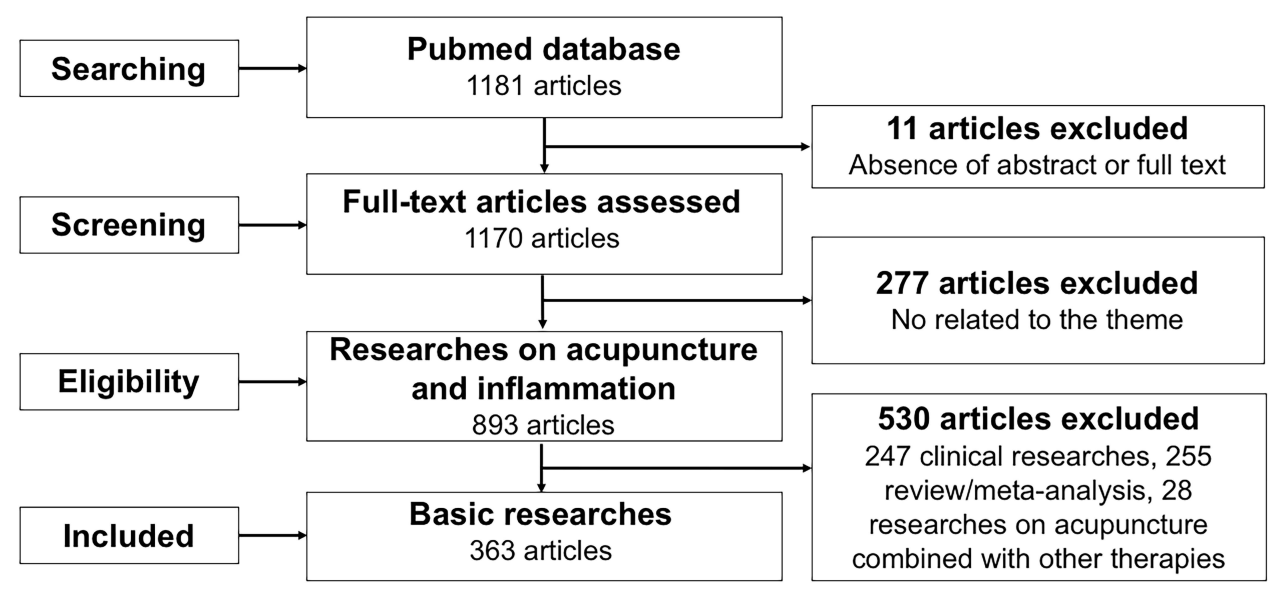

Figure I Flow chart of the search strategy and process.

\section{Results}

\section{The Anti-Inflammatory Effect of Acupuncture in Various Systems}

Multiple studies over the last five years have revealed that regulating inflammation and preventing immune overreaction are the key principles regulating the acupuncturedriven anti-inflammatory action in numerous diseases. These are summarized below according to the latest International Classification of Diseases 11 (ICD-11) standard (https://icd.who.int/browse11/1-m/en).

\section{Immune System}

Immune system diseases are caused by an imbalance in immune regulation, including structural or functional abnormalities of the immune system. RA is one of the most common autoimmune diseases, primarily manifested by the chronic inflammation of joints and infiltration of immune cells, which, in turn, releases a number of proinflammatory factors that aggravate inflammatory responses. $^{7}$

As shown in Table 1, acupuncture regulates the balance of local macrophages, thereby playing an antiinflammatory role. In a prior study, we demonstrated that manual acupuncture (MA) at Zusanli (ST36) modulates the macrophage polarization balance in an inflamed joint by inhibiting pro-inflammatory M1 macrophages and simultaneously promoting anti-inflammatory M2 macrophages. This, in turn, inhibits the expression of proinflammatory cytokines (such as TNF- $\alpha$ and IL-1) expression, and promotes the expression of anti-inflammatory and tissue-repair factors, including IL-10 and TGF- $\beta{ }^{8}$ EA at ST36, along with Kunlun (BL60), also downregulates the mRNA and protein expression of Toll-like receptor 4 (TLR4), myeloid differentiation factor 88 (MyD88), and nuclear factor kappa-B (NF-kB) in the ankle bone tissue of rats treated with complete Freund's Adjuvant (CFA), alleviating foot swelling, and reducing the joint symptom score. ${ }^{9}$ EA at ST36 and Sanyinjiao (SP6) activates the A2A receptor (A2AR) in inflamed synovial tissue, and reduces TNF- $\alpha$ levels in the serum and ankle, thereby inhibiting the receptor activator of NF$\kappa B$ (RANK) from presenting on the cell membrane of the osteoclast precursor. This, in turn, inhibits the association between RANK and receptor activator of nuclear factor$\kappa \mathrm{B}$ ligand (RANKL), down-regulates the expression of extracellular regulated protein kinases $1 / 2$ (ERK1/2) and $\mathrm{NF}-\kappa \mathrm{B}$, and inhibits differentiation and the formation of osteoclasts in CFA rats. ${ }^{10}$ Along with macrophages, acupuncture can also regulate lymphocyte balance. Some researchers quantitatively analyzed the complex immune regulatory process in RA using cell-cell communication (CCC) networks. It was suggested that MA can effectively stimulate both innate immune cytokines (namely, IL-1 $\beta$, IL-1 $\alpha$, IL-6, IL-7, IL-18, and TNF- $\alpha$ ) and adaptive immune cytokines (namely, IL-2, IL-12, IFN- $\gamma$, IL-4, IL5, IL-10, IL-13, and IL-17) to initiate the immune response and repair RA damage. The major target cells for MA regulation by $\mathrm{CCC}$ analysis are monocyte/macrophage and endothelial cells, along with key cells of the adaptive immune system such as Th1, Th2, and B cells. ${ }^{11}$ EA at ST36 and SP6 was shown to promote the proliferation and differentiation of spleen regulatory $\mathrm{T}$ cells (Treg) in CFA rats, which leads to the increased expression of the antiinflammatory cytokine IL-10 in the local hind paw and spinal cord tissues, which, in turn, inhibits macrophages and neutrophils, and reduces secretion of IL- $1 \beta$, NOD-like 
Table I Anti-Inflammatory Actions of Acupuncture in Immune System Diseases

\begin{tabular}{|c|c|c|c|c|c|c|c|}
\hline Refs. & $\begin{array}{l}\text { Inflammatory } \\
\text { Model }\end{array}$ & $\begin{array}{l}\text { Intervention } \\
\text { Methods }\end{array}$ & Acupoints & $\begin{array}{l}\text { Acupuncture } \\
\text { Parameters }\end{array}$ & $\begin{array}{l}\text { Inflammation- } \\
\text { Related } \\
\text { Behaviors }\end{array}$ & Test Sites & $\begin{array}{l}\text { Biochemical } \\
\text { Measurements }\end{array}$ \\
\hline Dong, $2018^{9}$ & RA & EA & ST36, BL60 & $\begin{array}{l}2 \mathrm{~Hz}, 2.0 \mathrm{~mA}, 30 \mathrm{~min}, 4 \\
\text { weeks }\end{array}$ & $\begin{array}{l}\text { Paw swelling, } \\
\text { arthritis index }\end{array}$ & Ankle tissues & $\begin{array}{l}\text { TLR4 } \downarrow, \text { MyD88 } \downarrow \text {, } \\
\text { NF-кB } \downarrow\end{array}$ \\
\hline $\mathrm{Du}, 2019^{10}$ & RA & EA & ST36, SP6 & $\begin{array}{l}2 \mathrm{~Hz}, 30 \mathrm{~min} \text {, from day } \\
35 \text { to day } 49 \text { after the } \\
\text { first immunization }\end{array}$ & - & $\begin{array}{l}\text { Ankle joint, } \\
\text { serum }\end{array}$ & 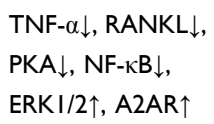 \\
\hline $\mathrm{Xu}, 2018^{11}$ & RA & MA & ST36 & $\begin{array}{l}3 \text { spins per second, } 2 \\
\text { min with } \\
\text { a } 5 \text {-min interval, } 28 \\
\text { min, day I-7 (once } \\
\text { a day) and day } 8-15 \\
\text { (once every other day) }\end{array}$ & $\begin{array}{l}\text { TWL, Paw } \\
\text { swelling }\end{array}$ & $\begin{array}{l}\text { Serum, hind } \\
\text { paw }\end{array}$ & 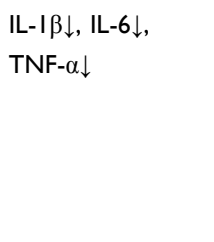 \\
\hline Yu, $2020^{12}$ & RA & EA & ST36, SP6 & $\begin{array}{l}2 / 100 \mathrm{~Hz}, 2.0 \mathrm{~mA}, 20 \\
\min \end{array}$ & MWT, TWL & $\begin{array}{l}\text { Hind paw, } \\
\text { spinal cord }\end{array}$ & 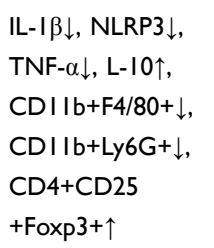 \\
\hline Su, $2019^{13}$ & RA & EA & $\begin{array}{l}\text { ST36, } \\
\text { GB39 }\end{array}$ & $\begin{array}{l}2 \mathrm{~Hz}, 15 \mathrm{~min} \text {, every } \\
\text { other day, } 16 \text { days }\end{array}$ & $\begin{array}{l}\text { Arthritic index, } \\
\text { paw swelling }\end{array}$ & $\begin{array}{l}\text { Synovial } \\
\text { tissues }\end{array}$ & $\begin{array}{l}\mathrm{Bax} \uparrow, \text { Noxa } \uparrow, \\
\mathrm{P} 53 \uparrow, \mathrm{PUMA} \uparrow, \\
\text { MDM } 2 \downarrow\end{array}$ \\
\hline Torres, $2014^{14}$ & Sepsis & $\begin{array}{l}\text { EA } \\
\text { pretreatment }\end{array}$ & ST36 & $15 \mathrm{~min}$ & Survival rate & Serum & $\begin{array}{l}\text { TNF- } \alpha \downarrow, \text { MCP-I } \downarrow \text {, } \\
\text { IL- } 6 \downarrow, \text { INF- } \gamma \downarrow\end{array}$ \\
\hline Chen, $2016^{15}$ & SAE & $\begin{array}{l}\text { EA } \\
\text { pretreatment }\end{array}$ & $\begin{array}{l}\text { ST36, } \\
\text { GV20 }\end{array}$ & $2-15 \mathrm{~Hz}, 2 \mathrm{~mA}, 30 \mathrm{~min}$ & MWM & $\begin{array}{l}\text { Brain tissues, } \\
\text { serum, } \\
\text { hippocampus }\end{array}$ & $\begin{array}{l}\text { MDA } \downarrow, \text { SOD } \downarrow \text {, } \\
\text { CAT } \downarrow, \text { TLR-4 } \downarrow \text {, } \\
\text { NF-кB } \downarrow, \text { IL-6 } \downarrow \text {, } \\
\text { TNF- } \alpha \downarrow \text {, Iba I } \downarrow\end{array}$ \\
\hline Zhang, $2018^{16}$ & Sepsis & EA & ST36 & $\begin{array}{l}2.0 \mathrm{~mA}, 2-100 \mathrm{~Hz} \text {, } \\
\text { I hour }\end{array}$ & - & $\begin{array}{l}\text { Cardiac } \\
\text { muscles }\end{array}$ & $\begin{array}{l}\text { TNF- } \alpha \downarrow, N O \downarrow, \\
\text { MPO } \downarrow, C K-M B \downarrow\end{array}$ \\
\hline Xie, $2020^{17}$ & Sepsis & EA & $\begin{array}{l}\text { ST36, LIII, } \\
\text { ST25 }\end{array}$ & $3 \mathrm{~Hz}, 15 \mathrm{~min}$ & - & $\begin{array}{l}\text { Serum, } \\
\text { mesenteric } \\
\text { lymph nodes }\end{array}$ & $\begin{array}{l}\text { IL-I0 } \downarrow, \text { TNF- } \alpha \downarrow \\
\text { CD3+CD4+ } \\
\text { CD3+CD8+ }\end{array}$ \\
\hline
\end{tabular}

Notes: $\uparrow$, upregulated by acupuncture; $\downarrow$, downregulated by acupuncture.

Abbreviations: RA, rheumatoid arthritis; SAE, sepsis-associated encephalopathy; MWT, mechanical withdrawal threshold; TWL, thermal withdrawal latency; MWM, Morris water maze; NLRP3, NOD-like receptor protein 3; TLR4, toll like receptors 4; MyD88, myeloid differentiation factor 88; NF-кB, nuclear factor kappa-B; RANKL, receptor activator of nuclear factor- $\mathrm{B}$ ligand; NO, nitric oxide; MPO, myeloperoxidase; MCP-I, monocyte chemotactic protein I; INF- $\gamma$, interferon- $\gamma$; MDA, malondialdehyde; SOD, superoxide dismutase; CAT, catalase; Iba I, ionized calcium binding adaptor molecule; CK-MB, creatine kinase-MB; ST36, Zusanli; SP6, Sanyinjiao; BL60, Kunlun; GB39, Xuanzhong; LIII, Quchi; ST25, Tianshu; GV20, Baihui.

receptor protein 3 (NLRP3), and TNF- $\alpha$. The reduction of these substances inhibits nociceptive sensitization in inflammatory states and relieves inflammatory pain. ${ }^{12}$ EA at ST36 and Xuanzhong (GB39) promotes expression of downstream pro-apoptotic proteins such as Bax, Noxa, Puma, and inflammatory factors via upregulation of p53 (a common transcription factor aiding certain antiapoptotic and pro-apoptotic proteins) and its key negative regulatory factor murine double minute 2 (MDM2), which, in turn, leads to a marked increase in synovial cell apoptosis, thereby alleviating CFA-induced RA progression in rats. $^{13}$

In the endotoxin-induced systemic inflammation model, EA pretreatment at ST36 or Tianshu (ST25) causes a reduction in TNF- $\alpha$, IL-6, and IL-1 $\beta$ levels in serum and spleen. ${ }^{6}$ EA pretreatment at the ST36 acupoint alone also 
significantly downregulates TNF- $\alpha$, monocyte chemotactic protein 1 (MCP-1), IL-6, and interferon- $\gamma(\mathrm{INF}-\gamma)$ in serum, ${ }^{14}$ thereby improving the survival rate of septic mice. Sepsis-associated encephalopathy (SAE) is the most serious complication of the central nervous system in patients with sepsis, and almost half of septic patients develop encephalopathy. EA pretreatment at Baihui (GV20) and ST36 regulates macrophage activation by inhibiting the TLR4 pathway, and by downregulating the NF- $\mathrm{KB}$ pathway, thereby reducing IL- 6 and TNF- $\alpha$ in the hippocampus and serum, which, in turn, reduces brain edema and injury, while subsequently improving survival. ${ }^{15}$ The abnormal distribution of inflammatory mediators in sepsis leads to cardiac insufficiency. EA at ST36 also inhibits inflammatory mediators such as TNF- $\alpha$, nitric oxide (NO), and myeloperoxidase (MPO), thereby upregulating creatine kinase-MB (CK-MB) activity and protecting the myocardium from sepsis. ${ }^{16}$ Inflammatory factors in sepsis enter the intestinal tract and promote apoptosis of intestinal epithelial cells, leading to hyperosmolarity, hypoperfusion, bacterial translocation, and alterations in microbiota. EA at ST36, Quchi (LI11), and ST25, on the other hand, upregulates IL-10 by increasing $\mathrm{CD}^{+} \mathrm{CD}^{+} \mathrm{T}$ cells and Treg cells levels in the mesenteric lymph nodes while down-regulating $\mathrm{CD}^{+} \mathrm{CD} 8^{+} \mathrm{T}$ cells, Th17 cells, and TNF- $\alpha$ levels to suppress intestinal inflammation during sepsis. ${ }^{17}$

In summary, the above studies demonstrate that ST36 is the most commonly used acupoint for the treatment of immunological disorders. EA at ST36, LI11, or ST25 regulates intestinal $\mathrm{T}$ lymphocytes and reduces sepsisinduced systemic inflammatory response. In addition, EA at ST36 and LI11 further inhibits intestinal permeability and exerts a protective effect on the intestinal barrier in septic rats, while EA at ST25 shows no obvious effect on intestinal permeability in model rats, suggesting that different acupoints target distinct forms of gastrointestinal dysfunction. ${ }^{17}$ EA, especially, EA pretreatment, is a common method of sepsis prevention, highlighting the anti-inflammatory action of EA. Acupuncture affects the immune system via innate and adaptive immune cells, such as monocytes/macrophages, endothelial cells, lymphocytes, and their related pro-inflammatory factors.

\section{Digestive System}

Inflammation is a common and basic pathological process in digestive system diseases. ${ }^{18}$ Acupuncture offers a great advantage in consolidating the curative effect, in reducing the recurrence rate, and in improving immunity in digestive system diseases, such as hepatitis, acute/chronic pancreatitis, chronic atrophic gastritis, inflammatory bowel disease (IBD), and other inflammatory diseases (Table 2).

\section{Monocytes/Macrophages}

Several lines of evidence demonstrate that acupuncture effectively inhibits macrophage activation of the M1 type by suppressing the TLR4/MyD88 pathway as well as the microorganisms and inflammatory substances released by macrophages into the intestinal tract, thereby maintaining the integrity of the intestinal barrier and alleviating IBD. For example, EA at ST36 reduces the M1 type macrophage population in colon tissues and up-regulates M2 type macrophages by inhibiting the TLR4/MyD88 pathway, before down-regulating NLRP3/IL-1 $\beta$ in colon macrophages, further lowering IL-6, IL-12, IL-17, TNF- $\alpha$, C-reactive protein (CRP), IFN- $\gamma$, TLR4, and MyD88 levels in the colon and serum while up-regulating antiinflammatory substances such as IL-10, reducing infiltration of white blood cells, and contributing to the repair of intestinal mucosal damage caused by colitis, thereby delaying the continuous loss of body weight. Meanwhile, the EAmediated up-regulation of adiponectin, secreted from the mesenteric adipose tissue by EA, also inhibits macrophage infiltration and pro-inflammatory cytokine release. ${ }^{19,20} \mathrm{MA}$ at ST36, SP6, and Taichong (LR3) inhibits NF- $\mathrm{kB}$ activation in the M1 macrophages to further restore the function of interstitial Cajal cells (ICCs, pacing cells for gastrointestinal movement) in the postoperative ileus (POI) by inhibiting the IL-6/miR-19a/KIT (a specific ICC marker) axis and effectively improving POI inflammation symptoms. ${ }^{21}$ Additionally, EA at ST25 and ST36 reduces the amount of macrophage-secreted IL-18 in the colon, which has a positive effect on reducing visceral allergy symptoms of post-inflammatory IBD. ${ }^{22}$ In addition to IBD, macrophage activation mediated by TLR4/MyD88 also plays an important role in the model of non-alcoholic steatohepatitis, induced by a high-fat diet. MA at ST36, Guanyuan (CV4), and Yongquan (KI1) inhibits the recruitment and activation of hepatic macrophages via the TLR4/MyD88 and NF- $\mathrm{KB}$ pathways and the expression of IL- $1 \beta$ and TNF- $\alpha$ downstream, thereby improving related symptoms. ${ }^{23}$ Recent studies discovered that the NF- $\mathrm{KB}$ pathway is markedly inhibited by the deacetylase sirtuin-1 (Sirt1), which is a representative histone deacetylase (HDAC). EA at Fenglong (ST40), Yinlingquan (SP9), and SP6 strongly enhances Sirt1 expression, further inhibiting 
Table 2 Anti-Inflammatory Actions of Acupuncture in Digestive System Diseases

\begin{tabular}{|c|c|c|c|c|c|c|c|}
\hline Refs. & $\begin{array}{l}\text { Inflammatory } \\
\text { Model }\end{array}$ & $\begin{array}{l}\text { Intervention } \\
\text { Methods }\end{array}$ & Acupoints & $\begin{array}{l}\text { Acupuncture } \\
\text { Parameters }\end{array}$ & $\begin{array}{l}\text { Inflammation- } \\
\text { Related } \\
\text { Behaviors }\end{array}$ & Test Sites & $\begin{array}{l}\text { Biochemical } \\
\text { Measurements }\end{array}$ \\
\hline Song, $2019^{19}$ & Colitis & EA & ST36 & $30 \mathrm{~min}$ & DAI & $\begin{array}{l}\text { Colonic tissues, } \\
\text { serum }\end{array}$ & 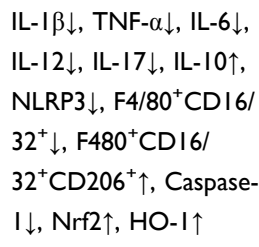 \\
\hline Liu, $2019^{20}$ & Colitis & EA & ST36 & $\begin{array}{l}2 \mathrm{~Hz}, 1.0 \mathrm{~mA} \\
15 \mathrm{~min}\end{array}$ & DAI & $\begin{array}{l}\text { Colonic tissues, } \\
\text { plasma }\end{array}$ & $\begin{array}{l}\text { TLR4 } \downarrow \text {, MyD88 } \downarrow \text {, } \\
\text { claudin-I } \uparrow, \text { ZO-I } \uparrow, \\
\text { adiponectin } \uparrow, \text { TNF- } \alpha \downarrow \text {, } \\
\text { IL- } 6 \downarrow, \text { CRP } \downarrow, \text { IFN- } \gamma \downarrow\end{array}$ \\
\hline Deng, $2017^{21}$ & $\mathrm{POI}$ & MA & $\begin{array}{l}\text { ST36, SP6, } \\
\text { LR3 }\end{array}$ & $\begin{array}{l}\text { Rotated } 30 \\
\text { s every } 5 \\
\text { min, } 15 \text { min }\end{array}$ & & $\begin{array}{l}\text { Colonic smooth } \\
\text { muscle cells }\end{array}$ & 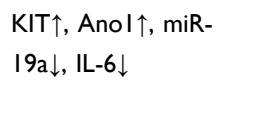 \\
\hline Song, $2020^{22}$ & PI-IBS & EA & ST25, ST36 & $\begin{array}{l}2 / 15 \mathrm{~Hz}, 0.5- \\
1.0 \mathrm{~mA}, 30 \mathrm{~min} \text {, } \\
10 \text { days }\end{array}$ & AWR & Colon tissues & 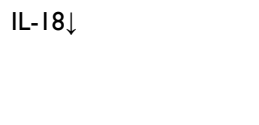 \\
\hline Meng, $2019^{23}$ & NAFLD & MA & $\begin{array}{l}\text { ST36, CV4, } \\
\text { KII }\end{array}$ & $\begin{array}{l}60 \text { rounds/min } \\
\text { for } 2 \mathrm{~min} \text {, } \\
\text { without } \\
\text { retaining the } \\
\text { needle }\end{array}$ & - & $\begin{array}{l}\text { Liver tissues, } \\
\text { serum }\end{array}$ & $\begin{array}{l}\text { IL-I } \beta \downarrow, \text { TNF- } \alpha \downarrow \text {, p-NF- } \\
\kappa B \downarrow, \text { TG } \downarrow, \text { FFA } \downarrow \text {, } \\
\text { 8-OHdG } \downarrow, \text { MDA } \downarrow \text {, } \\
\text { ROS } \downarrow\end{array}$ \\
\hline Ma, $2020^{24}$ & NAFLD & EA & $\begin{array}{l}\text { ST40, } \\
\text { GB34, SP6 }\end{array}$ & - & - & $\begin{array}{l}\text { Liver tissues, } \\
\text { serum }\end{array}$ & 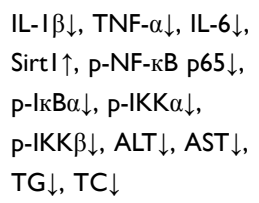 \\
\hline Yang, $2020^{25}$ & IBS & EA & ST36 & $\begin{array}{l}100 / 5 \mathrm{~Hz}, 1.0 \\
\mathrm{~mA}, 30 \mathrm{~min}, 5 \\
\text { days }\end{array}$ & VMR & $\begin{array}{l}\text { Colonic tissue, } \\
\text { serum }\end{array}$ & $\begin{array}{l}\text { TLR4 } \downarrow, \text { MCT } \downarrow, \text { IL-I } \beta \downarrow \text {, } \\
\text { IL-8 } \downarrow\end{array}$ \\
\hline Yang, $2020^{28}$ & $\mathrm{POI}$ & EA & $\begin{array}{l}\text { ST36, } \\
\text { ST37, } \\
\text { ST39, CV4 }\end{array}$ & $\begin{array}{l}2,10,30 \text {, and } \\
100 \mathrm{~Hz}, 1.0 \\
\mathrm{~mA}, 20 \mathrm{~min}\end{array}$ & $\begin{array}{l}\text { Gastrointestinal } \\
\text { transit } \\
\text { measurements }\end{array}$ & Intestine, serum & $\begin{array}{l}\text { TNF- } \alpha \downarrow, I L-6 \downarrow, \alpha- \\
\text { SMA } \uparrow, M P O \downarrow\end{array}$ \\
\hline Ramires, $2020^{29}$ & Peritonitis & $\begin{array}{l}\text { MA } \\
\text { pretreatment }\end{array}$ & SP6 & $\begin{array}{l}\text { Rotated for } \\
\text { a few sec, } 10 \\
\min \end{array}$ & - & $\begin{array}{l}\text { Peritoneal fluid, } \\
\text { brainstem }\end{array}$ & 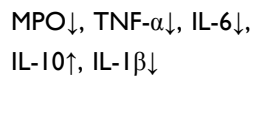 \\
\hline $\mathrm{Li}, 2018^{30}$ & $\begin{array}{l}\text { Liver ischemia- } \\
\text { reperfusion } \\
\text { injury }\end{array}$ & EA & $\mathrm{LI} 4$ & $\begin{array}{l}2 / 100 \mathrm{~Hz}, 3.0 \\
\mathrm{~mA}, 30 \mathrm{~min}\end{array}$ & - & $\begin{array}{l}\text { Liver tissues, } \\
\text { serum }\end{array}$ & $\begin{array}{l}\text { TNF- } \alpha \downarrow, I L-6 \downarrow, \text { MPO } \downarrow \text {, } \\
\text { ALT } \downarrow\end{array}$ \\
\hline
\end{tabular}

Notes: $\uparrow$, upregulated by acupuncture; $\downarrow$, downregulated by acupuncture.

Abbreviations: POI, postoperative ileus; PI-IBS, post inflammatory irritable bowel syndrome; NAFLD, nonalcoholic fatty liver disease; IBS, irritable bowel syndrome; DAI, disease activity index; AWR, abdominal withdrawal reflex; VMR, visceral motor reflex; ZO-I, zonula occludens I; CRP, C-reactive protein; IFN- $\gamma$, Interferon $\gamma$; Nrf2, NFErelated factor 2; HO-I, Heme oxygenase-I; TG, triglyceride; FFA, free fatty acid; 8-OhdG, 8-hydroxy-2-deoxyguanosine; TC, total cholesterol; ROS, reactive oxygen species; Sirt I, sirtuin-I; ALT, alanine aminotransferase; AST, aspartate aminotransferase; MCT, mast cell tryptase; LR3, Taichong; CV4, Guanyuan; KII, Yongquan; ST40, Fenglong; GB34, Yinlingquan; ST37, Shangjuxu; ST39, Xiajuxu; L14, Hegu.

the NLRP3/NF- $\kappa B$ signaling pathway and reducing downstream serum inflammatory cytokines such as IL-1 $\beta$, IL-6, and TNF- $\alpha$, as well as alanine aminotransferase (ALT), aspartate aminotransferase (AST), triglyceride (TG), and total cholesterol (TC) levels, thus improving lipid metabolism in non-alcoholic fatty liver disease (NAFLD) rats. ${ }^{24}$ 
Macrophages stimulate the oxygen-dependent sterilization pathway after ingesting pathogenic microorganisms, which is a massive oxygen-consuming process initiated with the help of nicotinamide adenine dinucleotide phosphate (NADPH). ${ }^{25}$ Multiple reports reveal that EA at ST36 strongly inhibits the expression of heme oxygenase-1 (HO-1) and its key transcription factor NFE-related factor 2 (Nrf2), thereby suppressing oxidative stress while promoting the formation of a positive feedback loop of antiinflammatory factors such as IL-10, which alleviates symptoms related to ulcerative colitis (UC). ${ }^{19} \mathrm{MA}$ at ST36, CV4, and KI1 dramatically reduces the number of 8-hydroxy-2-deoxyguanosine (8-OHdG)-positive cells and malondialdehyde (MDA) levels, reduces the levels of liver free fatty acids, and inhibits the production of reactive oxygen species (ROS), ameliorating oxidative stress in a rat model of NAFLD and thus relieving necrotizing inflammation and fibrosis. ${ }^{23}$ Morphine and acetaminophen-induced hepatotoxicity can also be relieved by acupuncture through the amelioration of antioxidant defense systems. ${ }^{26}$ Apart from macrophages, acupuncture also alleviates inflammatory diseases in the digestive system by regulating mast cells. For example, in the irritable bowel syndrome (IBS) model, EA at ST36 reduces the number of mast cells, down-regulates TLR4, IL-1 $\beta$, and IL-8 released by mast cells in the colon tissue, and improves visceral hypersensitivity in the trinitrobenzene sulfonic acid (TNBS)-induced colitis model. ${ }^{27}$

\section{Granulocytes}

Among the major features of gastrointestinal inflammation are leukocytes that penetrate into inflamed tissue via adhesion and transport along vascular endothelial cells. EA at ST36 up-regulates cadherin, claudin-1, and zonula occludens-1 (ZO-1) levels in colon tissue and prevents the migration and infiltration of leukocytes into the injured site. It is suggested that the repair of tight junctions may be one of the important mechanisms of EA in treating dextran sulfate sodium (DSS)-induced colitis. ${ }^{20} \mathrm{MPO}$, produced by granulocytes, via autocrine and paracrine pathways, reflects the activation level of polymorphonuclear leukocytes (PMNs) and contributes to a positive feedback loop that further promotes the activation of neutrophils. EA at ST36, Shangjuxu (ST37), Хiajuxu (ST39), or CV4 was shown to protect smooth muscle function from local immune cell infiltration by inhibiting MPO activity and inflammatory factors like TNF- $\alpha$ and IL-6, thereby increasing $\alpha$-smooth muscle actin (a-SMA) and improving gastrointestinal motility. ${ }^{28} \mathrm{MA}$ at SP6 also down-regulates TNF- $\alpha$ and IL- 6 in the peritoneal fluid, thereby upregulating IL-10 levels, inhibiting MPO activity, and treating the peritonitis model induced by lipopolysaccharide (LPS) ${ }^{29}$ Liver ischemia-reperfusion $(\mathrm{I} / \mathrm{R})$ injury is a common clinical complication, and excessive inflammation is the key risk factor. EA at Hegu (LI4) is also reported to downregulate TNF- $\alpha$ and IL-6 in serum and liver tissue, thereby inhibiting MPO activity and controlling excessive inflammatory response. ${ }^{30}$

In conclusion, ST36 and SP6 are the most commonly used and effective acupoints for the treatment of inflammatory diseases of the digestive system. The distal lower limb acupoints are more commonly used than the local abdominal acupoints, which reflects the treatment law of the meridians and indications. Some studies compared the effects of EA on inflammation of digestive system diseases under different acupoint selection and frequency. For example, in the POI model, the curative effects of the ST36, ST37, ST39, or CV4 groups are similar but there is no significant difference between ST25, Zhongwan (CV12), and non-acupoint groups, and there is no obvious therapeutic effect for POI, indicating that EA at the lower limb or abdomen acupoints, with the same stimulation parameters, exhibits different therapeutic effects. ${ }^{28}$ In case of the peritonitis model, MA at SP6 reduces both TNF- $\alpha$ and IL- 6 levels in the peritoneal fluid and brain stem, while MA at non-acupoints only partially prevents the increase of IL- 6 in the brain stem, suggesting strong specificity of acupoints in the treatment of diseases. ${ }^{29}$ In terms of the frequency of EA, it was found that $10 \mathrm{~Hz}$ or $30 \mathrm{~Hz}$ EA stimulation can significantly increase gastrointestinal peristalsis and reduce inflammation around POI, but $10 \mathrm{~Hz}$ was more effective, while $2 \mathrm{~Hz}$ or $100 \mathrm{~Hz}$ electrical stimulation did not produce any effect. ${ }^{28}$ Although both $10 \mathrm{~Hz}$ and $100 \mathrm{~Hz}$ EA at ST36 was shown to regulate macrophage polarization and affect inflammatory factors release in colitis rats, only highfrequency stimulation increased Nrf2/HO-1 levels, suggesting that high-frequency EA stimulation exerts a therapeutic effect via the modulation of oxidative stress. The studies mentioned above demonstrate that acupuncture regulates gastrointestinal macrophage polarization and reduces mast cell degranulation, thereby inhibiting the TLR4/MyD88-mediated NF- $\kappa B$ pathway to ultimately regulate production of inflammatory factors and gastrointestinal functional cells such as ICC, and reduce the 
gastrointestinal inflammatory reaction to restore gastrointestinal motor function.

\section{Respiratory System}

Inflammatory diseases are the most common diseases of the respiratory system. Several systematic reviews show that acupuncture vastly improves both nasal symptoms and lung function of patients, thus enhancing the overall quality of life of patients with asthma and chronic obstructive pulmonary disease (COPD) and confirming the antiinflammatory nature of acupuncture. ${ }^{31,32}$ Clinical guidelines such as the American Clinical Practice Guidelines also recommend acupuncture for the clinical treatment of allergic rhinitis and acute pharyngitis. ${ }^{33,34}$ The antiinflammatory actions are summarized below and in Table 3.

\section{Monocytes/Macrophages}

Acupuncture inhibits the TLR4/NF-kB or TLR4/mitogen activated protein kinase (MAPK) signaling pathway in pulmonary macrophages. For example, EA at LI4 stimulates peroxisome proliferator-activated receptor $\gamma$ (PPAR $\gamma$ ), a negative regulator of the TLR4/NF- $\mathrm{kB}$ pathway. This results in a suppression of the TLR4/MyD88 signaling pathway, leading to the activation of alveolar macrophages from the M1 to the M2 type, and further inhibiting the NF- $\mathrm{\kappa B}$ pathway and the downstream proinflammatory factors TNF- $\alpha$, IL-1 $\beta$, and IL-6, which alleviates LPS-induced acute respiratory distress syndrome (ARDS). ${ }^{35}$ EA pre-treatment at ST36 and SP6 also inhibits the alveolar monocyte/macrophage TLR4/NF- $\mathrm{B}$ pathway and down-regulates the expression of TNF- $\alpha$, IL-1, IL-6, and MPO in acute lung injury (ALI) induced by limb artery ischemia-reperfusion (LIR) in rats, leading to the alleviation of pulmonary interstitial edema, alveolar congestion, and bleeding, thus reinstating the damaged alveolar structure. ${ }^{36}$ It was also reported that EA at Feishu (BL13) and ST36 promotes HO-1 and Nrf2 protein accumulation in the nucleus through modulation of the Nrf2/ HO-1 pathway, mediated by the p38 MAPK signaling, further decreasing the secretion of TNF- $\alpha$, IL- $1 \beta$, and IL6 in lung tissues and plasma. This, in turn, plays an antiinflammatory role and prevents damage to the lung caused by the extensive release of oxygen free radicals and inflammatory factors in the ischemic region. ${ }^{37}$ Similarly, in a model of acute lung injury induced by cardiopulmonary bypass (CPB), EA pretreatment at BL13, ST36, Neiguan (PC6), and LI4 inhibits the Nrf2/HO-1 pathway mediated by the p38 MAPK pathway, which reduces MDA content, increases superoxide dismutase (SOD) activity, scavenges oxygen free radicals, and reduces oxygen injury in lung tissues. Furthermore, EA also suppresses NLRP3 inflammasome activation, reduces recruitment of pro-inflammatory protease caspase-1, prevents release of IL-1 $\beta$ into serum and bronchoalveolar lavage fluid (BALF), and decreases activation of caspase8 and caspase-3. Therefore, EA reduces cell apoptosis, secretion of inflammatory cytokines TNF- $\alpha$, IL- $1 \beta$, and IL-18 in lung tissue and plasma, and alleviates pulmonary fibrosis and interstitial edema. ${ }^{38-40}$

In addition to regulating NF- $\mathrm{kB}$ activation, TLR also promotes histone acetylation in macrophage nucleus, thereby participating in the functional activation or inhibition of the nasal mucosal and respiratory epithelial, immune cells, respectively, while regulating the pathological process via modulation of chromatin remodeling and inflammation. ${ }^{41}$ Emerging evidence suggests that reduced histone deacetylase inhibitor 2 (HDAC2) activity partially increases the inflammatory response in the respiratory tract of COPD patients, and MA at BL13, Shenshu (BL23), and Dingchuan increases HDAC2 mRNA and protein expression in COPD rats induced by smoking. Furthermore, acupuncture also reduces the secretion of IL-8 and TNF$\alpha$ by alveolar macrophages and provides a lung protective effect with long-term reversal of airway smooth muscle dysfunction. $^{42}$

\section{Lymphocytes}

Lymphocyte imbalance in immune cells of the acquired immune system, such as Th cells, plays a significant role in the formation, development, and outcome of various inflammation-mediated respiratory diseases. ${ }^{43}$ In the respiratory system, Th2 secretes IL-3, IL-4, IL-5, IL-6, IL-10, IL-13, IL-25, and IL-31, activates eosinophils, fights extracellular pathogens, contributes to humoral immunity, stimulates B cell proliferation, and produces antibodies that generate an inappropriate immune response, which, in turn, stimulates diseases such as allergy and asthma. Acupuncture can regulate the Th cell balance and can play a crucial role in managing inflammatory diseases of the respiratory system. For example, MA at Dazhui (GV14), Fengmen (BL12), and BL13 upregulates Th1 cytokines (such as, IL-2 and IL-12), the Treg marker Foxp3, and cytokine IL-10, and downregulates Th2 cytokines (IL-4, IL-5, and IL-13) and Th17 cytokines (IL-17A) in lung tissues. This alters the 
Table 3 Anti-Inflammatory Actions of Acupuncture in Respiratory System Diseases

\begin{tabular}{|c|c|c|c|c|c|c|c|}
\hline Refs. & $\begin{array}{l}\text { Inflammatory } \\
\text { Model }\end{array}$ & $\begin{array}{l}\text { Intervention } \\
\text { Methods }\end{array}$ & Acupoints & $\begin{array}{l}\text { Acupuncture } \\
\text { Parameters }\end{array}$ & $\begin{array}{l}\text { Inflammation- } \\
\text { Related } \\
\text { Behaviors }\end{array}$ & Test Sites & $\begin{array}{l}\text { Biochemical } \\
\text { Measurements }\end{array}$ \\
\hline Feng, $2020^{35}$ & ARDS & $\begin{array}{l}\text { EA pre- } \\
\text { treatment }\end{array}$ & LI4 & $\begin{array}{l}2 / 100 \mathrm{~Hz}, 4.0 \\
\mathrm{~mA}, 45 \mathrm{~min}\end{array}$ & - & $\begin{array}{l}\text { Lung tissues, } \\
\text { serum, BALF }\end{array}$ & $\begin{array}{l}\text { TNF- } \alpha \downarrow, \text { IL-I } \beta \downarrow \text {, } \\
\text { IL-6 } \downarrow, \mathrm{MPO} \downarrow, \\
\text { PPAR } \gamma \uparrow, \mathrm{MDA} \downarrow \text {, } \\
\text { SOD } \uparrow, \mathrm{GSH} \uparrow, \\
\mathrm{Bax} \downarrow, \mathrm{Bcl}-2 \uparrow, \\
\mathrm{P}-\mathrm{P} 65 \downarrow, \mathrm{P}-\mathrm{I} \mathrm{B} \alpha \downarrow \downarrow \\
\mathrm{I} \mathrm{B} \alpha \uparrow, \mathrm{PaO}{ }_{2} \uparrow\end{array}$ \\
\hline Lou, $2020^{36}$ & $\mathrm{ALI}$ & $\begin{array}{l}\text { EA pre- } \\
\text { treatment }\end{array}$ & ST36, SP6 & $\begin{array}{l}\text { 2/I5 Hz, I.0 } \\
\mathrm{mA} \text {, dispersed } \\
\text { waves, } 30 \mathrm{~min}\end{array}$ & $\begin{array}{l}\text { Lung injury } \\
\text { scores }\end{array}$ & Lung tissues & $\begin{array}{l}\text { TNF- } \alpha \downarrow, \text { IL-I } \\
\text { IL-6 } \downarrow \text {, MPO } \downarrow \text {, } \\
\text { TLR4 } \downarrow, \text { P-NF-KB } \downarrow\end{array}$ \\
\hline Gong, $2020^{37}$ & $\mathrm{ALI}$ & EA & BLI3, ST36 & $\begin{array}{l}2 / 15 \mathrm{~Hz}, 1.0 \\
\mathrm{~mA} \text {, disperse- } \\
\text { dense wave, } 15 \\
\text { min, } 5 \text { days }\end{array}$ & - & $\begin{array}{l}\text { BALF, lung } \\
\text { tissues, plasma }\end{array}$ & 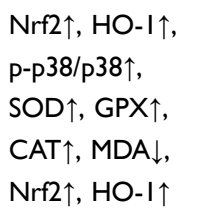 \\
\hline Huang, $2019^{38}$ & $\mathrm{CPB}$ & $\begin{array}{l}\text { EA pre- } \\
\text { treatment }\end{array}$ & BLI3, ST36 & $2 / 15 \mathrm{~Hz}, 30 \mathrm{~min}$ & - & $\begin{array}{l}\text { Lung tissues, } \\
\text { serum, BALF }\end{array}$ & NLRP3 $\downarrow, I L-I \beta \downarrow$ \\
\hline Dhar, $2019^{39}$ & $\mathrm{CPB}$ & $\begin{array}{l}\text { EA pre- } \\
\text { treatment }\end{array}$ & PC6, LI4 & $30 \mathrm{~min}$ & - & $\begin{array}{l}\text { Lung tissues, } \\
\text { serum }\end{array}$ & $\begin{array}{l}\text { TNF- } \alpha \downarrow \text {, IL- I8 } \downarrow \text {, } \\
\text { IL-I } \beta \downarrow, \text { NLRP } 3 \downarrow \text {, } \\
\text { Caspase-I } \downarrow \text {, } \\
\text { Caspase-8 } \downarrow \text {, } \\
\text { P-Nrf2 } \downarrow, \text { MDA } \downarrow \text {, } \\
\text { SOD } \uparrow\end{array}$ \\
\hline $\mathrm{Ma}, 2017^{40}$ & $\mathrm{CPB}$ & $\begin{array}{l}\text { EA pre- } \\
\text { treatment }\end{array}$ & PC6, LI4 & $\begin{array}{l}2 / 100 \mathrm{~Hz}, 0.5 \\
\text { ms pulse width, } \\
30 \mathrm{~min}\end{array}$ & - & Lung tissues & $\begin{array}{l}\text { MPO } \downarrow, M D A \downarrow \\
\text { SOD } \uparrow, \text { Caspase- } \\
3 \downarrow, \mathrm{p}-\mathrm{p} 38 / \mathrm{p} 38 \downarrow\end{array}$ \\
\hline $\mathrm{Li}, 2015^{42}$ & COPD & MA & $\begin{array}{l}\text { BLI3, } \\
\text { BL23, } \\
\text { Dingchuan }\end{array}$ & $\begin{array}{l}\text { Twisted } \\
\text { through } 360^{\circ}, \text { I } \\
\text { min every } 5 \\
\text { min, } 6 \text { times }\end{array}$ & $\begin{array}{l}\text { Pulmonary } \\
\text { function (IC, } \\
\text { PEF, MV) }\end{array}$ & $\begin{array}{l}\text { Lung tissues, } \\
\text { BALF }\end{array}$ & $\begin{array}{l}\text { TNF- } \alpha \downarrow, \text { IL-8 } \downarrow \text {, } \\
\text { HDAC2 } \uparrow\end{array}$ \\
\hline Dong, $2019^{44}$ & Asthma & MA & $\begin{array}{l}\text { GVI4, } \\
\text { BLI2, BLI3 }\end{array}$ & $30 \mathrm{~min}$ & $\begin{array}{l}\text { Airway } \\
\text { resistance, lung } \\
\text { dynamic } \\
\text { compliance }\end{array}$ & $\begin{array}{l}\text { Lung tissues, } \\
\text { serum }\end{array}$ & 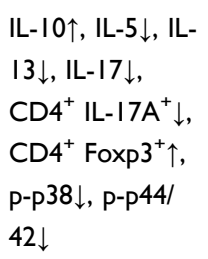 \\
\hline Zhou, $2019^{45}$ & Chronic sinusitis & EA & $\begin{array}{l}\text { ST36, } \\
\text { BLI3, } \\
\text { GV29, LI4 }\end{array}$ & $30 \mathrm{~min}, 10$ days & - & Nasal tissues & IFN- $\gamma \uparrow$, IL-IO^ \\
\hline Dong, $2018^{46}$ & Asthma & MA & $\begin{array}{l}\text { GVI4, } \\
\text { BLI2, BLI3 }\end{array}$ & $\begin{array}{l}\text { Manual } \\
\text { manipulations } \\
\text { every } 10 \mathrm{~min} \text { in } \\
30 \mathrm{~min}\end{array}$ & $\begin{array}{l}\text { Airway } \\
\text { resistance, lung } \\
\text { dynamic } \\
\text { compliance }\end{array}$ & $\begin{array}{l}\text { Lung tissues, } \\
\text { serum, BALF }\end{array}$ & 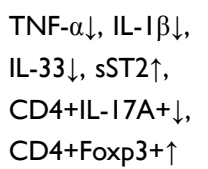 \\
\hline
\end{tabular}

(Continued) 
Table 3 (Continued).

\begin{tabular}{|c|c|c|c|c|c|c|c|}
\hline Refs. & $\begin{array}{l}\text { Inflammatory } \\
\text { Model }\end{array}$ & $\begin{array}{l}\text { Intervention } \\
\text { Methods }\end{array}$ & Acupoints & $\begin{array}{l}\text { Acupuncture } \\
\text { Parameters }\end{array}$ & $\begin{array}{l}\text { Inflammation- } \\
\text { Related } \\
\text { Behaviors }\end{array}$ & Test Sites & $\begin{array}{l}\text { Biochemical } \\
\text { Measurements }\end{array}$ \\
\hline Cui, $2020^{48}$ & Asthma & MA & $\begin{array}{l}\text { GVI4, } \\
\text { BLI2, BLI3 }\end{array}$ & $\begin{array}{l}\text { Twisted } 360^{\circ}, \\
60 \text { times } / \mathrm{min}, 5 \\
\text { times, } 20 \mathrm{~min}\end{array}$ & - & Serum, BALF & 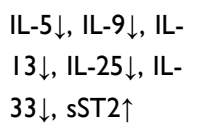 \\
\hline $\begin{array}{l}\text { Nurwati, } \\
2018^{49}\end{array}$ & Asthma & MA & $\mathrm{BLI} 3, \mathrm{ST} 36$ & $\begin{array}{l}15 \text { min, } 3 \\
\text { times/week, } 6 \\
\text { weeks from } \\
21 \text { st day after } \\
\text { modeling }\end{array}$ & - & $\begin{array}{l}\text { Peripheral } \\
\text { blood }\end{array}$ & $\begin{array}{l}\text { neutrophil } \downarrow \text {, } \\
\text { eosinophil } \downarrow\end{array}$ \\
\hline
\end{tabular}

Notes: $\uparrow$, upregulated by acupuncture; $\downarrow$, downregulated by acupuncture.

Abbreviations: ARDS, acute respiratory distress syndrome; ALI, acute lung injury; CPB, cardiopulmonary bypass; COPD, chronic obstructive pulmonary disease; IC, inspiratory capacity; PEF, peak expiratory flow; MV, minute volume; BALF, bronchoalveolar lavage fluid; PPAR $\gamma$, peroxisome proliferator-activated receptor $\gamma$; glutathione peroxidase; GPX, GSH, glutathione; HDAC2, histone deacetylase 2; sST2, soluble growth-stimulating expression gene 2 protein; BLI3, Feishu; PC6, Neiguan; BL23, Shenshu; GVI4, Dazhui; BLI2, Fengmen; GV29, Yingxiang.

asthma model from Th2- and Th17-dominant to Th1- and Treg-dominant. Moreover, IFN- $\gamma$ secreted from Th1 cells inhibits Th2 cell differentiation and function, whereas IL-4 secreted by Th2 cells prevents Th1 cell differentiation and function. Meanwhile, IL-2 in Th1 cells binds to IL-2R on the surfaces of activated $\mathrm{T}$ cells, producing autocrine and paracrine effects to further induce $\mathrm{T}$ cell proliferation. Acupuncture stimulates this process to alleviate airway inflammation in allergic asthma. ${ }^{44}$ In the sinusitis model, EA at ST36, BL13, Yingxiang (LI20), and LI4 also upregulates IFN- $\gamma$ and IL-10 via the same mechanism and promotes the differentiation of Th1 and Treg cells to produce an anti-inflammatory effect. This leads to the reduction in inflammatory cell infiltration in the sinus submucosa and the subsequent repair of damaged pseudostratified epithelial cells. $^{45}$ The regulatory effects of acupuncture on Th cells are also realized via the IL-33/ST2 pathway. GV14, BL12, and BL13 inhibit IL-33 association with the ST2L receptor and down-regulate TNF- $\alpha$, IL-1 $\beta$, and IL-33 levels by up-regulating the Soluble Growth Stimulation Expressed Gene 2 (SST2). Further upregulation of Treg cytokines and down-regulation of Th17 cytokines has been shown to effectively protect lung function in a mouse asthma model, thereby alleviating airway inflammation and mucus secretion. ${ }^{46}$

Innate lymphoid cells (ILCs), also known as innate immune cells due to their lack of adaptive antigen receptors, are a newly discovered subset of lymphocytes, distinct from $\mathrm{T}$ and $\mathrm{B}$ cells, that are primarily distributed in mucosal barrier tissues, and include ILC1s, ILC2s, ILC3s,
NKs, and LTi cells. ILC2s release Th2 cytokines and modulate the inflammatory response and tissue homeostasis, as well as repair mucosal damage in respiratory inflammatory diseases. ${ }^{47} \mathrm{MA}$ at GV14, BL12, and BL13 inhibits ILC2 influx in the lungs of asthmatic mice and reduces IL-5, IL-9, and IL-13 cytokine levels in the alveolar lavage fluid. The inhibitory effect of acupuncture on ILC2 is also realized via the up-regulation of SST2 expression, with subsequent down-regulation of IL-33 and IL-25 levels, thereby activating and alleviating epithelial injury induced by ovalbumin in the asthma model and significantly inhibiting airway inflammation and mucus secretion in the process. ${ }^{48}$

In summary, the acupoints for most of the various inflammatory diseases of the respiratory system include BL13, ST36, and LI4. In a control group of sham acupuncture, Huantiao (GB30) or $5 \mathrm{~mm}$ beside the acupoint are commonly used. The BL13, ST36, and GV14 compatibility mode and the BL12 and BL13 compatibility mode are the most common. In addition, a multi-point combination is often better than single acupoint. It was reported that EA at BL13, combined with ST36, reduces inflammatory cell aggregation, down-regulates the proinflammatory cytokines TNF- $\alpha$ and IL- $1 \beta$, reduces epithelial smooth muscle thickness and cup cell metaplasia, and improves bronchiole structure in an asthma model, while a single use of BL13 produces no significant effect. ${ }^{49}$ In the meantime, a combination of acupuncture and medicine often produces a specific synergistic effect on diseases. For example, the combined treatment of EA and IL-10 (Virus- 
encoded IL-10) enhances its curative effect on sinusitis by specifically targeting IFN- $\gamma \cdot{ }^{45}$ With increasing numbers of studies on the combination of acupuncture and medicine in recent years, some researchers have discussed this mechanism, which may be related to the theory of "meridian-viscera correlation", speculating that acupuncture can guide drugs to target organs, but the synergism of acupuncture and medicine needs further validation, as the law and mechanism are not clearly defined.

The aforementioned studies suggest a strong antiinflammatory property of acupuncture facilitated by the inhibition of innate immune cells such as monocytes/ macrophages or ILCs in the respiratory system. Acupuncture inhibits macrophage activation via pattern recognition receptors (PRRs) such as TLR4, which, in turn promotes PPAR $\gamma$ expression, and inhibits the NF- $\mathrm{BB}$ or MAPK pathways. Moreover, acupuncture may also affect the expression and acetylation of HDAC2 in the nucleus. Furthermore, it is also known to inhibit NLRP3 inflammasome synthesis via the ROS/Nrf2 pathway, which down-regulates pro-inflammatory factors such as TNF- $\alpha$, IL-1 $\beta$, IL-6, IL-5, IL-9, IL-13, and IL-18, while upregulating anti-inflammatory factors such as IL-10, IL25 , and IL-33 to exert its anti-inflammatory activity. In addition, acupuncture suppresses airway inflammation and relieves pulmonary fibrosis and interstitial edema by regulating the Th cell imbalance in the subgroup of effector CD4 T cells in cells of the acquired immune system, thus exerting a therapeutic effect on both acute and chronic respiratory diseases.

\section{Nervous System}

Neuroinflammation is a complex innate immune response process that clears infection, pathogens, cellular debris, and misfolded proteins from the nervous system. It is a key factor and among the most common pathological manifestations of various nervous system diseases, including central nervous system (CNS) injury and neurodegenerative diseases. ${ }^{50}$ Several lines of evidence show that acupuncture effectively inhibits glial cell activation, excessive proliferation, and structural damage to astrocytes after CNS injury and alleviates related symptoms and improves prognosis (Table 4).

\section{Glial Cells}

Glial cells (astrocytes, microglia, and oligodendrocytes) are the most abundant and widely distributed cells of the CNS. They interact with neurons, immune cells, and blood vessels, and act as the first line of defense against nervous system stimulation. Microglia belong to the innate immune system and are the most active immune cells in the CNS. They belong to the monocyte/macrophage lineage. In pathological states, the microglia are associated with the initial response and send immune signals to astrocytes, eventually leading to neuroinflammation. ${ }^{51}$

Pathogen-associated molecular patterns (PAMPs) or damage-associated molecular patterns (DAMPs) mediate the inflammatory response caused by CNS injury. ${ }^{52}$ Indeed, high mobility group box-1 (HMGB1), a DAMP, is considered to be the key mediator of inflammation in the nervous system. EA at Zhiyang (GV9), Jizhong (GV6), Yaoshu (GV2), and Changqiang (GV1) is known to reduce HMGB1, TNF- $\alpha$, and IL- $1 \beta$ levels after spinal cord injury in rats to restore the structure and motor function of the spinal cord and alleviate secondary inflammatory injury after spinal cord injury. ${ }^{53}$ It is reported that MA at GV20 and PC6 reduces NO, prostaglandin E2 (PGE2), iNOS, Cyclooxygenase-2 (COX-2), and NF- $\kappa \mathrm{B}$ expression in the hippocampus and prefrontal cortex, thereby alleviating depression-like behavior induced by chronic restraint stress (CRS). ${ }^{54}$ Following traumatic brain injury, EA at ST36 and GV14 inhibits various inflammatory cascades by inhibiting the TLR4 signaling pathway and its downstream pro-inflammatory proteins (TLR4, MyD88, TRAF6, TRAM, and TRIF) in the brain tissue to alleviate neurological functional defects. ${ }^{55}$ The interaction between receptor interacting protein kinase 1 (RIPK1), IKK complex, and transforming growth factor- $\beta$-activated kinase 1 (TAK1) also induces NF- $\mathrm{B}$ to aggravate traumatic neuritis after intracerebral hemorrhage. EA at Fengchi (GB20), and Yifeng (TE17) reduces up-regulation of RIPK1, p-RIPK3, and p-MLKL, partially blocking the interaction between RIPK1 and RIPK3, thereby reducing levels of TNF- $\alpha$, L-6, IL-8, and other inflammatory factors, to improve traumatic neuritis after intracerebral hemorrhage, and slow down the formation of perihematoma brain edema. $^{56}$ In the paclitaxel-induced neuropathic pain model, EA at ST36 and BL60 can alleviate the central inflammatory response by inhibiting the activation of spinal cord astrocytes and microglia and reducing the overexpression of TLR4 and the downstream signals MyD88 and transient receptor potential vanilloid-1 (TRPV-1) in the rat dorsal root ganglion (DRG). ${ }^{57} \mathrm{EA}$ at GV20, LI4, and LR3 also inhibits microglial activation and phosphorylation of $\mathrm{I} \kappa \mathrm{B} \alpha$ and prevents the nuclear translocation of NF- $\kappa \mathrm{B}$ p65 by upregulating the A20- 
Table 4 Anti-Inflammatory Actions of Acupuncture in Nervous System Diseases

\begin{tabular}{|c|c|c|c|c|c|c|c|}
\hline Refs. & $\begin{array}{l}\text { Inflammatory } \\
\text { Model }\end{array}$ & $\begin{array}{l}\text { Intervention } \\
\text { Methods }\end{array}$ & Acupoints & $\begin{array}{l}\text { Acupuncture } \\
\text { Parameters }\end{array}$ & $\begin{array}{l}\text { Inflammation- } \\
\text { Related } \\
\text { Behaviors }\end{array}$ & Test Sites & $\begin{array}{l}\text { Biochemical } \\
\text { Measurements }\end{array}$ \\
\hline Zhu, $2017^{53}$ & $\mathrm{sCl}$ & $\begin{array}{l}\text { EA } \\
\text { pretreatment }\end{array}$ & $\begin{array}{l}\text { GV9, GV6, } \\
\text { GV2, GVI }\end{array}$ & $\begin{array}{l}60 \mathrm{~Hz} \text { for } 1.05 \\
\mathrm{sec}, 2 \mathrm{~Hz} \text { for } \\
2.85 \mathrm{sec}, 20 \\
\text { min, every } \\
\text { other day, } 4 \\
\text { weeks }\end{array}$ & $\begin{array}{l}\text { Assessment of } \\
\text { Neurologic } \\
\text { Dysfunction }\end{array}$ & Spinal cord & $\begin{array}{l}\text { TNF- } \alpha \downarrow, I L-I \beta \downarrow \text {, } \\
\text { HMGBI } \downarrow\end{array}$ \\
\hline Lu, $2016^{54}$ & Depression & MA & GV20, PC6 & $\begin{array}{l}2 \text { times } \\
\text { per second for } \\
\text { I min in } 10 \mathrm{~min} \text {, } \\
\text { once every } \\
\text { other day, } 4 \\
\text { weeks }\end{array}$ & SPT, OFT & $\begin{array}{l}\text { Hippocampus, } \\
\text { prefrontal } \\
\text { cortex }\end{array}$ & $\begin{array}{l}\text { NO } \downarrow, \text { PGE } 2 \downarrow \text {, } \\
\text { iNO } \downarrow \text {, COX-2 } \downarrow \text {, } \\
\text { NF-kB } \downarrow\end{array}$ \\
\hline Ye, $2017^{55}$ & TBI & EA & $\begin{array}{l}\text { ST36, } \\
\text { GVI4 }\end{array}$ & $\begin{array}{l}2 / 15 \mathrm{~Hz}, 1.0 \\
\mathrm{~mA}, 30 \mathrm{~min}, 35 \\
\text { days }\end{array}$ & NSS, MWM & $\begin{array}{l}\text { Hippocampal } \\
\text { tissues }\end{array}$ & $\begin{array}{l}\text { TLR4 } \downarrow, \text { Myd88 } \downarrow \text {, } \\
\text { TRAF6 } \downarrow \text {, TRAM } \downarrow \text {, } \\
\text { TRIF } \downarrow, \text { TNF- } \alpha \downarrow \text {, IL- } \\
I \beta \downarrow, \text { IL- } 6 \downarrow\end{array}$ \\
\hline Cai, $2020^{56}$ & $\begin{array}{l}\text { Hemorrhagic } \\
\text { stroke }\end{array}$ & $\begin{array}{l}\text { Cross electro- } \\
\text { nape- } \\
\text { acupuncture } \\
\text { (CENA) }\end{array}$ & $\begin{array}{l}\text { GB20, } \\
\text { TEI7 }\end{array}$ & $30 \mathrm{~min}$ & $\begin{array}{l}\text { Neurological } \\
\text { functions, } \\
\text { encephaledema }\end{array}$ & Brain tissue & $\begin{array}{l}\text { RIPKI } \downarrow \text {, P- } \\
\text { RIPK } 3 \downarrow \text {, P-MLKI } \downarrow \text {, } \\
\text { TNF- } \alpha \downarrow, \text { IL-6 } \downarrow \text {, IL- } \\
\text { 8 }\end{array}$ \\
\hline Li, $2019^{57}$ & $\begin{array}{l}\text { Neuropathic } \\
\text { pain }\end{array}$ & EA & ST36, BL60 & $\begin{array}{l}2 \mathrm{~Hz}, 0.5-\mathrm{I} .5 \\
\mathrm{~mA}, 30 \mathrm{~min}\end{array}$ & MWT, TWL & DRG & $\begin{array}{l}\text { TLR4 } \downarrow \text {, MyD88 } \downarrow \text {, } \\
\text { TRPV-I } \downarrow\end{array}$ \\
\hline Zhou, $2020^{58}$ & IS & EA & $\begin{array}{l}\text { GV20, LI4, } \\
\text { LR3 }\end{array}$ & $\begin{array}{l}1.0 \mathrm{~mA}, 20 \mathrm{~Hz} \\
\text { for } 5 \mathrm{~min}, 2 \mathrm{~Hz} \\
\text { for } 30 \mathrm{~min}\end{array}$ & $\begin{array}{l}\text { Neurological } \\
\text { function } \\
\text { assessment }\end{array}$ & $\begin{array}{l}\text { Ischemic } \\
\text { cerebral cortex }\end{array}$ & 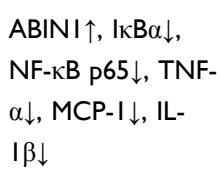 \\
\hline Liu, $2020^{59}$ & IS & EA & $\begin{array}{l}\text { GV20, } \\
\text { GVI4 }\end{array}$ & $\begin{array}{l}2 / 15 \mathrm{~Hz}, 1.0- \\
2.0 \mathrm{~mA}, 30 \mathrm{~min}\end{array}$ & - & $\begin{array}{l}\text { Ischemic } \\
\text { cerebral cortex }\end{array}$ & $\begin{array}{l}\text { NF- } \kappa B \downarrow, I L-I \beta \downarrow \text {, } \\
\text { TNF- } \alpha \downarrow\end{array}$ \\
\hline Liu, $2016^{60}$ & IS & EA & LIII, ST36 & $\begin{array}{l}\mathrm{I}-20 \mathrm{~Hz}, 0.2 \\
\mathrm{~mA}, 30 \mathrm{~min}, 3 \\
\text { days }\end{array}$ & $\begin{array}{l}\text { Assessment of } \\
\text { neurological } \\
\text { outcome }\end{array}$ & $\begin{array}{l}\text { Ischemic } \\
\text { cerebral cortex }\end{array}$ & 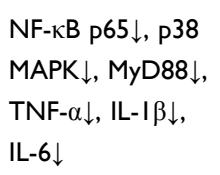 \\
\hline Jiang, $2017^{61}$ & IS & EA & $\begin{array}{l}\text { GV20, LI4, } \\
\text { LR3 }\end{array}$ & $\begin{array}{l}1.0 \mathrm{~mA}, 20 \mathrm{~Hz} \\
\text { for } 5 \mathrm{~min}, 2 \mathrm{~Hz} \\
\text { for } 30 \mathrm{~min}\end{array}$ & $\begin{array}{l}\text { Neurobehavioral } \\
\text { Evaluation }\end{array}$ & $\begin{array}{l}\text { Ischemic } \\
\text { cerebral cortex }\end{array}$ & $\begin{array}{l}\text { CYLD } \uparrow, ~ N F-\kappa B \downarrow \\
\text { TNF- } \alpha \downarrow, I L-I \beta \downarrow \\
\text { CX3CLI } \downarrow\end{array}$ \\
\hline $\mathrm{Hu}, 2020^{62}$ & CPIP & EA & ST36, BL60 & $\begin{array}{l}2 \mathrm{~Hz}, 0.5-\mathrm{I} .5 \\
\mathrm{~mA}, 30 \mathrm{~min}\end{array}$ & $\begin{array}{l}\text { MWT, TWL, } \\
\text { Hind paw edema } \\
\text { evaluation }\end{array}$ & $\begin{array}{l}\text { Spinal dorsal } \\
\text { horn }\end{array}$ & 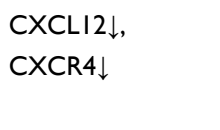 \\
\hline Wang, $2020^{63}$ & VD & MA & $\begin{array}{l}\text { GV20, } \\
\text { ST36 }\end{array}$ & $\begin{array}{l}10 \text { min, } 2 \\
\text { weeks }\end{array}$ & MWM & $\begin{array}{l}\text { Hippocampus, } \\
\text { plasma }\end{array}$ & 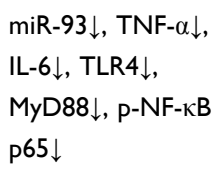 \\
\hline
\end{tabular}

(Continued) 
Table 4 (Continued).

\begin{tabular}{|c|c|c|c|c|c|c|c|}
\hline Refs. & $\begin{array}{l}\text { Inflammatory } \\
\text { Model }\end{array}$ & $\begin{array}{l}\text { Intervention } \\
\text { Methods }\end{array}$ & Acupoints & $\begin{array}{l}\text { Acupuncture } \\
\text { Parameters }\end{array}$ & $\begin{array}{l}\text { Inflammation- } \\
\text { Related } \\
\text { Behaviors }\end{array}$ & Test Sites & $\begin{array}{l}\text { Biochemical } \\
\text { Measurements }\end{array}$ \\
\hline Liu, $2016^{64}$ & IS & EA & LIII, ST36 & $\mathrm{I} / 20 \mathrm{~Hz}, 30 \mathrm{~min}$ & $\begin{array}{l}\text { Scoring of } \\
\text { neurological } \\
\text { deficits }\end{array}$ & $\begin{array}{l}\text { Ischemic } \\
\text { cerebral cortex }\end{array}$ & $\begin{array}{l}\text { miR-9 } \downarrow, \text { NF-кB } \downarrow \\
\text { TNF- } \alpha \downarrow, \text { IL-I } \beta \downarrow\end{array}$ \\
\hline Wang, $2017^{65}$ & MDD & MA & $\begin{array}{l}\text { GV29, } \\
\text { GV20 }\end{array}$ & $20 \mathrm{~min}, 28$ days & OFT & Frontal Cortex & Related to genes \\
\hline Liu, $2018^{66}$ & $\begin{array}{l}\text { Hemorrhagic } \\
\text { stroke }\end{array}$ & MA & GV20, GB7 & $\begin{array}{l}200 \mathrm{r} / \mathrm{min} \text { for } 5 \\
\mathrm{~min}, 3 \text { session }\end{array}$ & $\begin{array}{l}\text { mNSS, } \\
\text { encephaledema }\end{array}$ & Brain tissue & $\begin{array}{l}\text { Syk } \downarrow, \text { CARD9 } \downarrow \text {, } \\
\text { Mincle } \downarrow \text {, IL-I } \beta \downarrow\end{array}$ \\
\hline Zhao, $2020^{69}$ & Migraine & EA & $\begin{array}{l}\text { GB20, } \\
\text { GB34 }\end{array}$ & $\begin{array}{l}\text { 2/15 Hz, 0.5- } \\
1.0 \mathrm{~mA}, 20 \mathrm{~min}\end{array}$ & MWT & $\begin{array}{l}\text { Dura mater, } \\
\text { serum }\end{array}$ & $\begin{array}{l}\text { COX } 2 \downarrow, \text { CGRP } \downarrow \text {, } \\
\text { BDNF } \downarrow, I L-I \beta \downarrow, \text { IL- } \\
6 \downarrow, T N F-\alpha \downarrow\end{array}$ \\
\hline Huang, $2017^{70}$ & IS & EA & $\begin{array}{l}\text { GV20, } \\
\text { GV24 }\end{array}$ & $\begin{array}{l}2 / 20 \mathrm{~Hz}, 0.2 \\
\mathrm{~mA}, 30 \mathrm{~min}\end{array}$ & $\begin{array}{l}\text { Neurobehavioral } \\
\text { assessment, } \\
\text { MWM }\end{array}$ & $\begin{array}{l}\text { Hippocampal } \\
\text { CAI, ischemic } \\
\text { cerebral cortex }\end{array}$ & $\begin{array}{l}\mathrm{P} 2 X 7 \mathrm{R} \uparrow, \mathrm{P} 2 \mathrm{YIR} \uparrow, \\
\mathrm{IL}-10 \uparrow, \mathrm{IL}-\mathrm{I} \beta \downarrow\end{array}$ \\
\hline Wang, $2020^{71}$ & $A D$ & EA & $\begin{array}{l}\text { GV20, } \\
\text { BL23, KI3 }\end{array}$ & $\begin{array}{l}2 \mathrm{~Hz}, 0.6 \mathrm{~mA} \text {, } \\
15 \mathrm{~min}, 2 \\
\text { months }\end{array}$ & MWM & Cortex & $\begin{array}{l}\text { TNF- } \alpha \downarrow, \text { IL-6 } \downarrow \text {, IL- } \\
17 \downarrow, A \beta \downarrow\end{array}$ \\
\hline Cai, $2019^{72}$ & $A D$ & EA & $\mathrm{KI} 3$ & $\begin{array}{l}2 \mathrm{~Hz}, 1.0 \mathrm{~mA} \text {, } \\
15 \mathrm{~min}, 6 \\
\text { times } / 2 \text { weeks }\end{array}$ & $\begin{array}{l}\text { Cognitive } \\
\text { functions, Novel } \\
\text { object } \\
\text { recognition test, } \\
\text { Y-maze tests }\end{array}$ & $\begin{array}{l}\text { Prefrontal } \\
\text { cortex }\end{array}$ & $\begin{array}{l}\text { CDIII } \downarrow \text {, GFAP } \downarrow \text {, } \\
\text { COX-2 } \downarrow \text {, HO-I } \downarrow \text {, } \\
\text { transferrin } \downarrow, \text { Bax } \downarrow \text {, } \\
\text { A } \beta \downarrow\end{array}$ \\
\hline Jiang, $2018^{73}$ & $A D$ & EA & $\begin{array}{l}\text { GV20, } \\
\text { GV26, EX- } \\
\text { HN3 }\end{array}$ & $\begin{array}{l}2 \mathrm{~Hz}, 0.6 \mathrm{~mA} \text {, } \\
15 \text { days except } \\
\text { the 8th day }\end{array}$ & - & Hippocampus & $\begin{array}{l}\text { NLRP3 } \downarrow, \text { IL-I } \beta \downarrow \\
\text { ASC } \downarrow \text {, Caspase-I } \downarrow\end{array}$ \\
\hline Yu, $2020^{74}$ & PD & EA & $\begin{array}{l}\text { CVI2, } \\
\text { RN7, ST36, } \\
\text { LR3 }\end{array}$ & $\begin{array}{l}100 \mathrm{~Hz}, 1.0 \\
\mathrm{~mA}, 20 \mathrm{~min}, \mathrm{I} 4 \\
\text { days }\end{array}$ & $\begin{array}{l}\text { Rotational } \\
\text { behavior }\end{array}$ & $\begin{array}{l}\text { Substantia } \\
\text { nigra, striatum }\end{array}$ & $\begin{array}{l}\text { COX- } 2 \downarrow, \text { TNF- } \alpha \downarrow \text {, } \\
\text { IL-I } \beta \downarrow\end{array}$ \\
\hline $\mathrm{Du}, 2018^{76}$ & VD & MA & $\begin{array}{l}\text { ST36, } \\
\text { GV20 }\end{array}$ & $\begin{array}{l}2 \text { times/sec, } 30 \\
\text { sec, } 2 \text { weeks }\end{array}$ & MWM & Hippocampus & $\begin{array}{l}\text { TXNIP } \downarrow \text {, NLRP3 } \\
\text { inflammasome } \downarrow \text {, } \\
\text { IL- I } \beta \downarrow \text {, ROS } \downarrow\end{array}$ \\
\hline Zhu, $2020^{77}$ & $\mathrm{TBI}$ & MA & $\begin{array}{l}\text { GVI5, } \\
\text { GVI6, } \\
\text { GV20, } \\
\text { GV26, LI4 }\end{array}$ & $\begin{array}{l}360^{\circ} \text { twisting } \\
\text { range, } 120-160 \\
\text { beats } / \text { min for I } \\
\text { min, } 15 \text { min, } \\
\text { twisted once } \\
\text { every } 5 \text { min }\end{array}$ & - & Brain tissue & 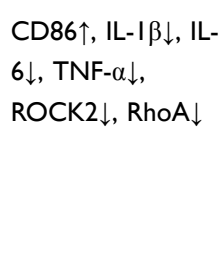 \\
\hline Frantz, $2017^{78}$ & Epilepsia & MA & GV20 & $\begin{array}{l}2 \mathrm{spins} / \mathrm{sec}, 15 \\
\mathrm{sec}, 10 \mathrm{~min}\end{array}$ & $\begin{array}{l}\text { Behavioral } \\
\text { seizure }\end{array}$ & Brain tissue & $\begin{array}{l}\text { TNF- } \alpha \downarrow, \text { SOD } \uparrow, \\
\text { CAT } \uparrow\end{array}$ \\
\hline
\end{tabular}

(Continued) 
Table 4 (Continued).

\begin{tabular}{|c|c|c|c|c|c|c|c|}
\hline Refs. & $\begin{array}{l}\text { Inflammatory } \\
\text { Model }\end{array}$ & $\begin{array}{l}\text { Intervention } \\
\text { Methods }\end{array}$ & Acupoints & $\begin{array}{l}\text { Acupuncture } \\
\text { Parameters }\end{array}$ & $\begin{array}{l}\text { Inflammation- } \\
\text { Related } \\
\text { Behaviors }\end{array}$ & Test Sites & $\begin{array}{l}\text { Biochemical } \\
\text { Measurements }\end{array}$ \\
\hline Zhang, $2020^{79}$ & Depression & EA & $\begin{array}{l}\text { GV29, } \\
\text { GV20 }\end{array}$ & $\begin{array}{l}2 \mathrm{~Hz}, 30 \mathrm{~min}, 7 \\
\text { days }\end{array}$ & OFT, FST, SPT & $\begin{array}{l}\text { Hippocampus, } \\
\text { serum }\end{array}$ & $\begin{array}{l}\text { IL-6 } \downarrow \text {, TNF- } \alpha \downarrow \text {, IL- } \\
\text { I } \beta \downarrow \text {, tryptophan } \uparrow \text {, } \\
\text { kynurenine } \downarrow \text {, } \\
\text { quinolinic acid } \downarrow \text {, } \\
5-H T \uparrow, \text { Kyn/Trp } \\
\text { radio } \downarrow, \text { NR2A } \downarrow \text {, } \\
\text { NR2B } \downarrow\end{array}$ \\
\hline Long, $2019^{80}$ & IS & $\begin{array}{l}\text { EA } \\
\text { pretreatment }\end{array}$ & $\begin{array}{l}\text { GV20, } \\
\text { BL23, SP6 }\end{array}$ & $\begin{array}{l}2 / 100 \mathrm{~Hz}, 1.0 \\
\mathrm{~mA}, 10 \mathrm{~min}, \mathrm{no} \\
\text { current for } 5 \\
\text { min, } 4 \text { times for } \\
\text { I h }\end{array}$ & $\begin{array}{l}\text { Neurological } \\
\text { deficit scores }\end{array}$ & Hippocampus & $\begin{array}{l}\text { TRPV-I } \downarrow, \text { P38 } \\
\text { MAPK } \downarrow, \text { TNF- } \alpha \downarrow \text {, } \\
\text { IL-I } \beta \downarrow\end{array}$ \\
\hline Kong, $2021^{81}$ & $\begin{array}{l}\text { Hemorrhagic } \\
\text { stroke }\end{array}$ & MA & GV20, GB7 & $\begin{array}{l}30 \mathrm{~min}, \\
200 \mathrm{rpm} / \mathrm{min}, 3 \\
\text { times, } 5 \mathrm{~min}, 3 \\
\text { days }\end{array}$ & $\begin{array}{l}\text { Neurobehavioral } \\
\text { assessment, } \\
\text { Motor functional } \\
\text { test, cognitive- } \\
\text { behavioral Tests, } \\
\text { encephaledema }\end{array}$ & $\begin{array}{l}\text { Perihematomal } \\
\text { area }\end{array}$ & 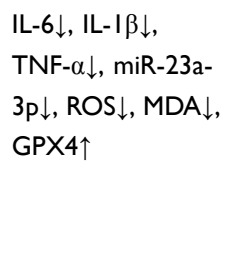 \\
\hline Zhang, $2016^{83}$ & Migraine & $\begin{array}{l}\text { EA pre- } \\
\text { treatment }\end{array}$ & GB20, TE5 & $\begin{array}{l}2 / 15 \mathrm{~Hz}, 1.0 \\
\mathrm{~mA}, 30 \mathrm{~min}, 5 \\
\text { days }\end{array}$ & - & $\begin{array}{l}\text { Trigeminal } \\
\text { ganglion }\end{array}$ & $\begin{array}{l}\text { CGRP } \downarrow, \text { PGE } 2 \downarrow \text {, } \\
\text { IL-I } \beta \downarrow, \text { COX } 2 \downarrow \text {, } \\
\text { CBI receptor } \uparrow\end{array}$ \\
\hline
\end{tabular}

Notes: $\uparrow$, upregulated by acupuncture; $\downarrow$, downregulated by acupuncture.

Abbreviations: SCl, spinal cord injury; TBI, traumatic brain injury; IS, ischemic stroke; CPIP, Chronic postischemia pain; VD, vascular dementia; MDD, major depressive disorder; AD, Alzheimer's disease; PD, Parkinson's disease; CENA, Cross electro-nape-acupuncture; SPT, sucrose preference test; OFT, open field test; NSS, neurological severity score; mNSS, modified neurological severity score; FST, forced swimming test; HMGBI, High mobility group box-I; PGE2, prostaglandin E2; TRAF6, TNF receptor associated factor 6; TRAM, Trif-related adaptor molecule; TRIF, TIR-domain-containing adaptor inducing interferon- $\beta$; RIPKI, receptor interacting protein kinase I; DRG, dorsal root ganglion; CYLD, cylindromatosis; ABINI, A20-binding inhibitor of NF- $\kappa B$ I; Syk, spleen Tyrosine Kinase; CARD9, caspase recruitment domain 9; CGRP, calcitonin gene related peptide; BDNF, brain-derived neurotrophic factor; A $\beta$, amyloid protein; P2X7R, purinergic P2X7 receptor; ASC, apoptosis-associated speck-like protein containing a CARD; TXNIP, thioredoxin-interacting protein; Rock2, Rho related protein kinase 2; TRPV-I, transient receptor potential vanilloid-I; GPX4, glutathione peroxidase 4; CBI, cannabinoid type I; GV9, Zhiyang; GV6, Jizhong; GV2, Yaoshu; GVI, Changqiang; GB20, Fengchi; TEI7, Yifeng; GB7, Qubin; GV24, Shenting; KI3, Taixi; GV26, Shuigou; EX-HN3, Yintang; CVI2, Zhongwan; RN7, Yinjiao; GVI5, Yamen; GVI6, Fengfu; TE5, Waiguan.

binding inhibitor of NF- $\mathrm{B} 1$ (ABIN1). The expression of TNF- $\alpha$, MCP-1, and IL- $1 \beta$ in the peri-infarct cortex is also down-regulated by EA, and the neuroinflammation in ischemic stroke rats is inhibited, with significant improvement of neurological functional deficit. ${ }^{58} \mathrm{MA}$ at GV20 +GV14 or LI11+ST36 can significantly improve microglial degeneration and necrosis in cortical brain tissue, inhibit transformation of microglia to the M1 phenotype, reduce infiltration of mononuclear phagocytes into and around the ischemic center, and down-regulate TNF- $\alpha$, IL-1 $\beta$, and IL-6 levels, which prevents apoptosis and necrosis of neurons in the ischemic penumbra after ischemic stroke. ${ }^{59,60}$

Chemokines and their receptors also play crucial roles in the anti-inflammatory effect of acupuncture. EA at
GV20, LI4, and LR3 inhibits the NF- $\kappa$ B signaling pathway and destroys the interaction of receptor-interacting protein 1 (RIP1) with KappaB kinase inhibitor $\gamma$ (IKK $\gamma)$ via upregulation of cylindromatosis (CYLD) expression in the cytoplasm of cortical neurons around the ischemic injury. It also induces the negative regulation of IKK (activated IKK) in the cortex around the injury and reduces the levels of the harmful pro-inflammatory cytokines TNF- $\alpha$, IL- $1 \beta$, and CX3CL1, thus inhibiting excessive microglial activation. ${ }^{61}$ EA at ST36 and BL60 also inhibits the overexpression of chemokine signal CXCL12/CXCR4 in the spinal dorsal horn and downstream ERK pathway of the chronic post-ischemic pain model, thereby decreasing neuronal and glial activity in the spinal dorsal horn, thus playing a strong anti-hypersensitivity role. ${ }^{62}$ 
MicroRNAs are also involved in NF- $\kappa \mathrm{B}$ signaling pathway activation in microglia. Acupuncture markedly reduces the inflammatory response of the nervous system by regulating microRNA. For instance, MA at GV20 and ST36 significantly inhibits microglial activation in vascular dementia (VD) rats induced by cerebral hypoperfusion via suppression of the miR-93-mediated TLR4/MyD88/ $\mathrm{NF}-\kappa \mathrm{B}$ signaling pathway, further reducing TNF- $\alpha$ and IL-6 levels in the hippocampus and plasma, thereby lowering the inflammatory response, and, simultaneously, enhancing memory, attention, and executive functions. ${ }^{63}$ EA at ST36 and LI11 up-regulates miR-9 and inhibits NF$\kappa \mathrm{B}$ activation while reducing TNF- $\alpha$ and IL-1 $\beta$ levels to reduce the inflammatory response of the cortex around the infarction. ${ }^{64}$

Significant advances in omics have clarified the antiinflammatory mechanism of acupuncture. In a major depressive disorder (MDD) model, a genomic analysis of MA at GV20 and Yintang (GV29) revealed that the multitarget antidepressant effect is related to amino acid metabolism and inflammatory pathways. TLR and NF- $\kappa B$ signaling are two important pathways through which acupuncture exerts its antidepressant effects. ${ }^{65}$ The NF$\kappa \mathrm{B}$ pathway is also activated by $\mathrm{C}$-type lectin receptors (CLRs), a subtype of PRRs. Syk is recruited and activated by the adaptor protein CARD9to promote the production of a variety of inflammatory cytokines. MA at GV20 via Qubin (GB7) was reported to reduce expression of the macrophage-inducible C-type lectin/spleen tyrosine kinase (Mincle/Syk) pathway protein in brain tissues after intracerebral hemorrhage. In particular, the reduced levels of the proteins Syk, CARD9, mincle, and IL-1 $\beta$ are thought to contribute to the alleviation of symptoms related to cerebral hemorrhage. ${ }^{66}$

Following external stimulation, for example, local ischemia or mechanical injury, dead neurons and oligodendrocytes release high concentrations of ATP, and rapidly hydrolyze, attract, and activate nearby microglia, which migrate to the injury site. ${ }^{67}$ This chemotaxis is mainly mediated by $\mathrm{P} 2 \mathrm{Y} 12 \mathrm{R}$ and purinergic $\mathrm{P} 2 \mathrm{X} 4$ receptor (P2X4R) ${ }^{68} \mathrm{MA}$ at GB20 and Yanglingquan (GB34) also affects P2Y12R, inhibits microglia activation, inhibits synthesis of Cox-2-dependent PGE2 in the trigeminal ganglion via suppression of the RhoA/ROCK pathway, and down-regulates calcitonin gene-related peptide (CGRP), brain-derived neurotrophic factor (BDNF), COX2, IL-1 $\beta$, IL- 6 , and TNF- $\alpha$ levels in the jugular vein serum. Therefore, acupuncture reduces plasma protein extravasation (PPE) and relieves migraine caused by dural neurogenic aseptic inflammation. ${ }^{69}$ EA at GV20 and Shenting (GV24) inhibits microglial activation, reduces IL-1 $\beta, \mathrm{P} 2 \mathrm{X} 7 \mathrm{R}$, and P2Y1R, and up-regulates IL10 in the hippocampus and prefrontal cortex, thereby inhibiting P2 purinoceptors-mediated inflammation in microglia after middle cerebral artery occlusion/reperfusion $(\mathrm{MCAO} / \mathrm{R})$ injury. $^{70}$

Inflammatory factors released by glial cells induce various chronic progressive neurodegenerative diseases. Amyloid protein $(\mathrm{A} \beta)$ exerts a direct toxic effect on neurons, which activates microglia to release inflammatory mediators that lead to the neuronal and cognitive impairment seen in Alzheimer's disease (AD). EA at GV20, BL23, or Taixi (KI3) inhibits glial cell activation in the cortex, down-regulates inflammatory factors, and reduces $\mathrm{A} \beta$ deposition in the brain. It also repairs neuronal damage and improves learning and memory ability. ${ }^{71,72}$ On the contrary, $A \beta$ induces NLRP3 inflammasome activation, IL-1 $\beta$ overexpression, and aggravation of neuroinflammation, which accelerates the development of Alzheimer's disease. EA at GV20, GV26, and GV29 inhibits activation of NLRP3, apoptosis-associated speck-like protein containing a CARD (ASC), and caspase-1, and reduces IL$1 \beta$ in hippocampus to exert its strong anti-inflammatory effect. ${ }^{73}$ Early aggregation of intracellular and extracellular $\alpha$-synuclein triggers inflammatory reaction, promotes glial cells to release toxic NOs and peroxides, and damages dopaminergic fibers and neurons in the striatum (ST) and substantia nigra (SN), leading to the symptoms of Parkinson's disease. EA at CV12, Yinjiao (RN7), ST36, and LR3 suppresses glial cell activation, down-regulates TNF- $\alpha$, IL- $1 \beta$, COX-2, and other inflammatory factors in SN and ST, improving spatial memory function by rescuing dopamine neurons on the verge of apoptosis, which, in turn, partially restores motor function, and alleviates anxiety, depression, and other symptoms. ${ }^{74}$

Brain oxidative stress, caused by an imbalance between the production and detoxification of ROS and reactive nitrogen species (RNS), plays a crucial role in brain inflammation. ${ }^{75}$ Acupuncture drastically reduces inflammation by inhibiting oxidative stress. Specifically, MA at ST36 and GV20 strongly down-regulates thioredoxininteracting protein (TXNIP), inhibits its binding with the NLRP3 inflammasome, and reduces IL-1 and ROS, thus relieving cognitive and neuronal impairment, as well as cerebral edema caused by $\mathrm{VD}^{76}$ Meanwhile, MA at Yamen (GV15), Fengfu (GV16), GV20, Shuigou (GV26), 
and LI4 enhances brain antioxidant defense, reduces expression of M1 microglia, inhibits RhoA/Rock2 signaling pathway and pro-inflammatory TNF- $\alpha$, IL-1 $\beta$, IL-6 in order to abrogate DNA damage of brain tissue near the lesion of traumatic brain injury (TBI) while enhancing neurological function. ${ }^{77}$ In the pentylenetetrazole (PTZ)induced epileptic model, MA at GV20 was shown to reduce ROS production, increase SOD and catalase (CAT) activity, inhibit expression of pro-inflammatory factor TNF- $\alpha$, produce anti-epileptic signal, inhibit abnormal discharge of damaged neurons, and finally reduce the degree of epileptic seizure. ${ }^{78}$

When oxygen and ATP energy, required for cell metabolism, are insufficient and the excitotoxicity of glutamate increases, over-activation of the N-methyl-D-aspartate receptor (NMDAR) and, eventually, cell death may result. Acupuncture modulates this process by inhibiting the inflammatory response. It was reported that EA at GV29 and GV20 reduces IL-1 $\beta$, IL-6, and TNF- $\alpha$ in the serum and hippocampus, restores the balanced expression between NMDAR subtypes, such as NR2B and NR2B, and produces an antidepressant effect. ${ }^{79}$ The TRPV-1 channel in the brain is activated by ischemic stroke. EA pretreatment at GV20, BL23, and SP6 is known to significantly inhibit the expression of TRPV-1 protein, MDA, TNF- $\alpha$, IL-1 $\beta$, and up-regulate glutathione (GSH) and SOD to produce a potent neuroprotective effect after ischemic stroke. ${ }^{80}$ Some microRNAs were also shown to be involved in oxidative stress and the inflammatory response in the brain. MA at GV20 and GB7 specifically reduces miR-23a-3p in brain tissues and further inhibits IL-6, IL-1 $\beta$, TNF- $\alpha$, ROS production, MDA, and glutathione peroxidase 4 (GPX4) activation, alleviating neuronal death, inflammation, and iron-induced death after intracerebral hemorrhage. ${ }^{81}$ The endocannabinoid system, which regulates and balances body's response to certain triggers, is primarily composed of endocannabinoids and the cannabinoid receptors $\mathrm{CB} 1$ and $\mathrm{CB} 2$. Cannabinoid type 1 receptor (CB1R) signaling plays an anti-injury, antihypersensitive, and anti-inflammatory role in this process. $^{82}$ EA pretreatment at GB20 and Waiguan (TE5) up-regulates CB1 receptor expression and inhibits electrical stimulation in trigeminal ganglion (TGES)-induced migraine. Moreover, IL-1 $\beta, \mathrm{COX} 2, \mathrm{PGE} 2$ and CGRP are down-regulated, which alleviates PPE and relieves dural neurogenic aseptic inflammation. ${ }^{83}$

The above evidence confirms that acupuncture can indeed promote the transformation of M1 microglia into
M2 microglia, and inhibit pro-inflammatory-related pathways and factors. Acupuncture also exerts its antiinflammatory role to achieve neuroprotection via inhibition of oxidative stress and activation of the endogenous cannabinoid system. Acupoints are mainly chosen from the Yangming Meridian of the hand and foot, and the Ren and Du Meridians. ST36, LI4, LI11, and GV20 are commonly used. Meanwhile, the effect of multiple acupoint stimulation is better than that of a single acupoint. For example, in a migraine rat model, the regulating effect of acupuncture GB20 + GB34 group on serum neuroinflammatory factors was better than that of a simple GB20 group. $^{69}$

\section{Motor System}

Among the diseases of the motor system, osteoarthritis (OA), as well as muscle and tendon injury, are common clinical diseases that respond well to acupuncture. Inflammatory symptoms including joint pain, swelling, and stiffness often occur, and these, as well as synovial inflammation, articular cartilage damage, and low bone density in OA patients, are induced by cytokines and chemokines released by infiltrating inflammatory cells. $^{84,85}$ Among them, $\mathrm{T}$ and $\mathrm{B}$ lymphocytes, synovial macrophages, and synovial fibroblasts typically infiltrate the locally diseased synovium, ${ }^{86-88}$ and pro-inflammatory factors such as IL-1 $\beta$, TNF- $\alpha$, IL- 6 , and matrix metalloproteinases (such as, MMP-1, MMP-3, and MMP-13) aggravate synovial inflammatory reactions, including synovial hyperplasia and fibrosis. ${ }^{89,90}$ This further erodes the cartilage and destroys the force balance of the joints. ${ }^{12}$ Acupuncture effectively alleviates inflammation of the motor system, and the known mechanisms are discussed below (Table S1).

\section{Monocytes/Macrophages}

Monocytes/macrophages can be activated by the chemokine MCP-1 in articular cartilage, synovial membrane, and synovial fluid. This induces the release of matrixdegrading enzymes, which drive and maintain leukocyte infiltration, causing synovial reactions and joint destruction. MA at Dubi (ST35) and ST36 inhibits expression of $\mathrm{MCP} 1$ and receptor $\mathrm{CCR} 2$ in the synovium and cartilage tissue, which further down-regulates levels of IL-1 $\beta$ and TNF- $\alpha$ in the joint tissue, as well as protects cartilage and synovium from inflammatory injury. ${ }^{91}$ EA at Neixiyan (Ex-LE4) and ST35 down-regulates IKK- $\beta$ and NF- $\kappa$ B p65, upregulates I $\mathrm{I} \mathrm{B}-\alpha$ in chondrocytes, and inhibits 
inflammatory cytokines like IL-1 $\beta$, IL-6, and TNF- $\alpha$ in cartilage and synovial fluid to delay degeneration of the cartilage. ${ }^{92}$ EA at ST36 and GB34 also inhibits the expression of TLR4, NF- $\kappa$ B p65, and NF- $\mathrm{B}$ p-p65 in the articular cartilage and exerts anti-inflammatory effects in an $\mathrm{OA}$ model. The combined effect of two acupoints was found to be better than that of GB34 alone. ${ }^{93}$ It was previously reported that serum from TNF- $\alpha$-treated chondrocytes, treated with EA serum (EAS), significantly reduces IL$1 \beta$ levels and enhances chondrocyte viability by inhibiting RAS, RAF, MEK1/2, and P-ERK1/2 protein expression. ${ }^{94}$ This study used post-acupuncture serum in the treatment regimen. This may provide some ideas for the transformation of "acupuncture drugs". EA at Ex-LE4 and ST35 inhibits NLRP3 inflammasome activation in the cartilage tissue of OA rats, inhibits downstream inflammatory factors IL- $1 \beta$ and its invertase caspase- 1 and its invertase, and alleviates inflammatory response. ${ }^{95}$ MA combined with EA at ST36, Chengshan (BL57), and ST36+BL57 reduces inflammation and leads to early remodeling, with increases in the non-collagen concentration within the achilles tendon, enhancing the strength of the tendon and shortening the early-stage tendon repair. ${ }^{96}$ In addition, acupuncture, in combination with low-frequency electrical stimulation (Acu-LFES) at GB34 and ST36, also attenuates denervation-induced muscle atrophy by stimulating the expression of macrophages and IL-6 in normal and denervated muscles or serum via upregulation of the insulin-like growth factor-1 (IGF-1)/Akt signaling pathway, further preventing soleus and plantaris muscle weight loss and increasing the muscle volume. $^{97}$

MMPs, derived from macrophages or fibroblasts in the synovium, cause destruction of the extracellular matrix structure and further aggravate the infiltration of inflammatory cells in OA. ${ }^{98}$ EA at ST36 and GB34 significantly reduces levels of macrophage inflammatory protein $1 \alpha$ (MIP-1 $\alpha$ ), MIP-2, and MCP-1 in serum and synovial fluid, thereby inhibiting MMPs expression and downregulating inflammatory mediators like vascular endothelial growth factor (VEGF), IP-10, IL-1 $\alpha$, TNF- $\alpha$, and leptin, which inhibit LPS-mediated arthritis in obese rats. EA inhibits the pro-inflammatory transformation of intestinal microbiota by increasing the ratio of Bacteroidetes/ Firmicutes, and promotes the recovery of the relative abundance of Clostridium, Ackermann, Butyricimonas, and Lactococcus. ${ }^{93}$ EA at ST35 and Ex-LE4 also reduces the expression of MMP-3 and MMP-13 in chondrocytes, regulates cartilage matrix metabolism, reduces degradation of type II collagen, and relieves knee arthritis. ${ }^{95}$

\section{The Endocannabinoid System}

The endocannabinoid system is involved in the analgesic and anti-inflammatory effects of acupuncture targeting acute inflammatory pain. It was revealed that EA at ExLE4 and ST35 enhances cannabinoid type 2 receptor (CB2R) expression in the knee meniscus and fibroblasts, inhibits release of IL- $1 \beta$ (thus reducing the inflammatory response), and improves mechanical and thermal pain thresholds, as well as the body weight percentage, prevents cartilage loss, and alleviates joint dysfunction in rats with knee osteoarthritis. ${ }^{99}$

To sum up, acupuncture inhibits the expression of chemokines and the TLR4/NF- $\mathrm{BB}$ signaling pathway, which, in turn, inhibits the activation of monocyte/macrophage cells and downregulates the expression of inflammatory mediators, such as MMPs, NLRP3, IL-1 $\beta$, and TNF- $\alpha$. This reduces the perception of inflammatory pain in motor system-related diseases, and inhibits the proliferation of synovial tissue as well as the destruction of articular cartilage morphology. Activation of the endocannabinoid system also forms part of the acupuncture antiinflammatory action. Both a local single acupoint and matching acupoints are used for acupuncture to treat motor system dysfunction. Among them, the ST36 acupoint is the most used, and ST35, Ex-LE4, and other acupoints, located near the knee or ankle joint, are also frequently used. Local muscle-rich acupoints, such as BL57, are used in muscle, tendon injury, and other models. Acupuncture provides bidirectional regulation. Upon appropriate acupuncture stimulation, the disordered function restores to normal. Acupuncture at the same acupoints, such as ST36 and GB34, not only down-regulates proinflammatory factors to treat OA but also, with appropriate stimulation, upregulates the expression of macrophage inflammatory factors in the muscles in a muscle atrophy model, which may be related to the type and varying stages of disease. $^{93,97}$

\section{Circulatory System}

The circulatory system is a continuous closed-pipeline system that is distributed all over the body. Inflammation is currently recognized as the main pathological basis of atherosclerosis, hypertension, and other circulatory diseases, as well as an important complication of these diseases. Tissue cell injury and subsequent pathogen invasion 
of the cardiovascular system causes necrotic cells to release DAMPs, act on TLRs and NLRs, and activate intracellular inflammasome signaling that initiates an innate immune response. As shown in Table S1, EA pretreatment at PC6 greatly improves ventricular function remodeling directly related to the inflammatory response, reduces the infarct size, and increases the left ventricular fraction shortening (FS) and ejection fraction (EF). The potential mechanisms include EA inhibiting the activation of M1 macrophages in the myocardium and spleen while promoting the activation of M2 macrophages. In addition, acupuncture was shown to further inhibit the activation of NLRP3 inflammatory bodies in M1 macrophages and reduce caspase- 1 and IL- $1 \beta$ in the myocardium. ${ }^{100}$ Several lines of evidence have confirmed that acupuncture effectively treats circulatory system diseases and adjusts the levels of a variety of chemical components, such as plasma proteins, blood ammonia, electrolytes, enzyme activities, and other biological active substances to regulate vascular function, promote the formation of collateral neovascularization, improve the microcirculation, and enhance the remodeling of ventricular function. However, there are relatively few studies on the mechanism of acupuncture-driven therapeutic effects from the perspective of regulating the inflammatory response.

\section{Endocrine System}

As many endocrine glands and hormones interact with one another, the clinical manifestations of endocrine system diseases are varied and complex, often involving the abnormal function of organs in multiple systems, resulting in abnormal metabolism of carbohydrates, proteins, fats, water, electrolytes, and purines. ${ }^{101}$

Chronic, subclinical, and non-specific inflammatory states are closely related to the occurrence and development of type 2 diabetes. PI3K/Akt signaling is a welldefined insulin signal transduction pathway, which is known to affect glucose metabolism and protein synthesis via the regulation of inflammatory responses and vascular homeostasis. As shown in Table S1, it was reported that EA at PC6, ST36, SP6, and BL23 inhibits weight gain in type 2 diabetic rats induced by a high-fat diet, activates the PI3K/Akt signaling pathway, inhibits the adhesion cascade and harmful vascular inflammation, and regulates the expression and action of eNOS in endothelial cells, thereby, ultimately, affecting the functional structure of pancreatic beta cells, insulin sensitivity, and insulin secretion. $^{102}$ Histone acetylation also regulates macrophage functions. EA at ST36, ST40, Zhongji (CV3), and CV4 also stimulates Sirt1 and Sirt1dependent deacetylation of histone (H3K9) in white adipocytes by activating Sirt1-dependent histone deacetylation, downregulating M1-type peritoneal macrophage expression, and inhibiting the NF- $\mathrm{BB}$ signaling, which, in turn, down-regulates pro-inflammatory factor TNF- $\alpha$ levels, and finally relieves chronic and low-grade inflammation caused by dietary obesity (DIO), improves insulin sensitivity, glucose tolerance, and lowers the blood lipid content. ${ }^{103} \mathrm{EA}$ at $\mathrm{CV} 12$ and CV4 inhibits proliferation and/or infiltration of macrophages into the adipose tissue of obese rats, and promotes an anti-inflammatory adipokine balance, reducing the adiponectin/leptin ratio to improve insulin sensitivity and reduce blood glucose levels. $^{104-106}$

Long-term hyperglycemia in diabetic patients causes significant damage to both large blood vessels and microvessels and gives rise to complications in the heart, stomach, and peripheral nerves. In a rat model of diabetic cardiomyopathy (DCM), MA at PC6 and ST36 reduces blood glucose by upregulating type 1 insulin-like growth factor receptor (IGF1R) to restore adenosine 5'monophosphate (AMP)-activated protein kinase, which is a key molecule in the regulation of energy metabolism. It also inhibits NLRP3-inflammasome activation and downregulates IL-1 $\alpha$, IL-1 $\beta$, IL-6, IL-8, TNF- $\alpha$, ICAM-1, and MCP-1 in the myocardial tissue and blood. Acupuncture can also improve myocardial remodeling, as well as systolic and diastolic function in DCM rats. ${ }^{107}$ Diabetic gastroparesis is a complication induced by gastrointestinal autonomic nerve dysfunction. Acupuncture is reported to relieve dyspepsia symptoms and promote gastric emptying in patients with diabetic gastroparesis. It was shown that ICC damage in gastric tissue is the main cause of delayed gastric emptying in diabetic patients. HO-1, expressed by ICCs, is an inducible heme oxygenase subtype, which catalyzes heme degradation and participates in antiinflammatory and oxidative stress reactions. EA at ST36 promotes HO-1 positive M2 macrophage expression, reduces M1 macrophage expression, upregulates IL-10, reverses pathological alterations in ICCs in diabetic gastroparesis rats, and protects the ICC network in gastric tissue. $^{108}$ Diabetic peripheral neuropathy (DPN) results from chronic sensory and motor nerve damage caused by hyperglycemia and metabolic disorders. MA at BL13, Pishu (BL20), and BL23 inhibits activation of the spinal microglia as well as the release of the inflammatory factors 
TNF- $\alpha$, IL-1 $\beta$, and IL-6 to improve peripheral nerve dysfunction. ${ }^{109}$

Taken together, in cases of endocrine diseases such as diabetes, obesity, and diabetic complications, ST36 is the most frequently used acupuncture point. Ample evidence confirms that acupuncture at ST36 has a satisfactory curative effect on DCM, diabetic gastroparesis, and DPN. Both low-frequency and high-frequency EA with ST36 promotes gastric emptying in rats, suggesting that for diabetic gastroparesis, the frequency of electroacupuncture was not the most critical factor affecting its efficacy. ${ }^{108}$ Therefore, acupuncture can regulate PI3K-Akt and NF- $\mathrm{KB}$ signaling pathways that affect the production of inflammatory cytokines to inhibit inflammation, and plays a satisfactory role in the treatment of diabetes. It also has a benign regulatory effect on the functions and hormones of endocrine glands, such as islets and endocrine cells (which are widely distributed in various organs). However, the exact mechanism requires further investigation.

\section{Genitourinary System}

The urinary and reproductive systems share a common origin during ontogenesis. Hence, they are closely related in structure and function, and diseases of one system often influence the other. In recent years, clinical studies have revealed that acupuncture has a therapeutic effect on the treatment of upper urinary tract inflammation, such as pyelonephritis and inflammation of the ureter, as well as lower urinary tract inflammation, such as cystitis and urethritis. Acupuncture also improves typical urinary tract irritation symptoms, such as frequent urination, urgency of urination, pain during urination, and hematuria, as well as systemic symptoms, such as shivering, fever, and fatigue caused by an inflammatory reaction. It also has good curative effects on genital system inflammation, such as vaginitis, cervicitis, pelvic inflammatory disease, endometritis, salpingitis, peritonitis, and pelvic connective tissue inflammation. As shown in Table S1, it was reported that EA pretreatment at SP6 and CV4 reduces the levels of inflammatory cytokines, such as IL-6, TNF- $\alpha$, MCP-1, and VEGF, reduces serum steroid hormones (progesterone and testosterone), decreases ovarian weight and vascular permeability in female rats with ovarian hyperstimulation syndrome (OHSS), and prevents disease progression. ${ }^{110}$ Further proteomic analysis suggests that the antiinflammatory effects of EA on OHSS may be mediated by the up-regulation of CD200, a member of the immunoglobulin superfamily, which inhibits the release of pro- inflammatory cytokines, thus affecting the progress of OHSS in the ovary. ${ }^{111}$ Acupuncture stimulation at Shenmen (HT7) alleviated the behavioral impairment (immobility time) and reduced the plasma levels of corticosterone, IL-1 $\beta$, IL- 6 and glial cell-derived neurotrophic factor by maternal separation, indicating that acupuncture helps to relieve maternal separation-induced depression. ${ }^{112}$ However, the specific cell types involved and detailed underlying mechanisms of this process remain unknown. There is also limited research on urinary inflammatory diseases, which requires further attention in the future.

\section{Summary}

The multi-system anti-inflammatory effect of acupuncture involves the regulation of innate immune cells (such as macrophages, granulocytes, and mast cells) as well as adaptive immune cells (such as lymphocytes; Figure 2). Following acupuncture, macrophages transform from the M1 pro-inflammatory type to the M2 antiinflammatory type, and the negative regulator of TLR4, $\operatorname{PPAR} \gamma$, is activated to inhibit the intracellular TLR/ MyD88 and NOD signaling pathways, which regulates the downstream I $\mathrm{B} \alpha / \mathrm{NF}-\kappa \mathrm{B}$ and P38 MAPK pathways, as well as other inflammation-related pathways, thereby inhibiting NLRP3 inflammasome activation, reducing ASC and caspase-1 recruitment, and down-regulating proinflammatory factors (such as TNF- $\alpha$, IL-1 $\beta$, IL-6, and IL-18), MCP-1, adhesion molecules (ICAM-1 and VCAM-1), and INF- $\gamma$, which promotes the release of anti-inflammatory cytokines (such as IL-10). Acupuncture also regulates the balance of lymphocyte Th cells. In the case of autoimmune diseases such as RA, acupuncture down-regulates Th1 cells and inhibits their secretion of pro-inflammatory cytokines such as INF- $\gamma$, IL-2, and TNF- $\alpha$, while simultaneously upregulating Th2 cells and promoting the secretion of antiinflammatory cytokines such as IL-4, IL-5, IL-6, IL-10, and IL-13. In the case of inappropriate immune response diseases such as asthma, acupuncture up-regulates Th1 cells and down-regulates Th2 cells to exert its antiinflammatory function. Acupuncture also regulates the process of oxidative stress, improves SOD activity through the Nrf2/HO-1 pathway, eliminates oxygen free radicals to reduce damage, and inhibits ROS, MDA, and MPO production, to inhibit inflammatory cell infiltration, and alleviate inflammation-induced tissue injury and dysfunction. 


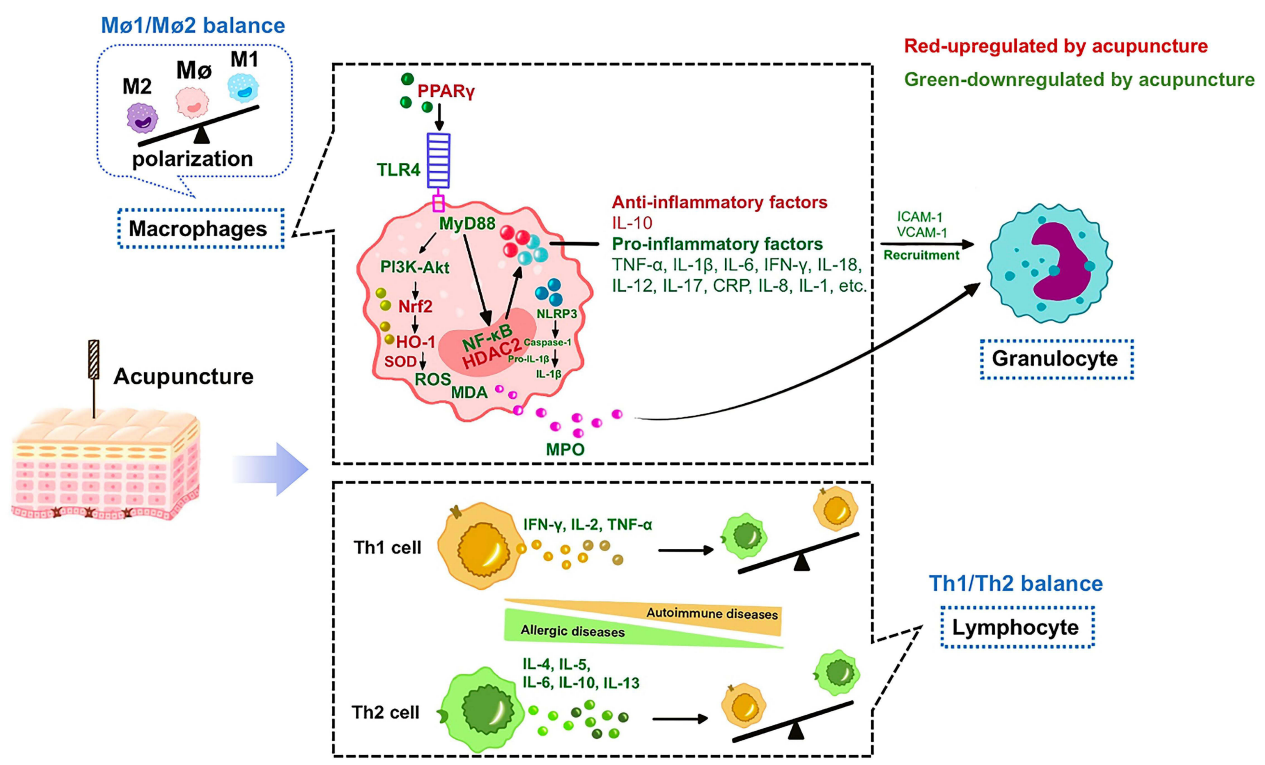

Figure 2 Common anti-inflammatory effects of acupuncture in various systems. Factors in red are up-regulated by acupuncture, while factors in green are down-regulated by acupuncture. Acupuncture fights against inflammation using two major pathways: regulating macrophage polarization and preserving Th cell balance.

Abbreviations: PPAR $\gamma$, peroxisome proliferator-activated receptor $\gamma$; TLR4, Toll-like receptors; MyD88, myeloid differentiation factor 88; SOD, superoxide dismutase; ROS, reactive oxygen species; MDA, malondialdehyde; HO-I, heme oxygenase-I; Nrf2, NFE-related factor 2; MPO, myeloperoxidase; NLRP3, NOD-like receptor protein 3; ASC, apoptosis-associated speck-like protein containing a CARD; INF- $\gamma$, interferon $\gamma$; p38 MAPK, p38 mitogen activated protein kinase; NF-kB, nuclear factor kappa-B; HDAC2, histone deacetylase inhibitor 2; CRP, C-reactive protein; ICAM-I, intercellular cell adhesion molecule-I; VCAM-I, vascular cell adhesion molecule-I.

\section{The Anti-Inflammatory Mechanisms of} Acupuncture from Acupoint to Target Organs via the Neuro-Immune Regulation Acupoint Initiation by Acupuncture Promoting Anti-Inflammatory Action

Most acupoints possess a three-dimensional structure, with a dense distribution of nerves, regular arrangement of blood vessels, and rich inherent connective tissue under a thin layer of skin. ${ }^{113}$ A variety of cells, signaling pathways, and molecules in acupoints mediate the therapeutic effects of acupuncture to combat inflammatory diseases. For instance, in CFA models, acupuncture enhances the network communication strength between the cells in the acupoint by using complex network analysis of multiple cytokines and chemokines, which amplifies and transmits acupuncture information from the acupoints. Fibroblasts and macrophages are the key cells that are stimulated with MA stimulation of the ST36 acupoint. ${ }^{114}$ Gene chip assays revealed that the MA stimulation of ST36 modulates the expression of 236 genes and seven signaling pathways (ERK, P38, JNK, P53, BCR, TCR, and TLR receptor signaling), among which the ERK pathway was the most notable. ${ }^{115}$ Apart from this, the upregulation of NF- $\mathrm{kB}$ signaling and the related cytokine gene expression (p-p65, p-p50, Nikbia, IL-1 $\beta$, IL-6, CXCL1, CCL2, Rela, and NF-kB1) are also associated with ST36 stimulation.
Alternately, NF- $\mathrm{kB}$ inhibitors suppress the acupuncture analgesic effect by reducing IL-6 levels and the proportion of $\mathrm{CD} 68^{+}$macrophages. ${ }^{116}$ In addition, the association of adenosine to adenylate A1 receptors in acupoints mediates the anti-inflammatory and analgesic effects of acupuncture in CFA models. ${ }^{117,118}$ It is also reported that EA at ST36 for 7 days increases CB2R expression, with no effect on CB1R in the acupoint, thereby inhibiting the influx of calcium ions, suppressing the TLR4/NF- $\mathrm{KB}$ pathway in the spleen, and eventually, down-regulating expressions of TNF- $\alpha$, IL- $1 \beta$, and IL- 6 in the serum, ${ }^{119}$ suggesting that the cannabinoid system in acupoints is intricately involved in the acupuncture-mediated anti-inflammatory process. Acupuncture also promotes mast cell degranulation and fibroblast structure remodeling to induce release of ATP, substance P (SP), tryptase, histamine (HA), interleukins, 5-hydroxytryptamine (5-HT), and other substances, which also mediate acupuncture action. ${ }^{120}$

As mentioned above, the anti-inflammatory effect of acupuncture is mediated by activating the immune response within the acupoints. The "minimally invasive" stimulation of acupuncture induces a variety of DAMPs at the local acupoints, including HMGB1, adenosine, ${ }^{117}$ and heat shock protein (HSP). ${ }^{121}$ Additionally, our unpublished work has shown that acupuncture increases HMGB1 protein content at acupoints, which mediates the analgesic 
effect of acupuncture. DAMPs activate immune cell functions and promote the release of inflammatory mediators such as interleukins. In addition, the content of local glucocorticoids in acupoints increases after MA, which may limit inflammation at local acupoints. We, therefore, speculate that the orderly and controllable inflammatory network at acupoints is highly beneficial to the activation of immunity throughout the body, thus achieving a strong anti-inflammatory effect.

Exosomes are membranous vesicles that transfer molecules, such as lipids, proteins, mRNA, miRNA, and DNA from one cell to another for informational exchange. Studies have revealed that exercise causes skeletal muscle contraction, which releases exosomes into the blood circulation, which, in turn, communicates with the peripheral and distant organs, and promotes metabolism in various systems. Our preliminary data confirmed that the analgesic and anti-inflammatory effect of acupuncture is weakened after blocking local exosome and mast cell activity at acupoints. $^{122}$ Mast cell-derived exosomes (MC-Exos) release is known to activate $\mathrm{B}$ and $\mathrm{T}$ lymphocytes, as well as TRPV receptors in sensory nerve endings via the release of multiple neuroimmune signaling molecules, ${ }^{123}$ which are speculated to mediate the acupuncture curative effect.

In short, upon stimulation of an acupoint, the local fibrous tissue entangles and breaks, resulting in cellular damage. As a result, damage-related factors are released, which activate the corresponding cells (macrophages, mast cells, and fibroblasts), inflammatory ERK and $\mathrm{NF}-\kappa \mathrm{B}$ pathways, and various neuroimmune molecules, including adenosine, CB2R, SP, and interleukins. This leads to the release of exosomes, which initiate the dynamic network within the acupoint, and the acupuncture information is locally amplified to produce an anti-inflammatory effect.

\section{Signal Transmission from the Afferent Pathway to the Central Nervous System After Acupuncture} Stimulation

In 2014, the US National Institutes of Health (NIH) specifically proposed the stimulating peripheral activity to relieve condition (SPARC) program, whereby the peripheral activity is stimulated to relieve a given condition. Since vagal nerve stimulation (VNS) involves an invasive surgical procedure, alternative methods such as EA gained much popularity in driving somatosensory-autonomic pathways. Torres-Rosas et al reported that sciatic nerve activation with EA at ST36 controls systemic inflammation. The same year, it was reported that EA pretreatment at ST36 and SP6 offers substantial protection against lung injury via the sciatic nerve. ${ }^{124}$ Results revealed that EA improves lung ventilation function and decreases IL-1 $\beta$, IL-6, TNF- $\alpha$, and MPO levels. Interestingly, the protective effect of EA disappears once the sciatic nerve is severed, but not when the peroneal or tibial nerves are severed. This indicates that the ST36 and SP6 stimulation promotes anti-inflammatory activities via the sciatic nerve. ${ }^{14}$ However, the DRG to spinal cord route of acupuncture signal transmission is not well studied and requires further investigation.

Acupuncture regulation also requires multi-level CNS participation. The somatosensory signals from acupoints project to the nucleus tractus solitarius (NTS), dorsal motor nucleus of vagus (DMV), hypothalamus, amygdala, and other primary parts of the brain. Upon acupuncture stimulation, there is a marked discharge of the brainstem nuclei, along with up-regulation of the c-Fos-positive cells in the NTS and DMV. ${ }^{125}$ Apart from this, it has been reported that MA at ST36 decreases TNF- $\alpha$ production in the spleen and serum via activation of the vagus nerve and splenic nerve activity originating from the dorsal vagal complex (DVC). ${ }^{126}$ Furthermore, Takahashi et al revealed that acupuncture at ST36 increases the number of c-Fosimmunopositive cells in the NTS and DMV, whereas acupuncture at ST25 increases the number of c-Fosimmunopositive cells in the NTS and rostral ventrolateral medulla (RVM). ${ }^{127}$ At the hypothalamic level, EA at LI4 and LI11, along with GV14 and GV20 increases the functional connectivity between the anterior hypothalamus and amygdala in both rats and humans, as evidenced by magnetic resonance imaging (MRI), and specifically increases the production of anti-inflammatory cytokines. ${ }^{128}$ The participation of the NTS, DMV, raphe nuclei, area postrema, lateral hypothalamic area (LHA), and paraventricular nucleus (PVN) of the hypothalamus in acupuncture was also confirmed by neuroanatomical tracing, following the injection of a neuronal tracer into the stomach and ST36. ${ }^{129}$ In conclusion, the somatic afferents activated by acupuncture are conveyed to the corresponding nuclei of the brainstem and hypothalamus.

\section{The Neuro-Immune Efferent Pathway of Acupuncture-Mediated Anti-Inflammatory Effects}

The CNS is a crucial integration site for acupuncturedriven information as well as information input from disease-associated inflammation. Moreover, it provides 
extrinsic neural outputs in a widespread and integrated manner. Several studies have revealed that acupuncture inhibits inflammation by activating interneurons in the brain stem (including the NTS). It also stimulates multiple pathways, such the cholinergic anti-inflammatory pathway (CAIP), vagus-adrenal medulla-dopamine, and sympathetic pathways, which offer rapid, accurate, and timely first aid, as well as the endocrine-immune pathway (particularly, the HPA axis), which covers broader functions over longer durations.

\section{The Cholinergic Anti-Inflammatory Pathway}

Prior to 2000, it was generally believed that the antiinflammatory response of acupuncture was realized through humoral regulation. In recent years, the antiinflammatory effect of acupuncture, mediated by CAIP, has received worldwide acknowledgment in different models. Acupuncture modulates the vagal nerve and exerts an anti-inflammatory effect via CAIP or the vagus-adrenal medulla-dopamine pathway, both of which are dependent on the integrity of the vagus nerve. As Lim et al reported, the application of MA or EA at ST36 is highly effective in attenuating phospho-ERK1/2 and TNF- $\alpha$ production in hepatic cells via vagal modulation in the concanavalin A model of hepatitis. On the other hand, vagotomy strongly suppresses acupuncture effects. ${ }^{130}$ Sepsis, often leading to myocardial injury, is effectively abolished by EA at ST36, which reduces TNF- $\alpha$ and NO levels, thereby strongly inhibiting neutrophil accumulation, and lowering the plasma activity of CK-MB. Upon vagotomy, EA stimulation shows considerably fewer anti-inflammatory and protective effects. ${ }^{16}$ As expected, after segmental blockage of the vagus nerve caused by subphrenic vagotomy or mecamylamine hydrochloride, the protective effects of pre-EA at LI4 on liver ischemia-reperfusion injury are abolished. These results suggest that the antiinflammatory effect of EA at different acupoints is associated with the corresponding segmental activation of CAIP. $^{30}$

Acetylcholine (ACh) and the $\alpha 7$ nicotinic acetylcholine receptor $(\alpha 7 \mathrm{nAChR})$ are the key components of CAIP. In a rat model of obesity, EA, but not MA, reduced rats' body weight by enhancing vagal activity. EA promotes ACh release and activates $\alpha 7 \mathrm{nAChRs}$ in mesenteric white adipose tissues (mWAT), inhibiting proinflammatory TNF- $\alpha$ production. $^{131}$ The $\alpha 7 \mathrm{nAChRs}$ are widely distributed in the hippocampus, prefrontal cortex, basal ganglia, temporal cortex and peripheral lymphocytes, macrophages and other regions, of which the highest $\alpha 7 \mathrm{nAChR}$ content is found in the hippocampus. ${ }^{132}$ In a postoperative cognitive dysfunction (POCD) model, established by the removal of the left lobe of the liver, EA at GV20, PC6, and LI4 for seven days reduced the inflammatory reaction by increasing $\alpha 7 \mathrm{nAChR}$ expression and decreasing the levels of pro-inflammatory cytokines TNF- $\alpha$ and IL-1 $\beta$ in hippocampal neurons. ${ }^{133}$ In ischemic stroke, EA at GV20 and GV24 for seven days also increases $\alpha 7 \mathrm{nAChR}$ expression and decreases pro-inflammatory cytokines TNF- $\alpha$ and IL-1 $\beta$ levels in hippocampal neurons to attenuate learning and memory impairment. ${ }^{134}$ Using $\alpha 7 \mathrm{nAChR}$ antagonists or agonists, it was demonstrated that $\alpha 7 \mathrm{nAChR}$ upregulation following acupuncture minimizes inflammatory responses in tissues. It was further revealed that EA pretreatment at ST36 and BL13 attenuates acute lung injury via restoration of $\alpha 7 \mathrm{nAChR}$-dependent cholinergic signaling and inhibition of HMGB1, IL- $1 \beta$, and TNF- $\alpha$ release in the CPB model. ${ }^{135} \mathrm{Li}$ et al demonstrated that EA pretreatment at LI4 or non-selective nicotinic ACh receptor (AChR) agonist administration ameliorates $\mathrm{I} / \mathrm{R}$-associated liver tissue damage in a time-dependent manner. The underlying EA mechanism was induced by the inhibition of liver neutrophil accumulation and serum inflammatory factors TNF- $\alpha$ and IL-6 release, but with little influence on IL-10. ${ }^{30}$ In intestinal ischemia-reperfusion injury, EA and $\alpha 7 \mathrm{nAChR}$ agonists exhibit similar effects on attenuating mucosal damage, which is done by promoting mucosal $\alpha 7 \mathrm{nAChR}$ mRNA expression and preventing mucosal NF- $\kappa \mathrm{B}$ p65, serum IL-6, and TNF- $\alpha$ production. Additionally, these protective effects of EA can be reversed by an $\alpha 7 \mathrm{nAChR}$ antagonist, suggesting that $\alpha 7 n A C h R$ plays an important role in EA. ${ }^{136}$ Another study reported that EA at GV20 for five consecutive days markedly reduces inflammation via increasing $\alpha 7 \mathrm{nAChR}$ and anti-inflammatory factor TGF-1 $\beta$ and IL10 expression, while decreasing pro-inflammatory cytokine TNF- $\alpha$ and IL-18 expression in ischemic brain neurons. ${ }^{137} \mathrm{Ma}$ et al revealed that EA pretreatment increases the expression of anti-inflammatory cytokines by conversion of microglia from the M1 to M2 phenotype via $\alpha 7 \mathrm{nAChR}$ signaling during cerebral ischemia. ${ }^{138}$

Besides the nicotinic receptor $\alpha 7 \mathrm{nAChR}$, muscarinic receptors are also present on cholinergic neurons in various areas of the brain. The anti-inflammatory role of EA GV20 and GV14 is also mediated by up-regulating the five subtypes of muscarinic receptors (M1, M2, M3, M4, and $\mathrm{M5})$ in the peri-infarct area to protect the brain during 
ischemic stroke. ${ }^{139}$ In addition, ACh synthesis is closely related to acetylcholine transferase (ChAT) and acetylcholinesterase (AChE) activities. In the ischemic stroke model, EA at GV14 and GV20 attenuates ischemiainduced impairment of the central cholinergic system via modulation of the ChAT mRNA level. ${ }^{139}$ Two major $\alpha 7$ nAChR downstream pathways, janus kinase 2 (JAK2)/ signal transducer and activator of transcription 3 (STAT3) and MAPK, play important roles in the occurrence and development of inflammation. In the chronic cerebral hypoperfusion model, MA at ST36 and GV20 upregulates $\alpha 7 \mathrm{nAChR}$, thus activating the JAK2/STAT3 pathway and reducing expression of TNF- $\alpha$ and IL- 6 in the hippocampus in order to protect neurons. ${ }^{140}$ Although normal levels of activated JAK2/STAT3 are essential for cellular functions, excess STAT3 activation is detrimental to the brain. EA at GV20 and GV14 for four weeks markedly reduces inflammatory injury by downregulating excessive activation of JAK2 and STAT3, as well as TNF- $\alpha$ and IL-1 $\beta{ }^{141}$ Neuroinflammation is involved in the occurrence and development of neuropathic pain, characterized by the release of proinflammatory cytokines in the DRG or spinal cord. EA at ST36 and SP6 alleviates SNI-induced mechanical hypersensitivity, possibly via the activation of $\alpha 7 \mathrm{nAChR}$, inhibition of the JAK2/STAT3 pathway, and down-regulation of pro-inflammatory cytokines TNF- $\alpha$, IL- 6 , and IL- $1 \beta$ in the DRG or spinal cord. ${ }^{142,143}$

In the respiratory system, acupuncture exerts the opposite effect on the regulation of the cholinergic system. ${ }^{144}$ ${ }^{147}$ It is well known that $\mathrm{ACh}$ is a major transmitter of parasympathetic nerve fibers, which innervate the glands and smooth muscles of the airway. ACh is also produced in a large number of non-neuronal cells in the lungs, such as $\mathrm{T}$ and $\mathrm{B}$ cells, alveolar macrophages, airway epithelial cells, dendritic cells, and pulmonary endothelial cells. It is a major contributor to COPD and asthma pathogenesis. ${ }^{148}$ EA at ST36 and BL13 regulates COPD inflammation via inhibition of ACh and $\alpha 7 \mathrm{nAChR}$ production. ${ }^{149}$ Multiple studies have suggested that MA is effective in treating asthma using the GV14, BL12, and BL13 acupoints. Among these, acupuncture at BL13 is the most beneficial for relieving asthma symptoms. This is achieved by downregulating ChAT expression and restoring the impaired mAChR M1 and M2 expression. ${ }^{150}$ Low ChAT levels, in combination with the restored $\mathrm{mAChRs}$, further inhibit ACh release from the pre-synapses of parasynaptic neurons. As a consequence, AChE expression declines. In
COPD patients, strong inhibition of the JAK2/STAT3 postreceptor and NF- $\mathrm{kB}$ pathways correlates with a decrease in $\mathrm{ACh}$ and $\alpha 7 \mathrm{nAChR}$ levels after EA treatment. ${ }^{149}$ It is evident that acupuncture has distinct regulatory effects on the ACh system in respiratory models. Therefore, further studies are necessary to explain the biodirectional regulatory mechanism of EA on the ACh system in respiratory and other systems.

In brief, acupuncture regulates the expression of $\mathrm{ACh}$ and its corresponding receptors either directly or indirectly via association with $\alpha 7 \mathrm{nAChR}$. This is done via the indirect regulation of ChAT and $\mathrm{AChE}$, and modulation of the downstream targets of JAK2/STAT3, NF- $\mathrm{BB}$, and MAPK signaling, which brings about an anti-inflammatory effect.

\section{The Vagus-Adrenal Medulla-Dopamine Pathway}

Acupuncture signals at ST36 have been demonstrated to reach the adrenal medulla via the vagus nerve, triggering the vagal-adrenal medulla reflex, and releasing dopamine (DA) to produce an anti-inflammatory effect in septic models. ${ }^{14}$ Similar studies reported that a 30 -min EA at ST36 shows strong potency in alleviating intestinal inflammation and barrier dysfunction by significantly increasing the DA plasma levels and lowering TNF- $\alpha$ via the DA type 1 (D1) receptor pathway in the intestinal ischemia model. ${ }^{151} \mathrm{Ma}$ et al provided a neuroanatomical explanation of EA at ST36 in driving the anti-inflammatory action via the vagal-adrenal axis. Deep, but not superficial ST36 stimulation, at low intensity is crucial for activating the major nerve bundles containing PROKR2ADV fibers that innervate the deep limb fascia. In contrast, spinal sympathetic reflexes, which are independent of the PROKR2ADV neurons, can be evoked by high-intensity EA at both ST25 and ST36 acupoints. ${ }^{152}$

\section{The Sympathetic Pathway}

Sympathetic nerves play dual roles in the regulation of inflammatory responses, mediating both pro- and antiinflammatory effects. ${ }^{153}$ It is reported that sympathetic tyrosine hydroxylase immunoreactive (TH-IR) fibers form "basket-like" structures around the coloninnervating DRG neurons following colonic inflammation and contribute to the inflammatory visceral pain and somatic hyperalgesia. ${ }^{154}$ EA at ST36 and ST37 for 7 or 14 consecutive days attenuates visceral motor responses to colorectal distention (CRD) and relieves inflammatory pain by inhibiting sympathetic TH expression in the sixth lumbar DRG. In addition, EA at ST36 and ST37 also 
decreases TH-IR neurons, and prevents excessive TH-IR sprouting toward sensory neurons in L6 DRG of colitis rats. ${ }^{27}$ Chen et al also reported that acupuncture at BL13, BL12, and GV14 improves asthmatic symptoms by decreasing the levels of sympathetic neuropeptides, such as neurokinin A (NKA), neurokinin B (NKB), SP, and vasoactive intestinal peptide (VIP) in the lung tissue. All of these molecules are asthma attack factors and are related to the release of inflammatory mediators. ${ }^{155}$ On the other hand, acupuncture also stimulates the sympathetic nerve to release NE, which specifically binds to the $\beta 2$-adrenergic receptor ( $\beta 2 \mathrm{AR})$ to enable antiinflammatory action, ${ }^{156,157}$ while EA increases the $\beta 3$ receptors during obesity, which is characterized by a chronic low-grade inflammatory state. ${ }^{158}$ More recently, Ma et al reported that high-intensity EA at ST25 or ST36 before modeling activates neuropeptide $\mathrm{Y}(\mathrm{NPY})^{+}$splenic sympathetic nerve in septic models via the spinalsympathetic axis. ${ }^{6}$ Based on the sympathetic nervemediated regulation of inflammatory responses, the effect of acupuncture is mainly affected by the concentration of neurotransmitters and immune cell surface receptor subtypes. Different concentrations of neurotransmitters and subtypes of receptors on the surfaces of immune cells produce different results, suggesting the presence of both pro- and anti-inflammatory bidirectional regulation.

The anti-inflammatory pathways of sympathetic and parasympathetic nerves achieve bidirectional benign regulation via antagonism, synergy, or succession, which are still not unified. The activation of the sympathetic nerves, by the $\alpha 2$ adrenergic receptors ( $\alpha 2 \mathrm{ARs}$ ), for instance, leads to increases in TNF synthesis, but the activation of the vagus nerves offsets excessive release of TNF, which is consistent with the notion that sympathetic and parasympathetic nerves exert opposing effects. However, the latest researchers demonstrated that the sympathetic and parasympathetic nerves have cooperative relationships that result in anti-inflammatory effects. It is reported that after an inflammatory signal is transmitted to the brain stem for processing, the vagus nerves are activated. The vagus nerves then stimulate the adrenergic nerves of the spleen to release norepinephrine (NE). Upon NE stimulation, $\mathrm{ChAT}^{+} \mathrm{T}$ cells are activated and release $\mathrm{ACh}$ that inhibits cytokine production by macrophages. ${ }^{159,160}$ It was confirmed that the vagus and splenic sympathetic neurons have no neural connection. ${ }^{161}$ Therefore, the sympatheticparasympathetic synergy anti-inflammatory effect may depend on other indirect communication pathways.
Neuroanatomical findings have highlighted the celiac plexus as a potential site of vagus nerve-splenic nerve communication. ${ }^{162}$ The efferent fibers of the vagus nerve likely act on the $\alpha 7 \mathrm{nAChR}$ of the celiac ganglion neurons to release ACh, which then activates the splenic sympathetic nerve. In addition, studies have revealed that stimulating $\mathrm{C} 1$ neurons in the medulla oblongata protects mice from ischemia-reperfusion injury, while increasing the activity of the sympathetic and vagus nerves. Interestingly, the protection conferred by $\mathrm{C} 1$ stimulation is eliminated by splenectomy, ganglionic-blockers, or 32 ARs blockade, while it remains after subdiaphragmatic vagotomy. This suggests that the protective effect of the $\mathrm{C} 1$ neuron stimulation against ischemia-reperfusion injury is primarily mediated via sympathetic nerves. There may also be a direct pathway from the central to the sympathetic nerve, which may include the vagus nerve. ${ }^{163}$ However, the distribution of anti-inflammatory effects of the sympathetic and parasympathetic nerves needs further exploration.

\section{The Hypothalamic-Pituitary-Adrenal (HPA) Axis}

The HPA axis is mainly composed of the hypothalamic PVN, adenohypophysis, and the adrenal cortex, among which the PVN is the most crucial. Cortisol synthesized and released by the HPA axis regulates gene expression of pro- and anti-inflammatory mediators by forming a complex with glucocorticoid receptors (GRs). This inhibits the production of various pro-inflammatory mediators and induces the production of various anti-inflammatory mediators. Simultaneously, cortisol provides a negative feedback to the hypothalamus and pituitary gland to prevent a decrease in GR sensitivity and cortisol antiinflammatory ability caused by the over-secretion of corticotropin-releasing hormone ( $\mathrm{CRH})$ and hyperactivity of the HPA axis.

Acupuncture directly activates the endogenous HPA axis and plays an anti-inflammatory role, which prevents overdose of exogenous cortisol and its related side effects. The persistent inflammatory condition associated with asthma up-regulates endogenous cortisol, leading to the hypo-responsiveness of the HPA axis due to the negative feedback mechanism. Wei et al revealed that acupuncture promotes both adreno-cortico-tropic hormone (ACTH) and cortisol secretion, shifting the hypo-responsiveness of the HPA axis to hyper-responsiveness, thus attenuating inflammation. ${ }^{164}$ This, in turn, decreases airway inflammatory cell (leukocyte, neutrophil, lymphocyte, and 
eosinophil) counts and attenuates inflammatory factors (TNF- $\alpha$, IL-1 $\beta$, IL-5, and eotaxin). Conversely, the sympathetic nervous system and HPA axis become activated during CNS injuries, which also induces release of inflammatory mediators and chemokines to accelerate inflammation. EA at GV20 and ST36 markedly down-regulates ACTH and HSP 70 in serum, accompanied by reduced inflammation. ${ }^{165}$ However, the acupuncture-mediated inhibitory ACTH action and the underlying mechanism of acupuncture-mediated bidirectionally HPA axis regulation require further investigation.

\section{The Brain-Gut Axis}

The brain-gut axis is a bidirectional pathway between the CNS and the enteric nervous system, and it includes parts of both the nervous and immune systems. Apart from direct neural connections, brain-gut peptides, secreted by the nervous and digestive systems, also contribute to certain neurodegenerative diseases and gastrointestinal dysfunction. Acupuncture affects the intestinal tract via the brain-intestinal peptides. Yu et al reported that EA treatment at CV12, Qihai (RN6), ST36, and LR3 alleviates Parkinson's disease by regulating brain-gut peptides, such as, NPY, cholecystokinin, somatostatin, gastrin, and peptide $\mathrm{YY}^{74}$ In addition to nerve conduction, the brain-gut axis also includes the intestinal flora as well as the immune interactions in the brain-gut system. ${ }^{166}$ Some studies have confirmed that the anti-inflammatory effect of acupuncture is related to its regulation of intestinal flora. It has been reported that Parkinson's disease likely originates in the gut. The $\alpha$-synuclein pathology may then spread to the brain stem and midbrain via the olfactory bulb and brain stem caudal, eventually spreading to the cerebral cortex. Continuous MA at GB34 and ST36 for 12 days significantly reduces levels of Bacteroides, which stimulates the secretion of TNF- $\alpha$ by macrophages and monocytes. Acupuncture also inhibits the activation of astrocytes and the NF- $\mathrm{kB}$ pathway in the ST and SN regions, and downregulates the expression of TNF- $\alpha$ to alleviate central neuroinflammatory responses, thus protecting the dopaminergic neurons in Parkinson's disease. ${ }^{167}$ Another study also reported that acupuncture at CV12, ST25, and CV4 reduces the expression of TNF- $\alpha$, IL- $1 \beta$, and IFN- $\gamma$ in the duodenum and blood of 6-OHDA-induced Parkinson's disease rats. Acupuncture protects DA neurons by affecting the brain-enteritis state. ${ }^{168}$ EA inhibits the NF- $\mathrm{KB}$ pathway, down-regulates expression of TNF- $\alpha$ and IL-8 in peritoneal macrophages, and improves the symptoms of depression. ${ }^{169}$ The above studies preliminarily explored the anti-inflammatory effect of acupuncture, particularly, in relation to the regulation of the brain-gut axis. However, the specific mechanisms still require further exploration.

\section{Discussion}

Clinical studies have revealed that acupuncture has a certain regulatory effect on systemic inflammation. In the early 2000 s, electrical stimulation of the cervical vagus nerve was shown to inhibit LPS-induced inflammation, revealing for the first time the mechanism of autonomic neuro-immune regulation. Subsequently, it was discovered that acupuncture at different acupoints, instead of invasive direct stimulation of the vagus nerve, also produces a strong anti-inflammatory effect. Studies from the last five years revealed that acupuncture suppresses systemic inflammation, completely or partially via the activation of vagal efferent nerves, CAIP, or vagus-adrenal medulladopamine pathway. Along with this, the sympathetic pathway or HPA axis also plays crucial roles. The specific process is as follows: acupuncture signals from ST36, GV20, SP6, BL13, ST37, LI4, GV14, BL60, GV24, and PC6 acupoints transmit primarily to the DVC, including the NTS, DMV, raphe nuclei, area postrema, LHA, and PVN. Upon information integration in the brain, the ACh system is activated, including ACh and its receptors, ChAT and AChE, and the cellular JAK2/STAT3, NF-kB, and MAPK pathways are modulated to realize the antiinflammatory effects. In the meantime, the acupuncture signal from ST36 also activates the vagus-adrenal medulla-dopamine pathway, stimulating the adrenal gland to release DA, acting on the D1 receptors to inhibit cytokine production. The anti-inflammatory action of acupuncture is mainly mediated through the activation of the vagus nerve. A sympathetic pathway is also reported to mediate the anti-inflammatory effects of acupuncture. Acupuncture information from ST25, ST36, ST37, GV14, BL12, and BL13 is transmitted via the NTS to the sympathetic nerve centers, such as the RVM. The secretion of NE and related neuropeptides also activates the sympathetic nerve pathway. The sympathetic nerve plays a dual role in the regulation of inflammatory responses, and it is dependent on neurotransmitters and receptor subtypes, as well as the interactions of sympathetic and parasympathetic nerves, which need further exploration. Acupuncture also bidirectionally regulates the HPA axis, such that the abnormal HPA axis can be restored to normal to achieve antiinflammatory action. Acupuncture information from 
ST36, GV14, BL12, BL13, and GV20 activates the HPA axis via PVN and releases glucocorticoid (GC) to act on macrophages and other inflammatory cells, exerting local and systemic anti-inflammatory effects. In addition, the anti-inflammatory role of acupuncture is related to the regulation of brain-intestine intestinal flora and intestinal immunity. Acupuncture induces somatosensory - autonomic nerve - target organ reflex, which plays a crucial role in the regulation of immune-inflammation in the body. Additionally, this effect is mainly associated with point location, intensity of stimulation, and state of the body.

The acupuncture-mediated anti-inflammatory action is highly acupoint-specific. Since the 1970s, pinch or EA in hindlimb or abdominal regions has been reported to differentially regulate vagal versus sympathetic efferent pathways associated with gastric motility control. Stimulation at heterotopic acupoints (with different spinal segments from the innervated visceral organs) facilitates GI motility via parasympathetic pathways, while stimulation at homotopic acupoints (with the same spinal segment from the innervated visceral organs) decreases GI pressure via the sympathetic pathways. Studies have demonstrated that low-intensity $(0.5 \mathrm{~mA})$ acupuncture at ST36 markedly activates the "vagus-adrenal $\mathrm{NPY}^{+}$medulla cell" pathway, and inhibits LPS-induced systemic inflammatory response, and at the least doubles the survival rate of mice. However, this anti-inflammatory pathway is not activated by abdominal ST25. ${ }^{6}$ A similar study published in the same year compared the anti-inflammatory mechanisms of ST36, LI11, and ST25. Studies have confirmed that the anti-inflammatory effects of these three acupoints target different pathways. In particular, ST36 and LI11 employ the vagal and parasympathetic pathways, whereas ST25 employs the sympathetic pathway. ${ }^{170}$ ST36 and LI11 acupoints are located on the legs or arms, and have similar effects regarding systemic inflammatory response, intestinal permeability, and intestinal $\mathrm{T}$ lymphocyte ratio regulation in the CLP model, which is also confirmed by a recent study showing that the PROKR $2^{+}$sensory neurons innervating the deep limb fascia mediate the antiinflammatory action of limb acupoints. ${ }^{17,152}$ Diverging from the actions of ST36 and LI11, ST25 only participates in the regulation of intestinal T cell components. ${ }^{170}$ Given this evidence, it is clear that discrete anti-inflammatory pathways are evoked by distinct acupoints.

It was previously unclear whether different electric intensities drove distinct somato-autonomic pathways until $\mathrm{Ma}$ et al reported that the anti-inflammatory effect of acupuncture is intensity-specific. Ma et al showed that different intensities of stimulation activate different autonomic circuits. For instance, high-intensity $(3.0 \mathrm{~mA})$ EA at ST25 activates the $\mathrm{NPY}^{+}$sympathetic neurons projected onto the spleen and inhibits LPS-induced inflammation, while low-intensity $(0.5 \mathrm{~mA})$ EA at ST25 is unable to activate this pathway. Notably, the anti-inflammatory effect of ST25 is suppressed after splenectomy, suggesting that the anti-inflammatory effect of ST25 is achieved via activation of the splenic sympathetic nerve. Low-intensity $(0.5 \mathrm{~mA})$ EA at ST36 is sufficient to activate the vagusadrenal $\mathrm{NPY}^{+}$medulla pathway, while high-intensity (3.0 $\mathrm{mA}$ ) EA at ST36 also activates the spinal-sympathetic axis to exert a combined anti-inflammatory effect. ${ }^{6}$ The antiinflammatory axis evoked by EA (0.5-mA) at ST36 operates via activation of the D1 receptor, but not $\beta 2$ ARs, in response to catecholamines, released from the adrenal gland. In contrast, the spinal-sympathetic axis, evoked by EA (3.0-mA) at ST25, does the opposite, and depends on the $\beta 2$ ARs, but not D1 receptor. This indicates that the high- and low-intensity EA at different acupoints provide different forms of anti-inflammatory action. As the stimulation intensity increases, the selective anti-inflammatory effects from ST36 or ST25 disappear. Strong stimulation primarily activates the splenic sympathetic nerve to resist inflammation. The extent of sympathetic activation and content of released neurotransmitters may explain the different acupuncture intensities that produce distinct immune responses, which requires further systematical examination.

The regulatory effect of acupuncture is also related to the body state. Prior to LPS exposure, low- $(0.5 \mathrm{~mA})$ and highintensity $(3.0 \mathrm{~mA})$ stimulation at ST36 produces strong antiinflammatory effects, while post LPS exposure, low- and high-intensity stimulation at the same ST36 stimulation produces opposite effects, ie, pro-inflammatory effects. Highintensity EA at ST25, prior to LPS, exerts anti-inflammatory effects via $\beta 2 A R s$, expressed in the spleen, by activating the peripheral $\mathrm{NPY}^{+}$sympathetic neurons. However, following LPS-induced inflammation, EA produces a proinflammatory effect that is mainly caused by elevated $\alpha 2$ ARs in the spleen. ${ }^{6}$ Hence, noradrenaline released from sympathetic nerves modulates inflammation via regulation of distinct adrenergic receptors.

In all, acupuncture stimulation modulates inflammation based on acupoint-, intensity-, and disease-states. Limb area acupoint primarily or partially activates vagal efferents that suppress systemic inflammation, while abdominal 
and back area acupoints primarily activate sympathetic efferents. In terms of intensity, low-intensity stimulation exerts anti-inflammatory action via the vagal nerves. In contrast, strong stimulation activates the splenic sympathetic nerve to resist inflammation. Different disease states induce distinct alterations in the adrenergic receptor profiles, which also affect acupuncture action. Whether acupuncture activates noradrenergic sympathetic neurons to produce anti- or pro-inflammatory effects in different disease states remains to be determined. In terms of ongoing severe systemic inflammation, high-intensity stimulation can be contraindicatory. In this case, we recommend the selection of low-intensity EA in the hind limb region to drive the vagal anti-inflammatory axis. Given the above evidence, one must develop the most appropriate and individualized acupuncture prescription to accommodate patients with inflammatory diseases.

\section{Conclusion}

Acupuncture is an effective therapy that is used worldwide for the treatment of multiple inflammatory diseases. Through an extensive review of the relevant literature, we have established that the anti-inflammatory action of acupuncture combating multi-system diseases involves the regulation of infiltrating immune cells, along with their associated cellular signaling and cytokines. Assessing the anti-inflammatory mechanisms of acupuncture, we revealed that acupuncture deforms connective tissues and induces the secretion of a variety of molecules in acupoints, activating the NF- $\mathrm{BB}, \mathrm{MAPK}$, and ERK pathways in mast cells, fibroblasts, keratinocytes, and monocytes/ macrophages. Moreover, the somatic afferents activated by acupuncture are conveyed to the spinal cord, brainstem (NTS, RVM, and DMV), and hypothalamic neurons. Upon information integration in the brain, acupuncture

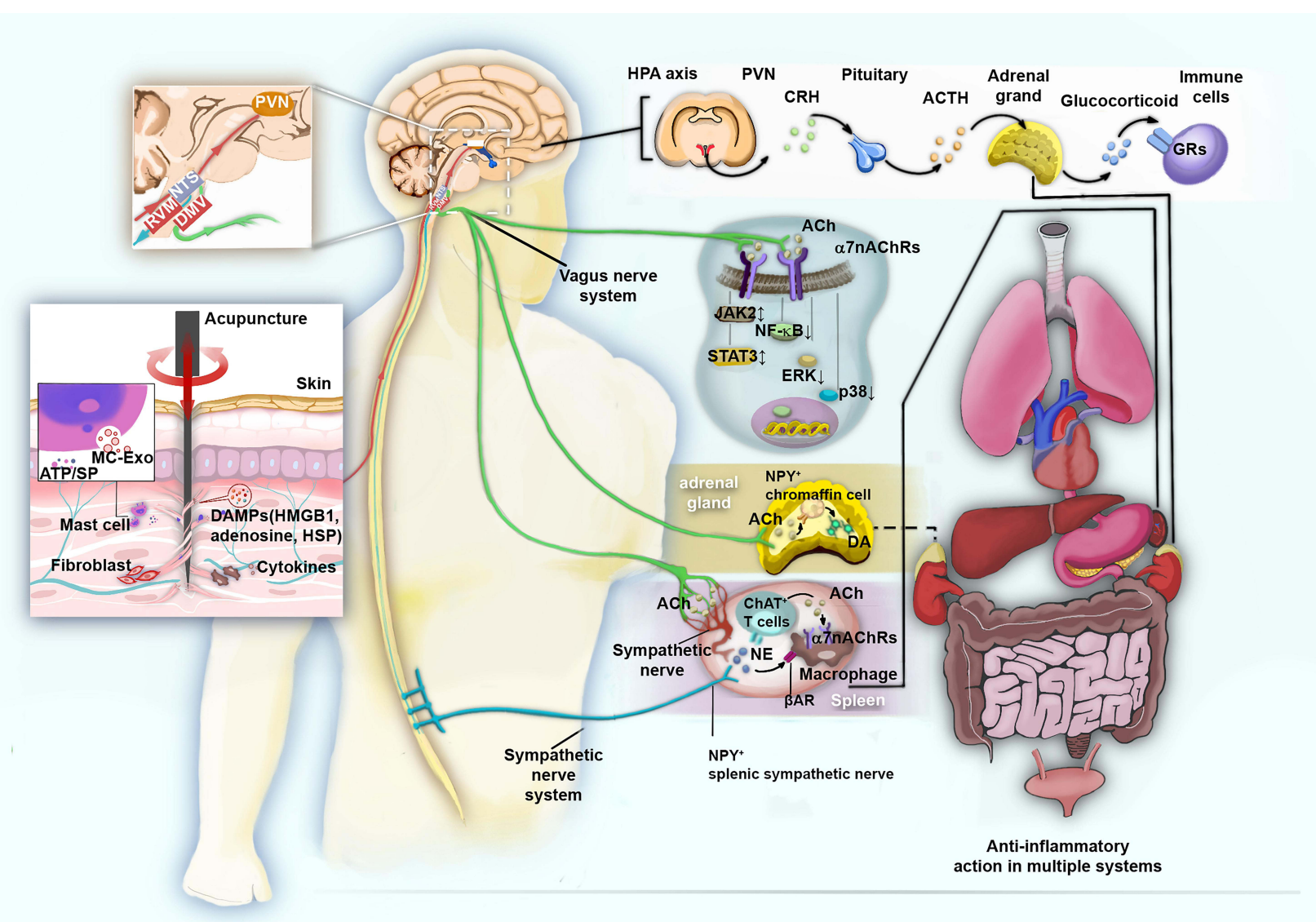

Figure 3 The anti-inflammatory mechanisms of acupuncture from acupoint to target organs.

Abbreviations: ATP, adenosine triphosphate; SP, substance P; MC-Exo, mast cell-derived exosome; DAMPs, damage associated molecular patterns; HSP, heat shock protein; NTS, nucleus tractus solitarius; RVM, rostral ventrolateral medulla; DMV, dorsal motor nucleus of vagus; PVN, paraventricular nucleus; CRH, corticotropin-releasing hormone; ATCH, adrenocorticotropic hormone; GRs, glucocorticoid receptors; ACh, acetylcholine; $\alpha 7 n A C h R$, nicotinic acetylcholine receptor $\alpha 7$; JAK2, Janus kinase 2; STAT3, signal transducer and activator of transcription 3; NF-kB, NF-kappaB; ERK, extracellular signal-regulated kinase; NE, noradrenaline; NPY, neuropeptide Y; DA, dopamine. 
stimulates multiple neuro-immune pathways, including CAIP, vagus-adrenal medulla-dopamine, and sympathetic pathways, as well as the HPA axis to release neurotransmitters and hormones that modulate immune cells. Upon CAIP activation (including ACh and its receptors, ChAT, and AChE), the cellular JAK2/STAT3, NF- $\mathrm{KB}$, and MAPK pathways are appropriately modulated to achieve an antiinflammatory effect. Acupuncture also activates the vagusadrenal medulla-dopamine pathway, stimulating the NPY ${ }^{+}$ chromaffin cells of the adrenal gland to release DA, which binds D1 receptors to inhibit production of cytokines. Apart from this, efferent fibers of the vagus nerve regulate $\alpha 7 \mathrm{nAChR}$ of the celiac ganglion neurons by releasing $\mathrm{ACh}$, which then activates the splenic sympathetic nerve. Following NE release, $\mathrm{ChAT}^{+} \mathrm{T}$ cells become activated, release $\mathrm{ACh}$, and inhibit cytokine production from macrophages. Furthermore, high-intensity abdominal EA activates $\mathrm{NPY}^{+}$splenic noradrenergic neurons to inhibit macrophage activity via the spinal-sympathetic axis. In addition, acupuncture bidirectionally regulates the HPA axis to display anti-inflammatory action (Figure 3). Notably, the anti-inflammatory effect of acupuncture is related to acupoint selection, stimulation intensity, state of the body, and so on. It is suggested that early intervention with acupuncture can inhibit excessive inflammatory responses and reduce the risk of "inflammatory factor storm". The evidence of acupuncture-mediated antiinflammatory actions and underlying mechanisms summarized in this study forms a map that optimizes stimulation parameters that can potentially enhance both safety and efficacy of acupuncture intervention.

\section{Abbreviations}

RA, rheumatoid arthritis; WHO, World Health Organization; RCTs, randomized controlled trials; EA, electroacupuncture; COVID-19, Corona Virus Disease 2019; TEAS, transcutaneous electrical acupoint stimulation; ICD-11, International Classification of Diseases 11; MA, manual acupuncture; TLR4, Toll-like receptor 4; MyD88, myeloid differentiation factor 88 ; NF- $\mathrm{kB}$, nuclear factor kappa-B; CFA, Complete Freund's Adjuvant; A2AR, A2A receptor; RANK, receptor activator of NF- $\mathrm{BB}$; RANKL, receptor activator of nuclear factor- $\mathrm{KB}$ ligand; ERK, extracellular regulated protein kinases; $\mathrm{CCC}$, cell-cell communication; Treg, regulatory $\mathrm{T}$ cells; NLRP3, NOD-like receptor protein 3; MDM2, murine double minute 2;
MCP-1, monocyte chemotactic protein 1 ; INF- $\gamma$, interferon- $\gamma$; SAE, sepsis-associated encephalopathy; $\mathrm{NO}$, nitric oxide; MPO, myeloperoxidase; CK-MB, creatine kinase$\mathrm{MB}$; IBD, inflammatory bowel disease; CRP, C-reactive protein; ICC, interstitial cell function of Cajal; POI, postoperative ileus; Sirt1, sirtuin-1; HDAC, histone deacetylase; ALT, alanine aminotransferase; AST, aspartate aminotransferase; TG, triglyceride; TC, total cholesterol; NAFLD, non-alcohol fatty liver disease; NADPH, nicotinamide adenine dinucleotide phosphate; HO-1, heme oxygenase-1; Nrf2, NFE-related factor 2; UC, ulcerative colitis; 8-OHdG, 8-hydroxy-2-deoxyguanosine; MDA, malondialdehyde; ROS, reactive oxygen species; IBS, irritable bowel syndrome; TNBS, trinitrobenzene sulfonic acid; ZO-1, zonula occludens-1; DSS, dextran sulfate sodium; PMNs, polymorphonuclear leukocytes; a-SMA, $\alpha$-smooth muscle actin; LPS, lipopolysaccharide; I/R, ischemia-reperfusion; COPD, chronic obstructive pulmonary disease; MAPK, mitogen-activated protein kinase; PPAR $\gamma$, peroxisome proliferator-activated receptor $\gamma$;ARDS, acute respiratory distress syndrome; ALI, acute lung injury; LIR, limb artery ischemia-reperfusion; CPB, cardiopulmonary bypass; SOD, superoxide dismutase; BALF, bronchoalveolar lavage fluid; HDAC2, histone deacetylase inhibitor 2; SST2, Soluble Growth Stimulation Expressed Gene 2; ILCs, Innate lymphoid cells; CNS, central nervous system; PAMPs, pathogen-associated molecular patterns; DAMPs, damageassociated molecular patterns; HMGB1, high mobility group box-1; PGE2, prostaglandin E2; COX-2, Cyclooxygenase-2; CRS, chronic restraint stress; RIPK1, receptor interacting protein kinase 1 ; TAK1, transforming growth factor- $\beta$-activated kinase 1 ; TRPV-1, transient receptor potential vanilloid-1; DRG, dorsal root ganglion; ABIN1, A20-binding inhibitor of NF- $\mathrm{BB} 1$; RIP1, receptorinteracting protein 1; IKK $\gamma, \mathrm{KappaB}$ kinase inhibitor $\gamma$; CYLD, cylindromatosis; VD, vascular dementia; MDD, major depressive disorder; CLRs, C-type lectin receptors; PRRs, pattern recognition receptors; Mincle/Syk, macrophage-inducible C-type lectin/spleen tyrosine kinase; P2X4R, purinergic P2X4 receptor; CGRP, calcitonin generelated peptide; BDNF, brain-derived neurotrophic factor; $\mathrm{PPE}$, plasma protein extravasation; $\mathrm{MCAO} / \mathrm{R}$, middle cerebral artery occlusion/reperfusion; $\mathrm{A} \beta$, amyloid protein; $\mathrm{AD}$, Alzheimer's disease; ASC, apoptosis-associated speck-like protein containing a CARD; ST, striatum; SN, substantia nigra; RNS, reactive nitrogen species; TXNIP, thioredoxin- 
interacting protein; TBI, traumatic brain injury; PTZ, pentylenetetrazole; CAT, catalase; NMDAR, N-methylD-aspartate receptor; GSH, glutathione; GPX4, glutathione peroxidase 4; CB1R, cannabinoid type 1 receptor; TGES, trigeminal ganglion; OA, osteoarthritis; MMP, matrix metalloproteinases; EAS, EA serum; LFES, low-frequency electrical stimulation; IGF-1, insulin-like growth factor-1; MIP-1, macrophage inflammatory protein 1; VEGF, vascular endothelial growth factor; CB2R, cannabinoid type 2 receptor; FS, fraction shortening; $\mathrm{EF}$, ejection fraction; H3K9, histone deacetylation of histone; DIO, inflammation of dietary obesity; DCM, diabetic cardiomyopathy; IGF1R, type 1 insulin-like growth factor receptor; AMP, adenosine 5'-monophosphate; DPN, diabetic peripheral neuropathy; OHSS, ovarian hyperstimulation syndrome; SP, substance P; HA, Histamine; 5-HT, 5-hydroxytryptamine; HSP, heat shock protein; MC-Exo, mast cell-derived exosomes; NIH, National Institutes of Health; SPARC, stimulating peripheral activity to relieve condition; VNS, vagal nerve stimulation; NTS, nucleus tractus solitarius; DMV, dorsal motor nucleus of vagus; DVC, dorsal vagal complex; RVM, rostral ventrolateral medulla; MRI, magnetic resonance imaging; LHA, lateral hypothalamic area; PVN, paraventricular nucleus; CAIP, cholinergic anti-inflammatory pathway; $\mathrm{ACh}$, acetylcholine; mWAT, mesenteric white adipose tissues; POCD, postoperative cognitive dysfunction; AChR, ACh receptor; ChAT, Choline Acetyl Transferase; JAK2, janus kinase 2; STAT3, signal transducer and activator of transcription 3; DA, dopamine; D1, DA type 1; TH-IR, tyrosine hydroxylase immunoreactive; $\mathrm{CRD}$, colorectal distention; NKA, neurokinin A; NKB, neurokinin B; VIP, vasoactive intestinal peptide; $\beta 2 \mathrm{AR}, \beta 2$-adrenergic receptor; NPY, neuropeptide Y; $\alpha 2 A R s, \alpha 2$ adrenergic receptors; NE, norepinephrine; HPA, hypothalamic-pituitary-adrenal; GRs, glucocorticoid receptors; $\mathrm{CRH}$, corticotropin-releasing hormone; ACTH, adreno-cortico-tropic hormone.

\section{Acknowledgments}

This study was financially supported by the National Natural Science Foundation of China (NSFC) (Nos. 82030125, 81873369, 82074534, 82105023, 82004467, and 82105024); the Key scientific program of integrated traditional Chinese and Chinese and Western medicine of Tianjin Health Commission (No. 2021019); and the National Key R\&D Program of China (No. 2019YFC17122002019YFC1712204).

\section{Disclosure}

The authors report no conflicts of interest in this work.

\section{References}

1. Yeung YT, Aziz F, Guerrero-Castilla A, Arguelles S. Signaling pathways in inflammation and anti-inflammatory therapies. Curr Pharm Des. 2018;24(14):1449-1484. doi:10.2174/1381612824 666180327165604

2. Liu D, Ahmet A, Ward L, et al. A practical guide to the monitoring and management of the complications of systemic corticosteroid therapy. Allergy Asthma Clin Immunol. 2013;9(1):30. doi:10.1186/1710-1492-9-30

3. Wang H, Yang G, Wang S, Zheng X, Zhang W, Li Y. The most commonly treated acupuncture indications in the United States: a cross-sectional study. Am J Chin Med. 2018;1-33. doi:10.1142/ S0192415X18500738

4. Chousterman BG, Swirski FK, Weber GF. Cytokine storm and sepsis disease pathogenesis. Semin Immunopathol. 2017;39 (5):517-528. doi:10.1007/s00281-017-0639-8

5. Yang G, Hu RY, Deng AJ, Huang Y, Li J. Effects of electro-acupuncture at zusanli, guanyuan for sepsis patients and its mechanism through immune regulation. Chin J Integr Med. 2016;22(3):219-224. doi:10.1007/s11655-016-2462-9

6. Liu S, Wang ZF, Su YS, et al. Somatotopic Organization and Intensity Dependence in Driving Distinct NPY-Expressing Sympathetic Pathways by Electroacupuncture. Neuron. 2020;108 (3):436-450.e7. doi:10.1016/j.neuron.2020.07.015

7. McInnes IB, Schett G. The pathogenesis of rheumatoid arthritis. $N$ Engl J Med. 2011;365(23):2205-2219. doi:10.1056/NEJMra 1004965

8. Yang F, Gong Y, Yu N, et al. ST36 Acupuncture Alleviates the Inflammation of Adjuvant-Induced Arthritic Rats by Targeting Monocyte/Macrophage Modulation. Evid Based Complement Alternat Med. 2021;2021:9430501. doi:10.1155/2021/9430501

9. Dong ZQ, Zhu J, Lu DZ, Chen Q, Xu YL. Effect of Electroacupuncture in "Zusanli" and "Kunlun" Acupoints on TLR4 Signaling Pathway of Adjuvant Arthritis Rats. Am J Ther. 2018;25(3):e314-e319. doi:10.1097/MJT.0000000000000477

10. Du ZH, Zhang CW, Xie WX, et al. Adenosine A2A Receptor Mediates Inhibition of Synovitis and Osteoclastogenesis after Electroacupuncture in Rats with Collagen-Induced Arthritis. Evid Based Complement Alternat Med. 2019;2019:4617464. doi:10.1155/2019/4617464

11. Xu Y, Hong S, Zhao X, et al. Acupuncture Alleviates Rheumatoid Arthritis by Immune-Network Modulation. Am J Chin Med. 2018;46(5):997-1019. doi:10.1142/S0192415X18500520

12. Yu ML, Wei RD, Zhang T, et al. Electroacupuncture Relieves Pain and Attenuates Inflammation Progression Through Inducing IL-10 Production in CFA-Induced Mice. Inflammation. 2020;43 (4):1233-1245. doi:10.1007/s10753-020-01203-2

13. Su C, Chen Y, Chen Y, et al. Effect of electroacupuncture at the ST36 and GB39 acupoints on apoptosis by regulating the p53 signaling pathway in adjuvant arthritis rats. Mol Med Rep. 2019;20(5):4101-4110. doi:10.3892/mmr.2019.10674

14. Torres-Rosas R, Yehia G, Peña G, et al. Dopamine mediates vagal modulation of the immune system by electroacupuncture. Nat Med. 2014;20(3):291-295. doi:10.1038/nm.3479

15. Chen Y, Lei Y, Mo LQ, et al. Electroacupuncture pretreatment with different waveforms prevents brain injury in rats subjected to cecal ligation and puncture via inhibiting microglial activation, and attenuating inflammation, oxidative stress and apoptosis. Brain Res Bull. 2016;127:248-259. doi:10.1016/j.brainresbull.2016.10.009 
16. Zhang L, Huang $\mathrm{Z}$, Shi $\mathrm{X}$, et al. Protective Effect of Electroacupuncture at Zusanli on Myocardial Injury in Septic Rats. Evid Based Complement Alternat Med. 2018;2018:65 09650. doi:10.1155/2018/6509650

17. Xie DP, Zhou GB, Chen RL, et al. Effect of Electroacupuncture at Zusanli (ST36) on Sepsis Induced by Cecal Ligation Puncture and Its Relevance to Spleen. Evid Based Complement Alternat Med. 2020;2020:1914031. doi:10.1155/2020/1914031

18. Hartenstein V, Martinez P. Structure, development and evolution of the digestive system. Cell Tissue Res. 2019;377(3):289-292. doi:10.1007/s00441-019-03102-x

19. Song S, An J, Li Y, Liu S. Electroacupuncture at ST-36 ameliorates DSS-induced acute colitis via regulating macrophage polarization induced by suppressing NLRP3/IL- $1 \beta$ and promoting Nrf2/HO-1. Mol Immunol. 2019;106:143-152. doi:10.1016/j. molimm.2018.12.023

20. Liu GH, Liu HM, Chen YS, Lee TY. Effect of Electroacupuncture in Mice with Dextran Sulfate Sodium-Induced Colitis and the Influence of Gut Microbiota. Evid Based Complement Alternat Med. 2020;2020:2087903. doi: $10.1155 / 2020 / 2087903$

21. Deng J, Yang S, Yuan Q, et al. Acupuncture Ameliorates Postoperative Ileus via IL-6-miR-19a-KIT Axis to Protect Interstitial Cells of Cajal. Am J Chin Med. 2017;45(4):737-755. doi:10.1142/S0192415X17500392

22. Song YF, Pei LX, Chen L, et al. Electroacupuncture Relieves Irritable Bowel Syndrome by Regulating IL-18 and Gut Microbial Dysbiosis in a Trinitrobenzene Sulfonic Acid-Induced Post-Inflammatory Animal Model. Am J Chin Med. 2020;48 (1):77-90. doi:10.1142/S0192415X20500044

23. Meng X, Guo X, Zhang J, et al. Acupuncture on ST36, CV4 and KI1 Suppresses the Progression of Methionine- and Choline-Deficient Diet-Induced Nonalcoholic Fatty Liver Disease in Mice. Metabolites. 2019;9(12). doi:10.3390/metabo 9120299

24. Ma B, Li P, An H, Song Z. Electroacupuncture Attenuates Liver Inflammation in Nonalcoholic Fatty Liver Disease Rats. Inflammation. 2020;43(6):2372-2378. doi:10.1007/s10753-020-0 1306-w

25. Liang S, Ma HY, Zhong Z, et al. NADPH Oxidase 1 in Liver Macrophages Promotes Inflammation and Tumor Development in Mice. Gastroenterology. 2019;156(4):1156-1172.e6. doi:10.1053/ j.gastro.2018.11.019

26. Lee YJ, Rong JZ, Kim YW, et al. Acupuncture inhibits liver injury induced by morphine plus Acetaminophen through antioxidant system. EUR J INTEGR MED. 2016;8(3):204-212. doi:10. 1016/j.eujim.2015.12.009

27. Wang YL, Su YS, He W, Jing XH. Electroacupuncture relieved visceral and referred hindpaw hypersensitivity in colitis rats by inhibiting tyrosine hydroxylase expression in the sixth lumbar dorsal root ganglia. Neuropeptides. 2019;77:101957. doi:10.10 16/j.npep.2019.101957

28. Yang NN, Ye Y, Tian ZX, et al. Effects of electroacupuncture on the intestinal motility and local inflammation are modulated by acupoint selection and stimulation frequency in postoperative ileus mice. Neurogastroenterol Motil. 2020;32(5):e13808. doi:10. 1111/nmo. 13808

29. Ramires CC, Balbinot DT, Cidral-Filho FJ, Dias DV, Dos Santos AR, da Silva MD. Acupuncture reduces peripheral and brainstem cytokines in rats subjected to lipopolysaccharide-induced inflammation. Acupunct Med. 2021;39(4):376-384. doi:10.1177/0964528420938379

30. Li Y, Chen Y, Zhang X, et al. Protective effect of electro-acupuncture on liver ischemia-reperfusion injury in rats. Exp Ther Med. 2018;16 (2):1373-1380. doi:10.3892/etm.2018.6287
31. Xiong J, Qi W, Yang H, et al. Acupuncture Treatment for Cough-Variant Asthma: a Meta-Analysis. Evid Based Complement Alternat Med. 2021;2021:6694936. doi:10.1155/2021/6694936

32. Fernández-Jané C, Vilaró J, Fei Y, et al. Filiform needle acupuncture for COPD: a systematic review and meta-analysis. Complement Ther Med. 2019;47:102182. doi:10.1016/j.ctim.2019.08.016

33. Seidman MD, Gurgel RK, Lin SY, et al. Clinical practice guideline: allergic rhinitis executive summary. Otolaryngol Head Neck Surg. 2015;152(2):197-206. doi:10.1177/019459 9814562166

34. McCullough AR, Pollack AJ, Plejdrup Hansen M, et al. Antibiotics for acute respiratory infections in general practice: comparison of prescribing rates with guideline recommendations. Med J Aust. 2017;207 (2):65-69. doi:10.5694/mja16.01042

35. Feng D, Zhou H, Jin X, et al. Electroacupuncture Pretreatment Alleviates LPS-Induced Acute Respiratory Distress Syndrome via Regulating the PPAR Gamma/NF-Kappa B Signaling Pathway. Evid Based Complement Alternat Med. 2020;2020:4594631. doi:10.1155/2020/4594631

36. Lou Y, Yu Q, Xu K, et al. Electroacupuncture pre-conditioning protects from lung injury induced by limb ischemia/reperfusion

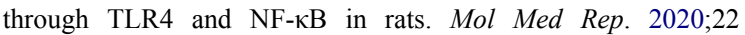
(4):3225-3232. doi:10.3892/mmr.2020.11429

37. Gong LR, Kan YX, Lian Y, et al. Electroacupuncture Attenuates Limb Ischemia-Reperfusion-Induced Lung Injury Via p38 Mitogen-Activated Protein Kinase-Nuclear Factor Erythroid-2-Related Factor-2/Heme Oxygenase Pathway. J Surg Res. 2020;246:170-181. doi:10.1016/j.jss.2019.08.021

38. Huang D, Chen M, Wang Z, Hou L, Yu W. Electroacupuncture Pretreatment Attenuates Inflammatory Lung Injury After Cardiopulmonary Bypass by Suppressing NLRP3 Inflammasome Activation in Rats. Inflammation. 2019;42(3):895-903. doi:10.1007/ s10753-018-0944-y

39. Dhar R, Zhang L, Li Y, et al. Electroacupuncture ameliorates cardiopulmonary bypass induced apoptosis in lung via ROS/ Nrf2/NLRP3 inflammasome pathway. Life Sci. 2019;238: 116962. doi:10.1016/j.lfs.2019.116962

40. Ma W, Li Z, Lu Z, et al. Protective Effects of Acupuncture in Cardiopulmonary Bypass-Induced Lung Injury in Rats. Inflammation. 2017;40(4):1275-1284. doi:10.1007/s10753-0170570-0

41. Lauterbach MA, Hanke JE, Serefidou M, et al. Toll-like Receptor Signaling Rewires Macrophage Metabolism and Promotes Histone Acetylation via ATP-Citrate Lyase. Immunity. 2019;51 (6):997-1011.e7. doi:10.1016/j.immuni.2019.11.009

42. Li J, Wu S, Tang $\mathrm{H}$, et al. Long-term effects of acupuncture treatment on airway smooth muscle in a rat model of smoke-induced chronic obstructive pulmonary disease. Acupunct Med. 2016;34(2):107-113. doi:10.1136/acupmed2014-010674

43. Lambrecht BN, Hammad H. Lung dendritic cells in respiratory viral infection and asthma: from protection to immunopathology. Annu Rev Immunol. 2012;30:243-270. doi:10.1146/annurev-immunol-020711075021

44. Dong M, Wang WQ, Chen J, et al. Acupuncture Regulates the Balance of CD4(+) T Cell Subtypes in Experimental Asthma Mice. Chin J Integr Med. 2019;25(8):617-624. doi:10.1007/ s11655-018-3055-6

45. Zhou L, Hong J, Wan Z, Lu X, Shao Y. Effects of electroacupuncture combined with interleukin-10 on chronic sinusitis in mice. Mol Med Rep. 2019;20(2):1952-1958. doi:10.3892/mmr.2019.10375

46. Dong M, Ma C, Wang WQ, Chen J, Wei Y. Regulation of the IL-33/ST2 pathway contributes to the anti-inflammatory effect of acupuncture in the ovalbumin-induced murine asthma model. Acupunct Med. 2018;36(5):319-326. doi:10.1136/acupmed2017-011377 
47. Vivier E, Artis D, Colonna M, et al. Innate Lymphoid Cells: 10 Years On. Cell. 2018;174(5):1054-1066. doi:10.1016/j.cell.2018. 07.017

48. Cui J, Dong M, Yi L, et al. Acupuncture inhibited airway inflammation and group 2 innate lymphoid cells in the lung in an ovalbumin-induced murine asthma model. Acupunct Med. 2021;39(3):217-225. doi:10.1177/0964528420924033

49. Nurwati I, Purwanto B, Mudigdo A, Saputra K, Prasetyo DH, Muthmainah M. Improvement in inflammation and airway remodelling after acupuncture at BL13 and ST36 in a mouse model of chronic asthma. Acupunct Med. 2019;37(4):228-236. doi:10.11 77/0964528418818705

50. Kwon HS, Koh SH. Neuroinflammation in neurodegenerative disorders: the roles of microglia and astrocytes. Transl Neurodegener. 2020;9(1):42. doi:10.1186/s40035-020-00221-2

51. Yang QQ, Zhou JW. Neuroinflammation in the central nervous system: symphony of glial cells. Glia. 2019;67(6):1017-1035. doi:10.1002/glia.23571

52. Li L, Acioglu C, Heary RF, Elkabes S. Role of astroglial toll-like receptors (TLRs) in central nervous system infections, injury and neurodegenerative diseases. Brain Behav Immun. 2021;91:74 0-755. doi:10.1016/j.bbi.2020.10.007

53. Zhu XL, Chen X, Wang W, et al. Electroacupuncture pretreatment attenuates spinal cord ischemia-reperfusion injury via inhibition of high-mobility group box 1 production in a LXA(4) receptor-dependent manner. Brain Res. 2017;1659:113-120. doi:10.1016/j.brainres.2017.01.008

54. Lu J, Shao RH, Jin SY, Hu L, Tu Y, Guo JY. Acupuncture ameliorates inflammatory response in a chronic unpredictable stress rat model of depression. Brain Res Bull. 2017;128: 106-112. doi:10.1016/j.brainresbull.2016.11.010

55. Ye Y, Yang Y, Chen C, et al. Electroacupuncture Improved Hippocampal Neurogenesis following Traumatic Brain Injury in Mice through Inhibition of TLR4 Signaling Pathway. Stem Cells Int. 2017;2017:5841814. doi:10.1155/2017/5841814

56. Cai GF, Sun ZR, Zhuang Z, et al. Cross electro-nape-acupuncture ameliorates cerebral hemorrhage-induced brain damage by inhibiting necroptosis. World J Clin Cases. 2020;8(10):1848-1858. doi:10.12998/wjcc.v8.i10.1848

57. Li Y, Yin C, Li X, et al. Electroacupuncture Alleviates Paclitaxel-Induced Peripheral Neuropathic Pain in Rats via Suppressing TLR4 Signaling and TRPV1 Upregulation in Sensory Neurons. Int J Mol Sci. 2019;20(23). doi:10.3390/ ijms 20235917

58. Zhou X, Lu W, Wang Y, Li J, Luo Y. A20-Binding Inhibitor of $\mathrm{NF}-\kappa \mathrm{B} 1$ Ameliorates Neuroinflammation and Mediates Antineuroinflammatory Effect of Electroacupuncture in Cerebral Ischemia/Reperfusion Rats. Evid Based Complement Alternat Med. 2020;2020:6980398. doi:10.1155/2020/6980398

59. Liu R, Xu NG, Yi W, Ji C. Electroacupuncture Attenuates Inflammation after Ischemic Stroke by Inhibiting NF$\kappa \mathrm{B}-$ Mediated Activation of Microglia. Evid Based Complement Alternat Med. 2020;2020:8163052. doi:10.1155/2020/8163052

60. Liu W, Wang X, Yang S, et al. Electroacupuncture improves motor impairment via inhibition of microglia-mediated neuroinflammation in the sensorimotor cortex after ischemic stroke. Life Sci. 2016;151:313-322. doi:10.1016/j.1fs.2016.01.045

61. Jiang J, Luo Y, Qin W, et al. Electroacupuncture Suppresses the NF$\kappa \mathrm{B}$ Signaling Pathway by Upregulating Cylindromatosis to Alleviate Inflammatory Injury in Cerebral Ischemia/Reperfusion Rats. Front Mol Neurosci. 2017;10:363. doi:10.3389/fnmol.2017.00363

62. $\mathrm{Hu} \mathrm{Q}$, Zheng $\mathrm{X}$, Li X, et al. Electroacupuncture Alleviates Mechanical Allodynia in a Rat Model of Complex Regional Pain Syndrome Type-I via Suppressing Spinal CXCL12/CXCR4 Signaling. $J$ Pain. 2020;21(9-10):1060-1074. doi:10.1016/j. jpain.2020.01.007
63. Wang L, Yang JW, Lin LT, et al. Acupuncture Attenuates Inflammation in Microglia of Vascular Dementia Rats by Inhibiting miR-93-Mediated TLR4/MyD88/NF-кB Signaling Pathway. Oxid Med Cell Longev. 2020;2020:8253904. doi:10. 1155/2020/8253904

64. Liu W, Wang X, Zheng Y, et al. Electroacupuncture inhibits inflammatory injury by targeting the miR-9-mediated NF- $\kappa \mathrm{B}$ signaling pathway following ischemic stroke. Mol Med Rep. 2016;13 (2):1618-1626. doi:10.3892/mmr.2015.4745

65. Wang $\mathrm{Y}$, Jiang $\mathrm{H}$, Meng $\mathrm{H}$, et al. Antidepressant Mechanism Research of Acupuncture: insights from a Genome-Wide Transcriptome Analysis of Frontal Cortex in Rats with Chronic Restraint Stress. Evid Based Complement Alternat Med. 2017;2017:1676808. doi:10.1155/2017/1676808

66. Liu XY, Dai XH, Zou W, et al. Acupuncture through Baihui (DU20) to Qubin (GB7) mitigates neurological impairment after intracerebral hemorrhage. Neural Regen Res. 2018;13 (8):1425-1432. doi:10.4103/1673-5374.235298

67. Badimon A, Strasburger HJ, Ayata P, et al. Negative feedback control of neuronal activity by microglia. Nature. 2020;586 (7829):417-423. doi:10.1038/s41586-020-2777-8

68. Peng J, Liu Y, Umpierre AD, et al. Microglial P2Y12 receptor regulates ventral hippocampal CA1 neuronal excitability and innate fear in mice. Mol Brain. 2019;12(1):71. doi:10.1186/ s13041-019-0492-x

69. Zhao L, Liu L, Xu X, et al. Electroacupuncture Inhibits Hyperalgesia by Alleviating Inflammatory Factors in a Rat Model of Migraine. J Pain Res. 2020;13:75-86. doi:10.2147/JPR.S225431

70. Huang J, You X, Liu W, et al. Electroacupuncture ameliorating post-stroke cognitive impairments via inhibition of peri-infarct astroglial and microglial/macrophage P2 purinoceptors-mediated neuroinflammation and hyperplasia. BMC Complement Altern Med. 2017;17(1):480. doi:10.1186/s12906-017-1974-y

71. Wang X, Li Z, Li C, Wang Y, Yu S, Ren L. Electroacupuncture with Bushen Jiannao improves cognitive deficits in senescence-accelerated mouse prone 8 mice by inhibiting neuroinflammation. J Tradit Chin Med. 2020;40(5):812-819. doi:10.19852/j.cnki.jtcm.2020.05.011

72. Cai M, Lee JH, Yang EJ. Electroacupuncture attenuates cognition impairment via anti-neuroinflammation in an Alzheimer's disease animal model. J Neuroinflammation. 2019;16(1):264. doi:10.11 86/s12974-019-1665-3

73. Jiang J, Ding N, Wang K, Li Z. Electroacupuncture Could Influence the Expression of IL-1 $\beta$ and NLRP3 Inflammasome in Hippocampus of Alzheimer's Disease Animal Model. Evid Based Complement Alternat Med. 2018;2018:8296824. doi:10.1155/2018/8296824

74. Yu J, Min D, Bai Y, Qu L, Zou T, Wang S. Electroacupuncture alleviates Parkinson disease and regulates the expression of brain-gut peptides. Exp Anim. 2020;69(4):448-460. doi:10.1538/ expanim.19-0153

75. Dumitrescu L, Popescu-Olaru I, Cozma L, et al. Oxidative Stress and the Microbiota-Gut-Brain Axis. Oxid Med Cell Longev. 2018;2018:2406594. doi:10.1155/2018/2406594

76. Du SQ, Wang XR, Zhu W, et al. Acupuncture inhibits TXNIP-associated oxidative stress and inflammation to attenuate cognitive impairment in vascular dementia rats. CNS Neurosci Ther. 2018;24(1):39-46. doi:10.1111/cns.12773

77. Zhu MM, Lin JH, Qing $\mathrm{P}$, et al. Manual acupuncture relieves microglia-mediated neuroinflammation in a rat model of traumatic brain injury by inhibiting the RhoA/ROCK2 pathway. Acupunct Med. 2020;38(6):426-434. doi:10.1177/0964528420912248

78. Frantz AL, Regner GG, Pflüger $P$, et al. Manual acupuncture improves parameters associated with oxidative stress and inflammation in PTZ-induced kindling in mice. Neurosci Lett. 2017;661:33-40. doi:10.1016/j.neulet.2017.09.044 
79. Zhang K, Liu R, Gao Y, Ma W, Shen W. Electroacupuncture Relieves LPS-Induced Depression-Like Behaviour in Rats Through IDO-Mediated Tryptophan-Degrading Pathway. Neuropsychiatr Dis Treat. 2020;16:2257-2266. doi:10.2147/NDT.S274778

80. Long M, Wang Z, Zheng D, et al. Electroacupuncture Pretreatment Elicits Neuroprotection Against Cerebral Ischemia-Reperfusion Injury in Rats Associated with Transient Receptor Potential Vanilloid 1-Mediated Anti-Oxidant Stress and Anti-Inflammation. Inflammation. 2019;42(5):1777-1787. doi:10. 1007/s10753-019-01040-y

81. Kong Y, Li S, Zhang M, et al. Acupuncture Ameliorates Neuronal Cell Death, Inflammation, and Ferroptosis and Downregulated miR-23a-3p After Intracerebral Hemorrhage in Rats. J Mol Neurosci. 2021;71 (9):1863-1875. doi:10.1007/s12031-020-01770-x

82. Cristino L, Bisogno T, Di Marzo V. Cannabinoids and the expanded endocannabinoid system in neurological disorders. Nat Rev Neurol. 2020;16(1):9-29. doi:10.1038/s41582-019-0284-z

83. Zhang H, He S, Hu Y, Zheng H. Antagonism of cannabinoid receptor 1 attenuates the anti-inflammatory effects of electroacupuncture in a rodent model of migraine. Acupunct Med. 2016;34 (6):463-470. doi:10.1136/acupmed-2016-011113

84. Scott DL, Wolfe F, Huizinga TW. Rheumatoid arthritis. Lancet. 2010;376(9746):1094-1108. doi:10.1016/S0140-6736(10)60826-4

85. Wang X, Hunter D, Xu J, Ding C. Metabolic triggered inflammation in osteoarthritis. Osteoarthritis Cartilage. 2015;23(1):22-30. doi:10.1016/j.joca.2014.10.002

86. Tolboom TC, van der Helm-van Mil AH, Nelissen RG, Breedveld FC, Toes RE, Huizinga TW. Invasiveness of fibroblast-like synoviocytes is an individual patient characteristic associated with the rate of joint destruction in patients with rheumatoid arthritis. Arthritis Rheum. 2005;52(7):1999-2002. doi:10.1002/art.21118

87. Moradi B, Rosshirt N, Tripel E, et al. Unicompartmental and bicompartmental knee osteoarthritis show different patterns of mononuclear cell infiltration and cytokine release in the affected joints. Clin Exp Immunol. 2015;180(1):143-154. doi:10.1111/cei.12486

88. Klein-Wieringa IR, de Lange-brokaar BJ, Yusuf E, et al. Inflammatory Cells in Patients with Endstage Knee Osteoarthritis: a Comparison between the Synovium and the Infrapatellar Fat Pad. $J$ Rheumatol. 2016;43(4):771-778. doi:10.3899/jrheum.151068

89. Feldmann M, Brennan FM, Maini RN. Rheumatoid arthritis. Cell. 1996;85(3):307-310. doi:10.1016/s0092-8674(00)81109-5

90. Choy EH, Isenberg DA, Garrood T, et al. Therapeutic benefit of blocking interleukin-6 activity with an anti-interleukin-6 receptor monoclonal antibody in rheumatoid arthritis: a randomized, double-blind, placebo-controlled, dose-escalation trial. Arthritis Rheum. 2002;46(12):3143-3150. doi:10.1002/art.10623

91. Li B, Jing L, Jia L, et al. Acupuncture reduces pain in rats with osteoarthritis by inhibiting MCP2/CCR2 signaling pathway. Exp Biol Med (Maywood). 2020;245(18):1722-1731. doi:10.1177/ 1535370220952342

92. Wu GW, Chen J, Huang YM, et al. Electroacupuncture Delays Cartilage Degeneration by Modulating Nuclear Factor- $\mathrm{KB}$ Signaling Pathway. Chin J Integr Med. 2019;25(9):677-683. doi:10.1007/s11655-018-2916-8

93. Xie LL, Zhao YL, Yang J, et al. Electroacupuncture Prevents Osteoarthritis of High-Fat Diet-Induced Obese Rats. Biomed Res Int. 2020;2020:9380965. doi:10.1155/2020/9380965

94. Chen H, Shao X, Li L, et al. Electroacupuncture serum inhibits TNF- $\alpha$-mediated chondrocyte inflammation via the Ras-Raf-MEK1/2-ERK1/2 signaling pathway. Mol Med Rep. 2017;16(5):5807-5814. doi:10.3892/mmr.2017.7366

95. Wang Z, Chen M, Wang B, et al. Electroacupuncture Alleviates Osteoarthritis by Suppressing NLRP3 Inflammasome Activation in Guinea Pigs. Evid Based Complement Alternat Med. 2020;2020:5476064. doi:10.1155/2020/5476064
96. Almeida Mdos S, Oliveira LP, Vieira CP, Guerra Fda R, Pimentel ER. Birefringence of collagen fibres in rat calcaneal tendons treated with acupuncture during three phases of healing. Acupunct Med. 2016;34(1):27-32. doi:10.1136/acupmed-2015010845

97. Su Z, Hu L, Cheng J, et al. Acupuncture plus low-frequency electrical stimulation (Acu-LFES) attenuates denervation-induced muscle atrophy. J Appl Physiol. 2016;120(4):426-436. doi:10.11 52/japplphysiol.00175.2015

98. Mehana EE, Khafaga AF, El-Blehi SS. The role of matrix metalloproteinases in osteoarthritis pathogenesis: an updated review. Life Sci. 2019;234:116786. doi:10.1016/j.1fs.2019.116786

99. Yuan XC, Wang Q, Su W, et al. Electroacupuncture potentiates peripheral CB2 receptor-inhibited chronic pain in a mouse model of knee osteoarthritis. J Pain Res. 2018;11:2797-2808. doi:10. 2147/JPR.S171664

100. Zhang T, Yang WX, Wang YL, et al. Electroacupuncture preconditioning attenuates acute myocardial ischemia injury through inhibiting NLRP3 inflammasome activation in mice. Life Sci. 2020;248:117451. doi:10.1016/j.1fs.2020.117451

101. Esser N, Legrand-Poels S, Piette J, Scheen AJ, Paquot N. Inflammation as a link between obesity, metabolic syndrome and type 2 diabetes. Diabetes Res Clin Pract. 2014;105 (2):141-150. doi:10.1016/j.diabres.2014.04.006

102. Lan D, Xu N, Sun J, et al. Electroacupuncture mitigates endothelial dysfunction via effects on the PI3K/Akt signalling pathway in high fat diet-induced insulin-resistant rats. Acupunct Med. 2018;36(3):162-169. doi:10.1136/acupmed-2016-011253

103. Luo D, Liu L, Liang FX, Yu ZM, Chen R. Electroacupuncture: a Feasible Sirt1 Promoter Which Modulates Metainflammation in Diet-Induced Obesity Rats. Evid Based Complement Alternat Med. 2018;2018:5302049. doi:10.1155/2018/5302049

104. Liaw JJ, Peplow PV. Differential Effect of Electroacupuncture on Inflammatory Adipokines in Two Rat Models of Obesity. J Acupunct Meridian Stud. 2016;9(4):183-190. doi:10.1016/j. jams.2016.02.002

105. Liaw JJ, Peplow PV. Effect of Electroacupuncture on Inflammation in the Obese Zucker Fatty Rat Model of Metabolic Syndrome. J Acupunct Meridian Stud. 2016;9 (2):73-79. doi:10.1016/j.jams.2015.08.004

106. Liaw JJ, Peplow PV. Effects of Electroacupuncture on Pro-/Antiinflammatory Adipokines in Serum and Adipose Tissue in Lean and Diet-induced Obese Rats. J Acupunct Meridian Stud. 2016;9 (2):65-72. doi:10.1016/j.jams.2015.06.011

107. Ye Y, Birnbaum Y, Widen SG, et al. Acupuncture Reduces Hypertrophy and Cardiac Fibrosis, and Improves Heart Function in Mice with Diabetic Cardiomyopathy. Cardiovasc Drugs Ther. 2020;34(6):835-848. doi:10.1007/s10557-020-07043-4

108. Tian L, Song S, Zhu B, Liu S. Electroacupuncture at ST-36 Protects Interstitial Cells of Cajal via Sustaining Heme Oxygenase-1 Positive M2 Macrophages in the Stomach of Diabetic Mice. Oxid Med Cell Longev. 2018;2018:3987134. doi:10.1155/2018/3987134

109. Tang HY, Wang FJ, Ma JL, Wang H, Shen GM, Jiang AJ. Acupuncture attenuates the development of diabetic peripheral neuralgia by regulating $\mathrm{P} 2 \mathrm{X} 4$ expression and inflammation in rat spinal microglia. J Physiol Sci. 2020;70(1):45. doi:10.1186/ s12576-020-00769-8

110. Chen L, Sun HX, Xia YB, et al. Electroacupuncture decreases the progression of ovarian hyperstimulation syndrome in a rat model. Reprod Biomed Online. 2016;32(5):538-544. doi:10.1016/j. rbmo.2016.02.006

111. Chen L, Huang X, Wang L, et al. Electroacupuncture Reduces Oocyte Number and Maintains Vascular Barrier Against Ovarian Hyperstimulation Syndrome by Regulating CD200. Front Cell Dev Biol. 2021;9:648578. doi:10.3389/fcell.2021.648578 
112. Kim D, Bae CH, Jun YL, Jeon H, Koo S, Kim S. Acupuncture alters pro-inflammatory cytokines in the plasma of maternally separated rat pups. Chin J Integr Med. 2017;23(12):943-947. doi:10.1007/s11655-017-2827-8

113. Langevin HM, Yandow JA. Relationship of acupuncture points and meridians to connective tissue planes. Anat Rec. 2002;269 (6):257-265. doi:10.1002/ar.10185

114. Zhang K, Zhao X, Ding S, et al. Applying Complex Network and Cell-Cell Communication Network Diagram Methods to Explore the Key Cytokines and Immune Cells in Local Acupoint Involved in Acupuncture Treating Inflammatory Pain. Evid Based Complement Alternat Med. 2020;2020:2585960. doi:10.1155/ 2020/2585960

115. Park JY, Park JJ, Jeon S, et al. From peripheral to central: the role of ERK signaling pathway in acupuncture analgesia. $J$ Pain. 2014;15(5):535-549. doi:10.1016/j.jpain.2014.01.498

116. Zhang K, Zhao X, Yang T, et al. Initiation of Acupoint Molecular Mechanisms for Manual Acupuncture Analgesia-Nuclear Factor кB Signaling Pathway. Chin J Integr Med. 2020. doi:10.1007/ s11655-020-3435-6

117. Goldman N, Chen M, Fujita T, et al. Adenosine A1 receptors mediate local anti-nociceptive effects of acupuncture. Nat Neurosci. 2010;13(7):883-888. doi:10.1038/nn.2562

118. Zhang RY, Zhu BF, Wang LK, et al. Electroacupuncture alleviates inflammatory pain via adenosine suppression and its mediated substance P expression. Arq Neuropsiquiatr. 2020;78(10):61 7-623. doi:10.1590/0004-282X20200078

119. Chen T, Xiong Y, Long $\mathrm{M}$, et al. Electro-acupuncture Pretreatment at Zusanli (ST36) Acupoint Attenuates Lipopolysaccharide-Induced Inflammation in Rats by Inhibiting $\mathrm{Ca}(2+)$ Influx Associated with Cannabinoid CB2 Receptors. Inflammation. 2019;42(1):211-220. doi:10.1007/s10753-018-08 $85-5$

120. Gong Y, Li N, Lv Z, et al. The neuro-immune microenvironment of acupoints-initiation of acupuncture effectiveness. J Leukoc Biol. 2020;108(1):189-198. doi:10.1002/JLB.3AB0420-361RR

121. Zhang ZJ, Wang XM, McAlonan GM. Neural acupuncture unit: a new concept for interpreting effects and mechanisms of acupuncture. Evid Based Complement Alternat Med. 2012;2012:429412. doi:10.1155/2012/429412

122. Li N, Li M, Lu Z, et al. Exosome Is an Important Novel Way of Acupuncture Information Transmission. World $J$ Tradit Chin Med. 2020;6(04):377-383.

123. Chen B, Li MY, Guo Y, Zhao X, Lim HC. Mast cell-derived exosomes at the stimulated acupoints activating the neuro-immune regulation. Chin $J$ Integr Med. 2017;23 (11):878-880. doi:10.1007/s11655-016-2269-8

124. Lin W, Jia D, Fu C, Zheng Y, Lin Z. Electro-Acupuncture on ST36 and SP6 Acupoints Ameliorates Lung Injury via Sciatic Nerve in a Rat Model of Limb Ischemia-Reperfusion. J Inflamm Res. 2020;13:465-470. doi:10.2147/JIR.S264093

125. Wang JJ, Ming Q, Liu XD, et al. Electro-acupuncture of Foot YangMing regulates gastric activity possibly through mediation of the dorsal vagal complex. Am J Chin Med. 2007;35(3):455-464. doi:10.1142/S0192415X07004977

126. Lim HD, Kim MH, Lee CY, Namgung U. Anti-Inflammatory Effects of Acupuncture Stimulation via the Vagus Nerve. PLoS One. 2016;11(3):e0151882. doi:10.1371/journal.pone.0151882

127. Takahashi T. Mechanism of acupuncture on neuromodulation in the gut-a review. Neuromodulation. 2011;14(1):8-12; discussion 12. doi:10.1111/j.1525-1403.2010.00295.x

128. Salazar TE, Richardson MR, Beli E, et al. Electroacupuncture Promotes Central Nervous System-Dependent Release of Mesenchymal Stem Cells. Stem Cells. 2017;35(5):1303-1315. doi:10.1002/stem.2613
129. Lee CH, Jung HS, Lee TY, et al. Studies of the central neural pathways to the stomach and Zusanli (ST36). Am J Chin Med. 2001;29(2):211-220. doi:10.1142/S0192415X01000241

130. Lim HD, Kim KJ, Jo BG, Park JY, Namgung U. Acupuncture stimulation attenuates TNF- $\alpha$ production via vagal modulation in the concanavalin A model of hepatitis. Acupunct Med. 2020;38 (6):417-425. doi:10.1177/0964528420907338

131. Jie X, Li X, Song JQ, Wang D, Wang JH. Anti-inflammatory and autonomic effects of electroacupuncture in a rat model of diet-induced obesity. Acupunct Med. 2018;36(2):103-109. doi:10.1136/acupmed-2016-011223

132. Hawkins BT, Egleton RD, Davis TP. Modulation of cerebral microvascular permeability by endothelial nicotinic acetylcholine receptors. Am J Physiol Heart Circ Physiol. 2005;289(1):H212-9.

133. Liu PR, Zhou Y, Zhang Y, Diao S. Electroacupuncture alleviates surgery-induced cognitive dysfunction by increasing $\alpha 7-n A C h R$ expression and inhibiting inflammatory pathway in aged rats. Neurosci Lett. 2017;659:1-6. doi:10.1016/j.neulet.2017.08.043

134. Liu J, Li C, Peng H, et al. Electroacupuncture attenuates learning and memory impairment via activation of $\alpha 7 \mathrm{nAChR}$-mediated antiinflammatory activity in focal cerebral ischemia/reperfusion injured rats. Exp Ther Med. 2017;14(2):939-946. doi:10.3892/etm.2017.4622

135. Wang Z, Hou L, Yang H, et al. Electroacupuncture Pretreatment Attenuates Acute Lung Injury Through $\alpha 7$ Nicotinic Acetylcholine Receptor-Mediated Inhibition of HMGB1 Release in Rats After Cardiopulmonary Bypass. Shock. 2018;50 (3):351-359. doi:10.1097/SHK.0000000000001050

136. Geng Y, Chen D, Zhou J, Jiang H, Zhang H. Role of Cholinergic Anti-Inflammatory Pathway in Treatment of Intestinal Ischemia-Reperfusion Injury by Electroacupuncture at Zusanli. Evid Based Complement Alternat Med. 2017;2017:6471984. doi:10.1155/2017/6471984

137. Jiang $\mathrm{T}$, Wu $\mathrm{M}$, Zhang $\mathrm{Z}$, et al. Electroacupuncture attenuated cerebral ischemic injury and neuroinflammation through $\alpha 7 \mathrm{nAChR}-$ mediated inhibition of NLRP3 inflammasome in stroke rats. Mol Med. 2019;25(1):22. doi:10.1186/s10020-019-0091-4

138. Ma Z, Zhang Z, Bai F, Jiang T, Yan C, Wang Q. Electroacupuncture Pretreatment Alleviates Cerebral Ischemic Injury Through $\alpha 7$ Nicotinic Acetylcholine Receptor-Mediated Phenotypic Conversion of Microglia. Front Cell Neurosci. 2019;13:537. doi:10.3389/fncel.2019.00537

139. Chi L, Du K, Liu D, Bo Y, Li W. Electroacupuncture brain protection during ischemic stroke: a role for the parasympathetic nervous system. J Cereb Blood Flow Metab. 2018;38(3):479-491. doi:10.1177/0271678X17697988

140. Cao Y, Wang L, Lin LT, et al. Acupuncture attenuates cognitive deficits through $\alpha 7 \mathrm{nAChR}$ mediated anti-inflammatory pathway in chronic cerebral hypoperfusion rats. Life Sci. 2021;266:118732. doi:10.1016/j.1fs.2020.118732

141. Han D, Liu Z, Wang G, Zhang Y, Wu Z. Electroacupuncture Improves Cognitive Deficits through Increasing Regional Cerebral Blood Flow and Alleviating Inflammation in CCI Rats. Evid Based Complement Alternat Med. 2017;2017:5173168. doi: $10.1155 / 2017 / 5173168$

142. Wang Y, Xue M, Xia Y, Jiang Q, Huang Z, Huang C. Electroacupuncture treatment upregulates $\alpha 7 \mathrm{nAChR}$ and inhibits JAK2/STAT3 in dorsal root ganglion of rat with spared nerve injury. J Pain Res. 2019;12:1947-1955. doi:10.2147/JPR.S203 867

143. Wang Y, Xia YY, Xue M, Jiang Q, Huang Z, Huang C. Electroacupuncture ameliorates mechanical hypersensitivity by down-regulating spinal Janus kinase 2/signal transducer and activation of transcription 3 and interleukin 6 in rats with spared nerve injury. Acupunct Med. 2021;39(4):358-366. doi:10.1177/ 0964528420938376 
144. Pera T, Penn RB. Crosstalk between beta-2-adrenoceptor and muscarinic acetylcholine receptors in the airway. Curr Opin Pharmacol. 2014;16:72-81. doi:10.1016/j.coph.2014.03.005

145. Soler X, Ramsdell J. Anticholinergics/antimuscarinic drugs in asthma. Curr Allergy Asthma Rep. 2014;14(12):484. doi:10.1007/s11882-014-0484-y

146. Cavallotti C, Tonnarini G, Andrea V, Cavallotti D. Cholinergic staining of bronchus- associated lymphoid tissue. Neuroimmunomodulation. 2005;12(3):141-145. doi:10.1159/00008 4845

147. Degano B, Prévost MC, Berger P, et al. Estradiol decreases the acetylcholine-elicited airway reactivity in ovariectomized rats through an increase in epithelial acetylcholinesterase activity. Am J Respir Crit Care Med. 2001;164(10 Pt 1):1849-1854. doi:10.1164/ajrccm.164.10.2102009

148. Montalbano AM, Di Sano C, Chiappara G, et al. Cigarette smoke and non-neuronal cholinergic system in the airway epithelium of COPD patients. J Cell Physiol. 2018;233(8):5856-5868. doi:10.1002/jcp.26377

149. Zhang XF, Xiang SY, Geng WY, et al. Electro-acupuncture regulates the cholinergic anti-inflammatory pathway in a rat model of chronic obstructive pulmonary disease. J Integr Med. 2018;16 (6):418-426. doi:10.1016/j.joim.2018.10.003

150. Liu YL, Zhang LD, Ma TM, et al. Feishu Acupuncture Inhibits Acetylcholine Synthesis and Restores Muscarinic Acetylcholine Receptor M2 Expression in the Lung When Treating Allergic Asthma. Inflammation. 2018;41(3):741-750. doi:10.1007/s10753017-0726-y

151. $\mathrm{Li} \mathrm{Y}, \mathrm{Xu} \mathrm{G}, \mathrm{Hu} \mathrm{S}$, et al. Electroacupuncture alleviates intestinal inflammation and barrier dysfunction by activating dopamine in a rat model of intestinal ischaemia. Acupunct Med. 2021;39 (3):208-216. doi:10.1177/0964528420922232

152. Liu S, Wang Z, Su Y, et al. A neuroanatomical basis for electroacupuncture to drive the vagal-adrenal axis. Nature. 2021;598 (7882):641-645. doi:10.1038/s41586-021-04001-4

153. Elenkov IJ, Wilder RL, Chrousos GP, Vizi ES. The sympathetic nerve-an integrative interface between two supersystems: the brain and the immune system. Pharmacol Rev. 2000;52(4):595-638.

154. Xia CM, Colomb DG Jr, Akbarali HI, Qiao LY. Prolonged sympathetic innervation of sensory neurons in rat thoracolumbar dorsal root ganglia during chronic colitis. Neurogastroenterol Motil. 2011;23(8):801e339. doi:10.1111/j.1365-2982.2011.01728.x

155. Chen YJ, Gao YL, Lu WW, Gao W. Influence of acupuncture on the expression of VIP, SP, NKA and NKB, cAMP/cGMP and HE content and treatment of bronchial asthma in rats[J]. Cell Mol Biol. 2020;66(5):29-35. doi:10.14715/cmb/2020.66.5.6

156. Xiao LY, Wang XR, Yang JW, et al. Acupuncture Prevents the Impairment of Hippocampal LTP Through $\beta 1$-AR in Vascular Dementia Rats. Mol Neurobiol. 2018;55(10):7677-7690. doi:10.1007/s12035-018-0943-x
157. Yang JW, Ye Y, Wang XR, et al. Acupuncture Attenuates Renal Sympathetic Activity and Blood Pressure via Beta-Adrenergic Receptors in Spontaneously Hypertensive Rats. Neural Plast. 2017;2017:8696402. doi:10.1155/2017/8696402

158. Lu M, He Y, Gong M, et al. Role of Neuro-Immune Cross-Talk in the Anti-obesity Effect of Electro-Acupuncture. Front Neurosci. 2020;14:151. doi:10.3389/fnins.2020.00151

159. Rosas-Ballina M, Olofsson PS, Ochani M, et al. Acetylcholinesynthesizing $\mathrm{T}$ cells relay neural signals in a vagus nerve circuit. Science. 2011;334(6052):98-101. doi:10.1126/science.1209985

160. Vida G, Peña G, Deitch EA, Ulloa L. $\alpha 7$-cholinergic receptor mediates vagal induction of splenic norepinephrine. J Immunol. 2011;186(7):4340-4346. doi:10.4049/jimmunol.1003722

161. Bratton BO, Martelli D, McKinley MJ, Trevaks D, Anderson CR, McAllen RM. Neural regulation of inflammation: no neural connection from the vagus to splenic sympathetic neurons. Exp Physiol. 2012;97(11):1180-1185. doi:10.1113/expphysiol.2011.061531

162. Pavlov VA, Tracey KJ. Neural circuitry and immunity. Immunol Res. 2015;63(1-3):38-57. doi:10.1007/s12026-015-8718-1

163. Abe $\mathrm{C}$, Inoue $\mathrm{T}$, Inglis $\mathrm{MA}$, et al. $\mathrm{C} 1$ neurons mediate a stress-induced anti-inflammatory reflex in mice. Nat Neurosci. 2017;20(5):700-707. doi:10.1038/nn.4526

164. Wei Y, Dong M, Zhong L, et al. Regulation of hypothalamic-pituitary-adrenal axis activity and immunologic function contributed to the anti-inflammatory effect of acupuncture in the OVA-induced murine asthma model. Neurosci Lett. 2017;636:177-183. doi:10.1016/j.neulet.2016.11.001

165. Shi P, Sun LL, Lee YS, Tu Y. Electroacupuncture regulates the stress-injury-repair chain of events after cerebral ischemia/reperfusion injury. Neural Regen Res. 2017;12(6):925-930. doi:10.4103/1673-5374.208574

166. Forsythe P, Bienenstock J, Kunze WA. Vagal pathways for microbiome-brain-gut axis communication. Adv Exp Med Biol. 2014;817:115-133. doi:10.1007/978-1-4939-0897-4 5

167. Jang JH, Yeom MJ, Ahn S, et al. Acupuncture inhibits neuroinflammation and gut microbial dysbiosis in a mouse model of Parkinson's disease. Brain Behav Immun. 2020;89:641-655. doi:10.1016/j.bbi.2020.08.015

168. Li L, Lu J, Sun Y, Jin X. Acupuncture protects from 6-OHDA-induced neuronal damage by balancing the ratio of DMT1/Fpn1. Saudi J Biol Sci. 2019;26(8):1948-1955. doi:10.1016/j.sjbs.2019.07.003

169. Zhu S, Li L, Li Y, Cao W. Macrophage related cytokine expressions in depression mouse model induced by chronic unpredictable mild stress. Pak J Pharm Sci. 2017;30(5(Supplementary)):1951-1955.

170. Yu Z. Neuromechanism of acupuncture regulating gastrointestinal motility. World J Gastroenterol. 2020;26(23):3182-3200. doi:10.3748/wjg.v26.i23.3182
Journal of Inflammation Research

\section{Publish your work in this journal}

The Journal of Inflammation Research is an international, peerreviewed open-access journal that welcomes laboratory and clinical findings on the molecular basis, cell biology and pharmacology of inflammation including original research, reviews, symposium reports, hypothesis formation and commentaries on: acute/chronic inflammation; mediators of inflammation; cellular processes; molecular mechanisms; pharmacology and novel anti-inflammatory drugs; clinical conditions involving inflammation. The manuscript management system is completely online and includes a very quick and fair peerreview system. Visit http://www.dovepress.com/testimonials.php to read real quotes from published authors. 